\title{
Bone Marrow Microenvironment regulation of BCL6 in Acute Lymphoblastic Leukemia
}

\author{
William Lee Slone
}

Follow this and additional works at: https://researchrepository.wvu.edu/etd

\section{Recommended Citation}

Slone, William Lee, "Bone Marrow Microenvironment regulation of BCL6 in Acute Lymphoblastic Leukemia" (2016). Graduate Theses, Dissertations, and Problem Reports. 6656.

https://researchrepository.wvu.edu/etd/6656

This Dissertation is protected by copyright and/or related rights. It has been brought to you by the The Research Repository @ WVU with permission from the rights-holder(s). You are free to use this Dissertation in any way that is permitted by the copyright and related rights legislation that applies to your use. For other uses you must obtain permission from the rights-holder(s) directly, unless additional rights are indicated by a Creative Commons license in the record and/ or on the work itself. This Dissertation has been accepted for inclusion in WVU Graduate Theses, Dissertations, and Problem Reports collection by an authorized administrator of The Research Repository @ WVU.

For more information, please contact researchrepository@mail.wvu.edu. 


\title{
Bone Marrow Microenvironment regulation of BCL6 in \\ Acute Lymphoblastic Leukemia
}

\author{
William Lee Slone
}

Dissertation submitted to the School of Medicine at West Virginia University in partial fulfillment of the requirements for the degree of

\author{
Doctor of Philosophy \\ In \\ Cancer Cell Biology \\ Linda Vona-Davis, PhD (Chair) \\ Karen Martin, $\mathrm{PhD}$ \\ William P. Petros, PharMD \\ John Barnett, $\mathrm{PhD}$ \\ Jeffrey A. Vos, MD \\ Laura F. Gibson, PhD (Mentor)
}

West Virginia University Cancer Institute

Cancer Cell Biology Program

Morgantown, West Virginia

2016

Key Words: In vitro Bone Marrow Model, Microenvironment, Quiescence, Chemotherapy Resistance, Sensitization, Caffeine, BCL6, Acute Lymphoblastic Leukemia 


\title{
ABSTRACT
}

\section{Bone Marrow Microenvironment regulation of BCL6 in Acute Lymphoblastic Leukemia}

\author{
William L Slone
}

Acute lymphoblastic leukemia (ALL) is a hematological malignancy with approximately 6000 newly diagnosed cases every year. Although ALL is the most common malignancy in children, it can occur in patients of all ages. Great strides have been made in the treatment of $A L L$ and remission rates are at all-time highs. However, relapse rates have remained relatively consistent, and relapse continues to be correlated with a poor prognosis in patients with ALL. As the site of origin and progression of $A L L$, the bone marrow microenvironment (BMM) is important in regulating tumor cell quiescence and proliferation. Of clinical relevance is the frequency with which quiescent leukemic cells survive treatment, initiate proliferation, and contribute to relapse of aggressive disease. In order to design innovative therapies, a better understanding of the mechanisms by which this regulation occurs is needed.

In order to investigate the mechanisms of BMM mediated protection, and to develop innovative targeted strategies to disrupt it, in vitro co-culture models remain critical. Classically, co-culture models that include hematopoietic cells have only investigated the tumor population as a whole, without regard for potential different phenotypes based on location of the leukemic cell relative to the adherent BMM cells. In the first study (Chapters 2 and 3 ), we investigated whether ALL cells have a variance in phenotype based on their spatial location within the co-culture. Utilizing bone marrow stromal cells (BMSC) and human osteoblasts ( $\mathrm{HOB})$ as representative elements of the 
BMM, in culture with ALL cells, we found that ALL cells form three distinct populations relative to the BMSC or $\mathrm{HOB}$. ALL tumor cells that migrated beneath the stromal layer, referred to as phase dim (PD), were characterized by a quiescent and chemotherapy resistant phenotype. Cell labeling experiments demonstrated that the co-culture model was dynamic and that ALL cells readily transitioned between populations relative to the adherent BMM cells. Furthermore, co-culture studies using non-bone marrow derived adherent layers found that while these co-cultures supported formation of a PD population, they did not protect ALL cells from chemotherapy exposure. These results suggest that the increased chemotherapy resistance seen in the PD population is specific to the crosstalk between ALL cells and the BMSC or HOB. PD ALL cells were also seen to have an altered metabolic profile, which may contribute to their increased resistance to chemotherapy. Additionally, we provide a written and video protocol for the isolation of the three ALL populations from the stromal adherent layers. This extension of the standard co-culture model will provide researchers a more biologically relevant method to investigate resistant ALL disease in the context of BMM derived support.

In the final study (Chapter 4), data suggest that microenvironment regulation of BCL6 in leukemic cells is one factor involved in the transition between the proliferative and quiescent states of ALL. Observations utilizing Bcr-Abl negative (Ph-), positive $(\mathrm{Ph}+) \mathrm{ALL}$ cell lines, and primary patient samples suggest that tumor cell BCL6 protein expression is decreased due to BMSC and HOB derived signals. Leukemic cells with decreased BCL6 are characterized by diminished proliferation, $\mathrm{G}_{0}$ accumulation, and chemotherapy resistance. Conversely, removal of ALL cells from marrow-derived stroma results in leukemic cells with increased BCL6 expression that are proliferative 
and sensitive to chemotherapy. Chemical inhibition or knock-down of BCL6 by shRNA in ALL cells results in diminished proliferation reminiscent of the quiescent tumor cells supported by the marrow microenvironment which are chemotherapy resistant and contribute to relapse of disease. We have developed a unique in vitro recovery model to test chemotherapy protection of tumor in this unique niche. $\mathrm{BMSC} / \mathrm{HOB}$ co-cultured tumor cells are exposed to chemotherapy, and subsequently allowed to recover from drug imposed insult to determine factors important to tumor survival and repopulation. While down regulation of leukemic BCL6 leads to a quiescent phenotype, surviving leukemic cells released from microenvironment constraint have increased BCL6 expression and undergo a period of aggressive proliferation. Since many chemotherapy regimens require tumor cell proliferation for optimal efficacy, we investigated the consequences of forced BCL6 expression in leukemic cells when in the protective microenvironment niche. Data suggest that forcing leukemic cells to express BCL6 when co-cultured with BMSC or HOB sensitizes the tumor to chemotherapy induced cell death. Furthermore, pre-treatment with drugs that increase BCL6 expression such as the proteasome inhibitor MG132 or the ATM pathway inhibitor caffeine sensitize microenvironment protected ALL cells to chemotherapy treatment. These data suggest that BCL6 is one factor, modulated by microenvironment derived cues that may contribute to regulation of ALL cell cycle progression and subsequently therapeutic response.

The overall goal of the studies presented herein was to provide a platform to investigate treatment resistant ALL that is due to BMM support through the use of our in vitro co-culture model. Additionally, through the use of this model we are able to 
demonstrate mechanistic changes, which can lead to chemotherapy resistance such as downregulation of BCL6 in ALL subsequent to BMM interaction. These studies provide mechanistic insight that will contribute to the design of novel treatment strategies that disrupt protective microenvironment signaling, with a goal of increased chemotherapy efficacy and less intensive therapies for ALL patients. With a primary goal of reducing the frequency of relapse, a critical secondary advantage would be the reduction of longterm effects from cytotoxic therapies and potential reduction of treatment induced secondary malignancies. 


\section{DEDICATION}

I would like to dedicate this dissertation to the Stouffer family. Jarod Stouffer was my best friend from grade school through high school. Jarod was diagnosed with leukemia during our junior year of high school and unfortunately passed away due to complications associated with this terrible disease. Watching this disease take my best

friend and the subsequent toll it took on his family has served as a talisman when things have gotten difficult as I have pursued this degree. It has always reminded me why I started this research and continues to drive my motivation today. Again, I dedicate this dissertation to Jarod, Jason, Nancy, and Keith, you will forever serve as an inspiration to me as I pursue my career in research. 


\section{ACKNOWLEDGEMENTS}

I must begin these acknowledgments by saying that I am deeply grateful to my mentor Dr. Laura Gibson. I cannot thank Dr. Gibson enough for taking me into her lab and helping me progress into the scientist I am today. Dr. Gibson's support and encouragement have been second to none, and I will forever be indebted to her for everything she has done.

In addition to having a great mentor, I could not have been successful without the guidance of my dissertation committee. I would like to thank Dr. Linda Vona-Davis, Dr. William Petros, Dr. John Barnett, Dr. Karen Martin, and Dr. Jeffrey Vos for serving on my committee. Their sacrifice of time and their input to improve my project has been very much appreciated. I would also like to thank Dr. Kathy Brundage for all of her help with our flow cytometry experiments, her guidance, and her troubleshooting input. I want to also thank Dr. Michael Craig, the WVU biospecimen processing core, and all of the patients that have donated their cells so that we may conduct our research. I also want to thank Dr. John Thomas and Linda Corum for providing the opportunity of my first research position.

Without the support of our lab team, I would never have been able to accomplish this research. Additionally, this group has become like family. To Deb, Beckie, Blake, Ian, and Jim, you made these years tremendous and I cannot thank you enough. I would also like to thank Patrick and Zack for their help with this project, as well as all of the past Gibson lab members for their contributions that made this work possible. 
I am also grateful for the amazing friendships I have made during my tenure as a graduate student. To Katie, Dan, John, Blake, and Beckie, you have become great friends and I look forward to our continued friendship. Additionally, Blake you have become my best friend and there is no way I could have survived this demanding experience without you there to be a sounding board, a person to vent to, and a great friend, thank you.

Finally, I want to thank my amazing family for everything they have done for me. Mom and Dad (Sheri and Devin Slone) I cannot thank you enough for attending all of the baseball, basketball, football games, as well as, all of my academic events. Your encouragement, tough love, and support in all things has made me who I am today, and has provided me with the strength to continue on when things got tough. Your sacrifices to ensure that I was always involved in as many things as possible has allowed me to achieve my goals, be well-rounded, and able to think outside of the box. I believe these are my greatest strengths, which I have because of you both. Mom, you probably never thought that those last minute, night before science projects you helped me with in grade school would turn into a career in science, but as with everything, your encouragement in times such as those have enabled me to get to where I am today. Dad, you have always pushed me to be the best I can be, taught me to always give everything my all, and most of all too always work hard. These lessons, as well as your constant reminder that "nothing worth having comes easy" has always served me well and has helped me more than you could ever imagine. Kohl you are an amazing sister and your belief in me has always provided me with motivation and pushed me to be better, and for this I cannot thank you enough. Grandma (Faith) your love, support, and 
prayers have been second to none. You have always been there for me, for which I will always be grateful. Finally, to Kaitie I cannot tell you how thankful I am to have you in my life. When I thought I had no chance to get into graduate school, your encouragement (and the drawing you gave me) pushed me to go for it. We are five years down the road and you have been by my side for the ups, downs, the early mornings, and the late nights. I cannot thank you enough and I look forward to our continued adventures. 


\section{Table of Contents}

Bone Marrow Microenvironment regulation of BCL6 in Acute Lymphoblastic Leukemia.. i

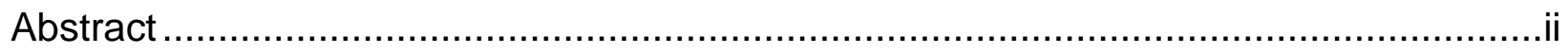

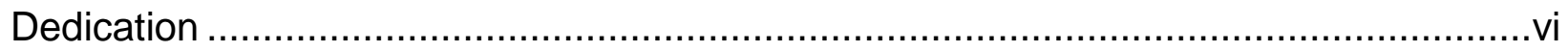

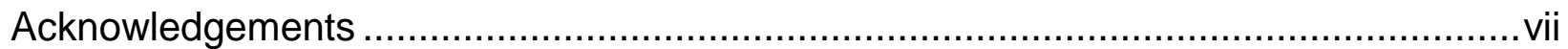

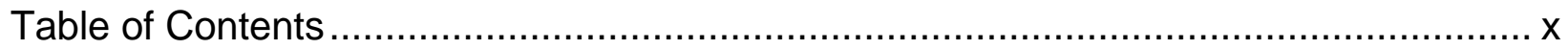

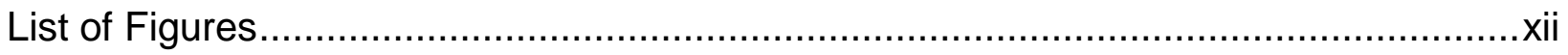

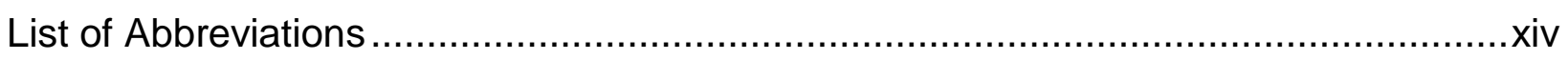

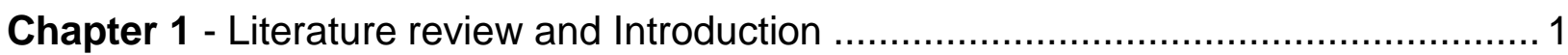

Acute Lymphoblastic Leukemia .................................................................... 2

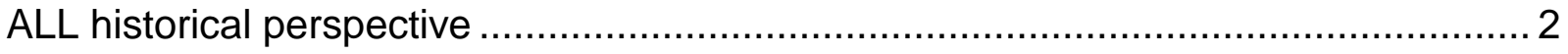

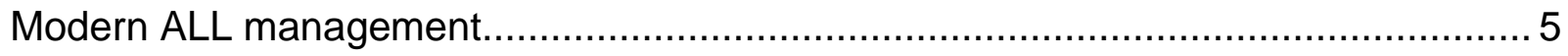

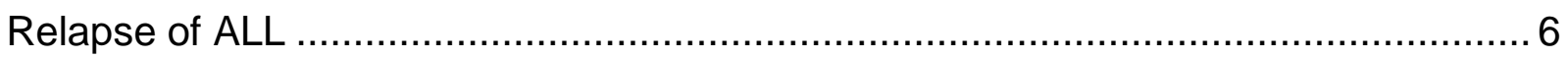

Bone marrow microenvironment contributions to ALL chemotherapy resistance......... 7

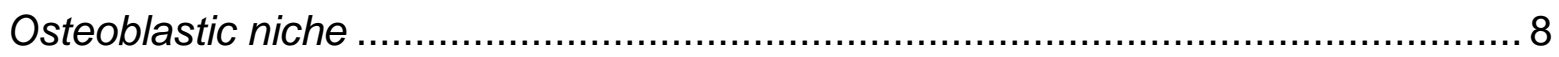

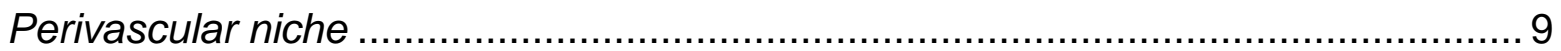

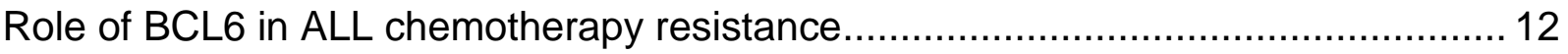

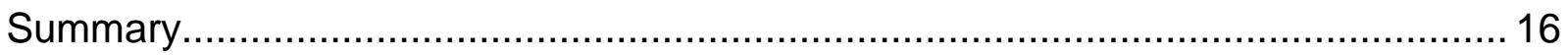

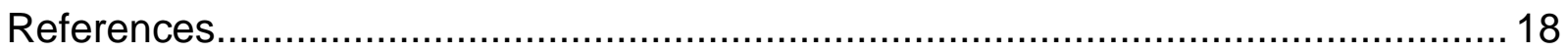

Chapter 2 - Modeling chemotherapy resistant leukemia in vitro ................................ 31

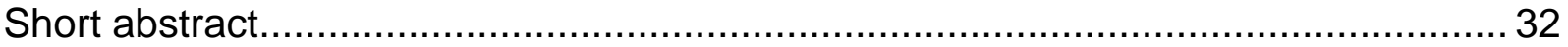

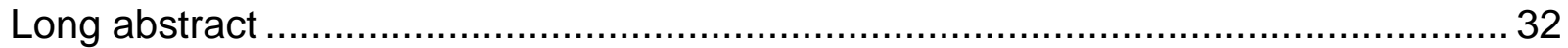

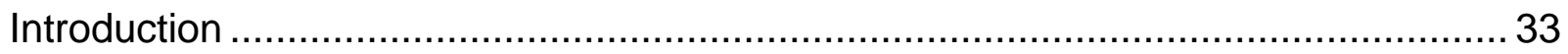

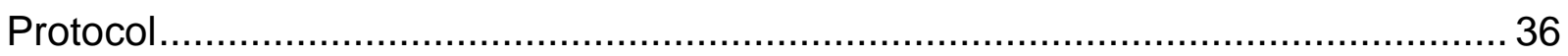

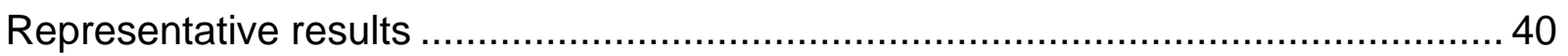

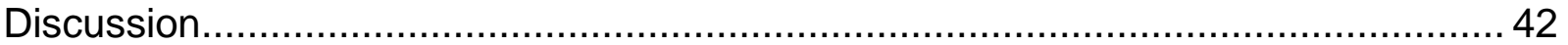

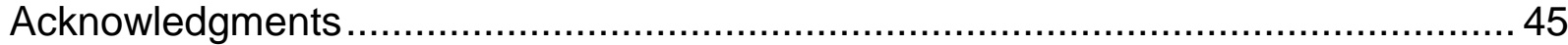

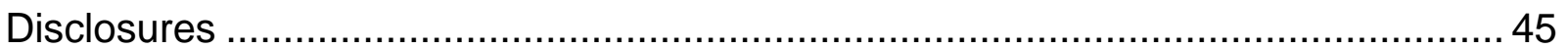

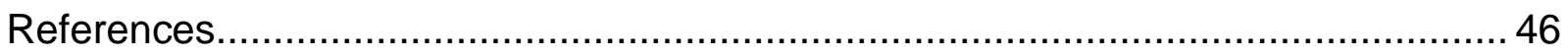

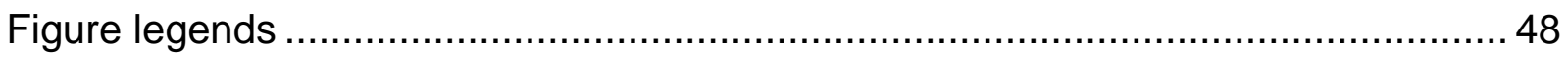

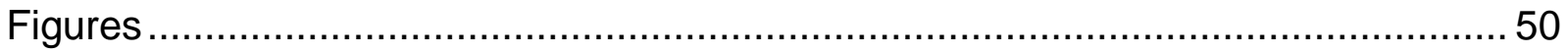


Chapter 3 - Bone Marrow Microenvironment Modulation of Acute Lymphoblastic

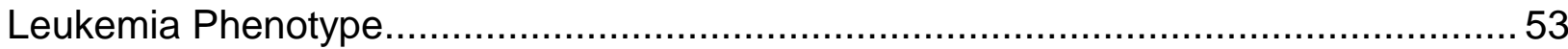

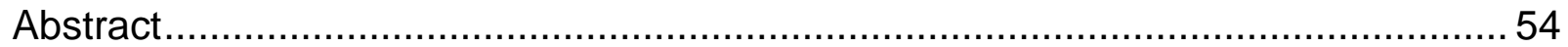

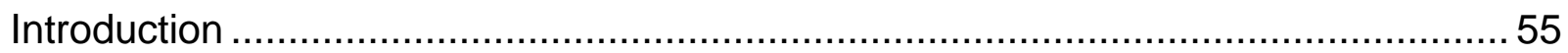

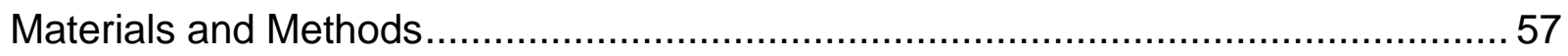

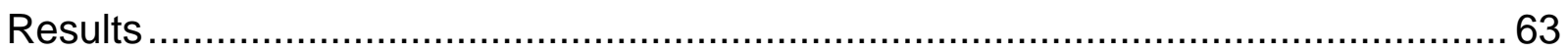

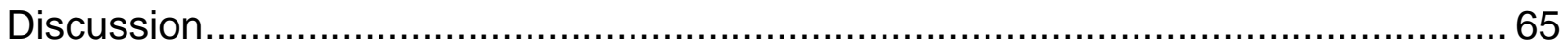

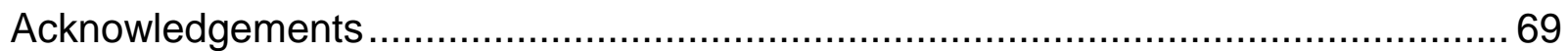

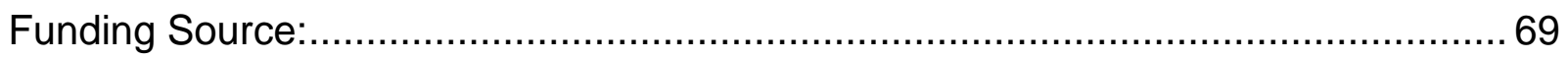

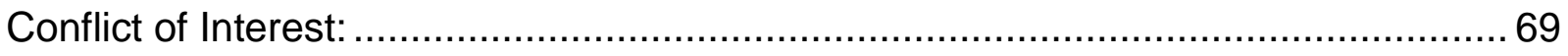

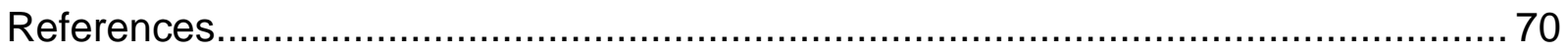

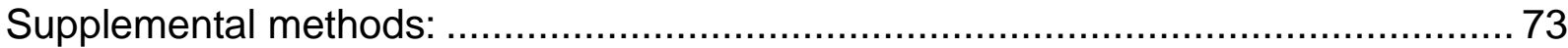

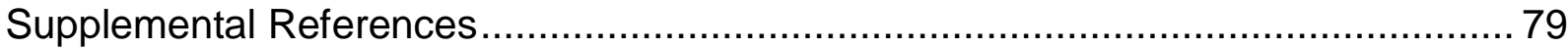

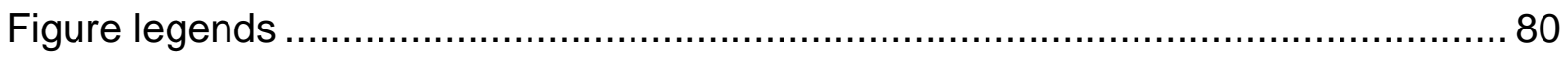

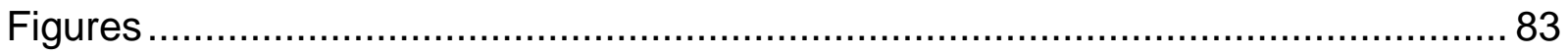

Chapter 4 - BCL6 Modulation of Acute Lymphoblastic Leukemia Response to

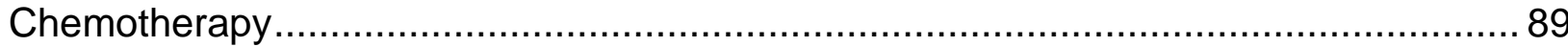

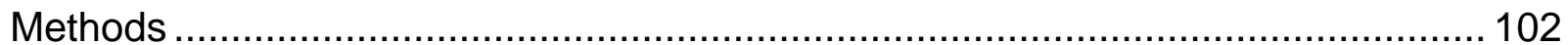

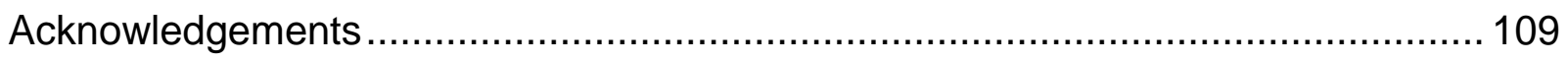

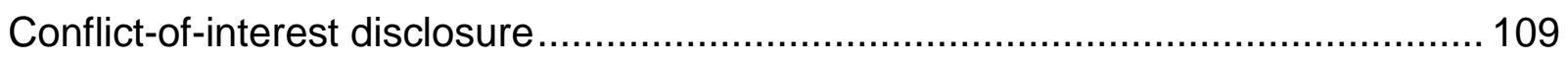

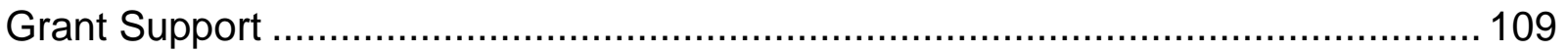

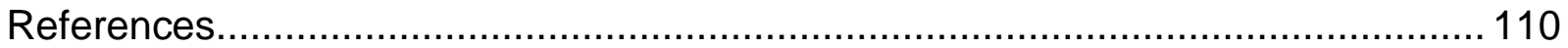

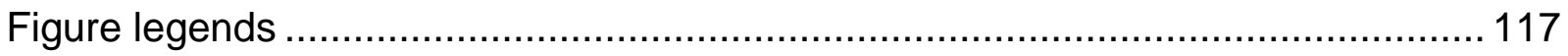

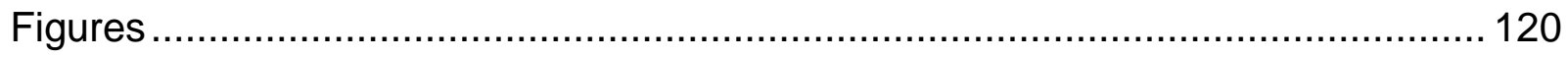

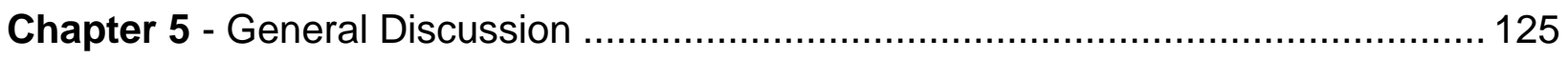

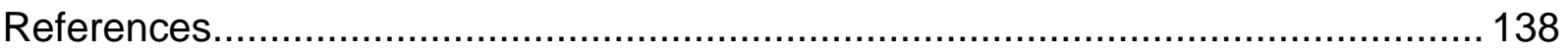




\section{List of Figures}

\section{Chapter 1}

Figure 1. Mechanisms involved in HSCs and LICs maintenance in osteoblastic and vascular niches.

Figure 2. The adult bone marrow HSC niche.

Figure 3. Schematic representation of BCL6 illustrating its key domains and binding partners.

\section{Chapter 2}

Figure 1: ALL cells in co-culture with BMSC or OB form three spatial populations.

Figure 2: Use of G10 columns allows for separation of ALL cells from BMSC/OB.

Figure 3: PD leukemic cells have increased resistance to chemotherapy exposure.

\section{Chapter 3}

Figure 1. Human acute lymphoblastic leukemia cells (ALL) occupy three functionally distinct spatial compartments during co-culture with BMSC.

Figure 2. Each subpopulation of Nalm-27 ALL cells re-established the PD fraction when provided BMM niche cells.

Figure 3. PD leukemic cells have pronounced resistance to chemotherapy induced death.

Figure 4. BMM cells influence the PD subpopulation cell cycle profile and increase quiescence.

Figure 5. BMM alters global protein expression in ALL cells.

Figure 6. PD cells isolated from bone marrow niche co-culture have a distinct metabolic phenotype when compared to ALL cells in the absence of microenvironment signals.

\section{Chapter 4}

Figure 1. Co-culture with BMSC or $\mathrm{HOB}$ reduces BCL6 in ALL cells.

Figure 2. Modulation of BCL6 alters cell cycle progression and proliferation of ALL cells. 
Figure 3. BCL6 modulates the cell cycle regulating protein cyclin D3.

Figure 4. Forced expression of BCL6 sensitizes PD ALL cells to chemotherapy exposure.

Figure 5. In vivo sensitivity to Ara-C is increased by BCL6 overexpression or pretreatment with caffeine. 


\section{List of Abbreviations}

293T

3T3

ALL

AML

Ang-1

Ara-C

BCL6

BMM

BMSC

CALGB

CAR

CCG

CML

CNS

CXCL-12

DLBCL

DNS

ECAR human embryonic fibroblasts

3T3 mouse embryonic fibroblasts

acute lymphoblastic leukemia

acute myelogenous leukemia

Angiopoietin-1

Cytarabine

B-cell CLL/lymphoma 6, zinc finger protein 51

bone marrow microenvironment

bone marrow stromal cell

Cancer and Leukemia Group B

abundant reticular cell

Children's Cancer Group

Chronic myeloid leukemia

central nervous system

C-X-C motif chemokine-12

diffuse large B-cell lymphoma

data not shown

extracellular acidification rate 


\begin{tabular}{|c|c|}
\hline EFS & event free survival \\
\hline FBS & fetal bovine serum \\
\hline G10 & gel type 10 cross-linked dextran \\
\hline H/PY & Hoechst33342/Pyronin Y \\
\hline HDAC & histone deacetylate \\
\hline HLA & human leukocyte antigen \\
\hline $\mathrm{HOB}$ or $\mathrm{OB}$ & human osteoblast \\
\hline HSC & hematopoietic stem cell \\
\hline HT & HT-1080 human fibrosarcoma \\
\hline IP & intraperitoneal \\
\hline LAESI & laser ablation electrospray ionization \\
\hline LepR + & leptin receptor positive \\
\hline M & media alone or media control \\
\hline MEF & mouse embryonic fibroblasts \\
\hline MRD & minimal residual disease \\
\hline MSC & mesenchymal stromal cell \\
\hline MTX & Methotrexate \\
\hline NES + & nestin positive \\
\hline NSG & NOD-SCID gamma mice \\
\hline
\end{tabular}




\begin{tabular}{|c|c|}
\hline OCR & oxygen consumption rate \\
\hline P1, P2 & Patient sample 1, 2 \\
\hline PB & phase bright ALL cells \\
\hline PBS & phosphate buffered saline \\
\hline PD & phase $\operatorname{dim}$ ALL cells \\
\hline $\mathrm{Ph}-, \mathrm{Ph}+$ & Philadelphia chromosome negative, positive \\
\hline $\mathrm{Pl}$ & propidium iodide \\
\hline S & suspended ALL cells \\
\hline SCF & stem cell factor \\
\hline SCP & sheep choroid plexus \\
\hline SEM & standard error mean \\
\hline shRNA & short hairpin RNA \\
\hline SLAM & signaling lymphocyte attractant molecule \\
\hline SWOG & Southwest Oncology Group \\
\hline TGF- $\beta 1$ & transforming growth factor- $\beta 1$ \\
\hline T-regs & regulatory T-cells \\
\hline VCR & Vincristine \\
\hline
\end{tabular}




\section{Chapter 1}

Literature review and Introduction 


\section{Acute Lymphoblastic Leukemia}

Acute lymphoblastic leukemia (ALL), also known as acute lymphocytic leukemia, is a malignancy that arises from uncontrolled proliferation of abnormal immature lymphocytes in the absence of differentiation. Typically, this disease initiates and progresses in the bone marrow. Due to its aggressive or "acute" nature, ALL progression rapidly leads to damage or loss of normal hematopoiesis and eventual systemic damage as the immature lymphocytes infiltrate the blood stream and other organs. It is estimated that there are 6000 new cases of ALL yearly ${ }^{1,2}$. ALL tends to be more common in Caucasians and is more prevalent in males than females at a ratio of $3: 1^{1,2}$. ALL most commonly occurs in children with $60 \%$ of patients being younger than 21 years old and peak incidence between $2-5$ years of age ${ }^{1,2}$. Remission rates for childhood ALL approach 90\%, however infants 12 months of age or less and adults over 16 as the age have a worse overall prognosis ${ }^{1-3}$. Modern chemotherapy regimens, which will be discussed later, have greatly improved patient outcomes; however, leukemia in general has a long documented history and only in the last century has the medical and research community began to make strides in the treatment of this previously consistently fatal disease.

\section{ALL historical perspective}

To understand modern ALL treatment regimens, and to consider future therapeutic strategies, it is important to look at the historical development of early treatments. While ancient Greek texts describe a disease of the blood which has characteristics of leukemia as we recognize it today, the first work that lead to leukemia 
being classified as its own clinical entity took place in the early $1800 \mathrm{~s}^{4,5}$. Before these works, many physicians considered what we know today as leukemia to be secondary to an unknown infection leading to "pus" in the blood. These physicians understood that infections of the skin resulted in pus production, though they did not yet appreciate that pus was actually white blood cells ${ }^{4,5}$. The advent and improvements in microscope technology allowed for the visualization of the blood and the first accurate descriptions of white blood cells ${ }^{4}$. This leap in technology positioned physicians such as Bennett, Donne and Virchow to piece together that the disease they were observing was a separate disease of the blood that caused the blood to appear white, which led to the disease being termed leukemia ${ }^{4,5}$. In 1865, Lissauer described the first known treatment for leukemia, which relied on the use of an arsenic solution ${ }^{4}$. Arsenic solutions were standard of care to be followed by use of $\mathrm{x}$-rays and early attempts at blood transfusions ${ }^{4}$. These treatments continued to be used as treatments for all forms of leukemia into the 1900s, without any long term benefit to patients, and leukemia continued to be considered incurable. World Wars I and II brought about research involving mustard gas derivatives. In the United States, Gilman and Philips observed that certain nitrogen mustard gas compounds had an impact on lymphoid tissues ${ }^{6}$. One of the first mustard gas derivatives shown to have efficacy against hematologic malignancies was methyl-bis-( $\beta$-chloroethyl) amine, following clinical trials at Yale University ${ }^{4}$. These findings were follow by the work of Sidney Farber and others, on anti-folate treatments using the aminopterin ${ }^{7,8}$. The use of folic acid antagonists, which are now known to function through disruption of DNA synthesis, provided some of the first temporary remissions in children ${ }^{9,10}$. Farber along with Yellapragada Subbarow 
expanded upon these works with the development of methotrexate, which functions as an antimetabolite resulting in depletion of activated folates needed for DNA synthesis ${ }^{4}$. These advances began to improve patient outcomes and lead to some of the first large scale clinical trials. Of note, in the treatment of ALL are the three cooperative children patient groups; Acute Leukemia Group A (eventually Children's Cancer Group [CCG]), Acute Leukemia Group B (which became Cancer and Leukemia Group B [CALGB]), Southwest Cancer Chemotherapy Study Group (which evolved into the Southwest Oncology Group [SWOG] ${ }^{11}$. These patient groups were used to test the efficacy of the newly derived anti-folate, methotrexate, and mustard gas derivatives. Also, a critical discovery of these research studies was that they established the first combination therapy strategies, which continue to be critical to successful treatment outcomes in patients ${ }^{10-12}$. These studies mark a turning point in the treatment of ALL as they provided the first successful curative treatments. During these clinical group trials, vincristine was discovered as a possible treatment due to its myelosuppressive effect and in combination with prednisone and I-asparginase, these agents were added to the treatment arsenal which lead to increased and lengthened remission rates ${ }^{11}$. In the 1960s, prophylactic treatment of the central nervous system (CNS) began, which further improved outcomes by minimizing the likelihood of relapse of disease that can occur in this protected anatomical location ${ }^{10,11,13}$. The use of combination treatments and prophylactic CNS treatment resulted in ALL cure rates approaching $50 \%$ by the $1970 \mathrm{~s}^{11}$. These successes resulted in further research leading to risk based treatment strategies, as well as the use of human leukocyte antigen (HLA) matched bone marrow transplant, further increasing the survival rate for patients with $\operatorname{ALL}^{10,11}$. 


\section{Modern ALL management}

On the backs of the fundamental work described above, modern treatment strategies result in greater than $90 \%$ of ALL patients achieving remission ${ }^{1}$. As was first discovered with the cooperative children groups of the 1950s, the key to current treatment has been further optimization of treatment regimens as a majority of today's chemotherapy drugs for the treatment of ALL were discovered prior to the 1970s. Today's treatments typically consist of three treatment phases which take place over a 2-2.5 year time frame 1,3,14. Treatment phases for ALL are induction, consolidation, and maintenance. Induction therapy typically consists of treatment with some combination of vincristine, cytarabine, dexamethasone, prednisone, doxorubicin, daunorubicin, or a similar anthracycline drug ${ }^{1,3,14}$. Induction therapy is followed by consolidation, which is typically retreatment with high doses of induction therapy drugs ${ }^{1,3,14}$. Maintenance therapy follows consolidation treatments and typically consists of treatment regimens containing methotrexate and 6-mercaptopurine. In addition, consolidation treatments may be combined with other drugs such as vincristine or prednisone, as well as specifically targeted drugs such as tyrosine kinase inhibitors ( i.e imatinib, dasatinib, and nilotinib) ${ }^{1,3,14}$. Increased awareness and tools for determination of genetic alterations, and their subsequent use for more informed risk stratification, along with combination treatment strategies has combined to greatly improve patient outcomes. These treatment approaches have advanced patient outcomes to all-time highs, with children having an overall complete remission rate between $90-96 \%$ and adults ranging from 80 to $90 \%$ complete remission ${ }^{1-3,14}$. While these complete remission rates are extremely 
encouraging, relapse of $A L L$ remains a significant issue that often leads to aggressive disease and poor outcomes.

\section{Relapse of ALL}

Modern chemotherapy regimens have greatly increased the number of complete remission in both children and adults suffering from ALL. Relapse of ALL occurs in 20 to $25 \%$ of children and greater than $50 \%$ of adult cases of $A L L^{15-19}$. In both patient populations, relapse of ALL has a poor prognosis with long term survival of children with a relapse event ranging from 15 to $50 \%$, and similar or worse outcomes in adults ${ }^{3,14-16}$. Relapse of ALL can arise from a number of anatomical locations with the most common sites being the bone marrow, CNS and testis ${ }^{20}$. Although these are the most common sites of $A L L$ relapse, extramedullary relapses have been observed to arise from the iris, ovaries, and skin ${ }^{21}$. Though ALL relapse can arise from any of these sites, bone marrow relapses are the most common and confer the worst prognosis as detailed below.

While genetic mutations such as BCR-Abl or $\mathrm{MLL}^{+}$rearrangements play a critical role in the progression and likelihood of relapse ${ }^{22}$, two fundamental characteristics of ALL relapses, length of initial remission and site of relapse, are the most important predictors of long term survival of ALL patients ${ }^{20,23}$. Length of remission has been found to be the most significant predictor of overall survival and is commonly stratified into three categories early ( $<18$ months), intermediate (18 to 36 months), and late relapse (>36 months) with early relapse events having a poor prognosis compared to longer remission duration ${ }^{23}$. Work by Nguyen et al. and others has also shown that the site of relapse is also an indicator of long term survival. As noted previously, the sites of relapse vary with bone marrow relapses having the worst prognosis compared 
to relapses arising in the CNS, testis, or other organs ${ }^{20,23}$. Long term survival of patients who suffer an early bone marrow relapse has a range from $0-15 \%$, intermediate medullary relapse ranges from 10 to $40 \%$, late bone marrow range is $14-50 \%{ }^{23}$. This is compared to CNS relapses which have a long term survival rate of approximately $51 \%$ and isolated testicular relapses that range from 53 to $84 \%{ }^{23}$. Together these observations highlight the need for further research to improve outcomes in patients with relapse by investigating strategies that promote longer remissions. This requires a mechanistic understanding of the bone marrow microenvironment's contribution to resistance and progression of ALL disease.

\section{Bone marrow microenvironment contributions to ALL chemotherapy resistance}

To fully understand bone marrow microenvironment (BMM) facilitation of ALL progression and contribution to chemotherapy resistance, it is important to appreciate the supportive role the BMM plays in normal hematopoiesis, the "healthy" counterpart of leukemia, as they respond to many of the same development cues. Neumann and Bizzozero first postulated that the bone marrow was the site of red blood cell production in the late $1800 \mathrm{~s}^{24}$. Works by Osler elaborated upon Neumann and Bizzozero's work to conclude that the bone marrow was an organ with the primary function of producing all cellular components of the blood ${ }^{24}$. Today it is understood that the bone marrow is a complex organ that consists of specific microenvironment niches that function to regulate hematopoiesis. Furthermore, research continues to determine the functional role of individual niches within the bone marrow. It is widely accepted that two niches, the endosteal and the perivascular niche, are critical for normal maintenance and development of both immature and mature blood cells. However, their specific 
contributions to white blood cell development is still currently being debated. The complexity of this anatomical site drives the need for careful consideration of model development, realizing that while some elements (osteoblasts and stromal cells) may have overlapping roles, there are likely very specific contributions to steady state hematopoiesis, and support of leukemic disease as well.

\section{Osteoblastic niche}

The endosteal or osteoblastic niche, is localized near the inner bone surface or endosteum. This niche is comprised of a variety of cell types which include; osteoblasts, osteoclasts, glial non-myelinating Schwann cells, and regulatory T-cells (T-regs) (Figure $1,2)^{25,26}$. One key component of this niche is osteoblasts, which in coordination with osteoclasts have been classically described to maintain bone homeostasis ${ }^{27,28}$. In addition to the role in bone homeostasis, osteoblasts have been shown in both in vitro and in vivo studies to regulate hematopoietic stem cells (HSC), as well as progenitor hematopoietic cell proliferation and differentiation ${ }^{26,29-32}$. One classic example is osteoblast mediated Notch signaling which has been shown to regulate HSC proliferation, self-renewal, and prevention of HSC differentiation ${ }^{31,33}$. Furthermore, osteoblast derived growth factors such as granulocyte colony-stimulating factor can be used to promote HSC expansion in vitro and loss of osteoblasts in vivo results in decreased abundance of $\mathrm{HSCs}^{29,30,34}$. Additionally, osteoblast production of Angiopoietin-1 (Ang-1), N-cadherin signaling, and osteopontin appear to promote HSC quiescence and are hypothesized to maintain the HSC pool preventing stem cell exhaustion ${ }^{35-37}$. Due to osteoblast's propensity to promote hematopoietic cell phenotypes that promote self-renewal and quiescence, it is of little surprise that 
malignant immature hematopoietic cells also invade this niche to take advantage of these "protective" signaling cues. For this reason, we and others have interrogated the signaling that occurs in this site and demonstrated that leukemic cell interaction with osteoblasts promotes a chemotherapy resistant phenotype ${ }^{38-41}$. Similar to observations that have been described for normal HSC, adhesion of ALL cells to ostopontin in the osteoblastic niche promoted a dormant phenotype and subsequently facilitated chemotherapy resistance ${ }^{38}$. Likewise, Saito et al demonstrated in an acute myelogenous leukemia $(A M L)$ mouse model that $C D 34^{+} C D 38^{-}$human primary $A M L$ stem cells localized to the endosteum, where they exhibited a chemotherapy resistant quiescent phenotype ${ }^{42}$. These observations together illustrate the protective nature of the osteoblastic niche and are the bases for our investigations into the role this niche plays in promotion of ALL resistance, which will be further discussed below.

\section{Perivascular niche}

Like the osteoblastic niche, there is a wealth of evolving research demonstrating the impact of the perivascular niche on normal and leukemic physiology. The perivascular niche is localized at the sinusoidal and arteriole walls, and this niche has been shown to be made up of C-X-C motif chemokine-12 (CXCL12)-abundant reticular cells (CAR), endothelial cells, nestin-positive (NES+) mesenchymal stromal cells (MSCs), leptin receptor positive [LepR(+)] perivascular stromal cells, and non-

myelinating Schwann cells (Figure 1, 2) ${ }^{25,26}$. The perivascular niche has been described to promote both proliferative and quiescent HSC phenotypes, and research continues to delineate the local niches that are responsible for these different states. For example, non-myelinating Schwann cells that are part of both the osteoblastic niche and the 
perivascular niche have been reported to activate transforming growth factor- $\beta 1$ (TGF$\beta 1)$, which supports HSC quiescence ${ }^{43,44}$. On the other hand, expression of Notch ligands Jagged-1, Jagged-2, and Delta-like-1 \&4 increased self-renewal of HSCs in vitro $^{25,45}$. Even among the same stromal cell population, localization and protein expression profiles can dramatically alter impacts on HSCs. This was demonstrated by Kunisaki et al using NES+ MSCs segregated into high nestin phenotype verses those with lower nestin expression ${ }^{46}$. Not only did this group show that nestin high and nestin low MSCs localize to different perivascular niches (arteriolar vs. sinusoidal respectively), they displayed that the arteriolar nestin high MSC promoted HSC quiescence compared to the cell cycle active HSCs which localized to areas with nestin low MSCs ${ }^{46}$. These examples illustrate the heterogeneity of the "classic" perivascular niche and suggests that this one niche may, in fact, be two unique niches (arteriolar verses sinusoidal). More generally this heterogeneous population of stromal cells and MSCs has been defined as "bone marrow stromal cells" (BMSC). BMSC have been shown to maintain HSC homeostasis through impacting HSC and progenitor cell proliferation, self-renewal, differentiation, and homing properties ${ }^{26,47-50}$. BMSC expression of CXCL12, as well as signaling lymphocyte attractant molecule (SLAM) proteins, are important to retention of HSC and progenitor lymphocytes respectively within the perivascular niche ${ }^{51}$. BMSC also produce stem cell factor (SCF), the ligand for the c-kit kinase receptor, which maintains HSC pools. Correspondingly, deletion of SCF in BMSC resulted in a marked reduction of HSC numbers ${ }^{52}$.

In addition to the role BMSCs play in HSC physiology, they also make up niches that committed progenitor cells occupy and rely on for proliferation and differentiation 
cues. Specifically, work by Ding et al revealed that committed B-lineage progenitors are dependent on BMSC that reside within the perivascular niche ${ }^{51}$. The observation that committed B-lineage progenitors rely on BSMC in this niche is significant to $A L L$, as greater than $80 \%$ of ALL cases are malignant pre- or pro B-cells that are lineage committed but lack full productive rearrangement of immunoglobulin genes ${ }^{19,53}$. BMSC within this niche can even promote or regulate fate of malignant cells as seen in the case of MLL-AF9 leukemia where BMSC cues can drive the leukemia into either an AML or B-cell ALL fate ${ }^{54}$. In addition to differentiation cues, our laboratory and others have shown that BMSC supported ALL cells are known to exhibit increased chemotherapy resistance through BMSC induced quiescence and anti-apoptotic signaling $39,40,55-57$. These findings were further extended by the identification that in a multiple patient cohort, resistant ALL cells tended to have upregulation of IL-7 and CXCR-4 signaling, both of which are known mediators of normal B-cell development and are signaling pathways driven by BMSC interactions ${ }^{58}$. Additionally, BMSC mediated engagement of leukemic Beta1 integrin leads to anti-apoptotic effects through downregulation of BCL-2 family members such as $\mathrm{BIM}^{57,59}$. Collectively, these studies highlight the impact the perivascular niche has on normal hematopoiesis and leukemic proliferation, differentiation, and survival. As BMSCs are key components of this niche, the studies below utilize human primary bone marrow stromal cells as representative elements of the perivascular niche to test the impacts on ALL cell chemotherapy resistance.

Combined, the osteoblastic and perivascular niches of the bone marrow are key microenvironment sites required for normal hematopoiesis and are a major contributor 
to the leukemia phenotype. As highlighted above and reviewed by others, leukemic cells communicate intimately with normal niche cues and to some extent rely on these signals for survival and disease progression ${ }^{60}$. Reciprocally, the impact of leukemic cells in the microenvironment has been shown to be detrimental to normal hematopoiesis with leukemia cells out competing and "hijacking" the normal HSC niches ${ }^{61}$. Recent work utilizing an ALL mouse model revealed that cancer-propagating leukemic cells (CPCs) were able to create small foci CPCs surrounded by BMSC, which resulted in the leukemic cells being more resistant to chemotherapy at the expense of normal niche architecture $^{62}$. Together these studies illustrate the complexity of the BMM and its important role in leukemic disease, as well as the crosstalk between cells. Greater understanding of the relationship between the BMM and ALL will allow for targeted treatment strategies aimed at resistant niche supported cells. In response to this clinical challenge, our laboratory continues to investigate BMM interactions that support resistant $A L L$ cells through generation of new in vitro BMM/ALL models and innovative combination treatment strategies targeting refractory ALL as highlighted below.

\section{Role of BCL6 in ALL chemotherapy resistance}

As reviewed above, the BMM plays a critical role in the development of ALL chemotherapy resistance. In addition to niche cues, intrinsic mutations are known to promote chemotherapy resistance and correspond with poor outcomes in ALL patients. Well described translocations such as the Philadelphia chromosome (BCR-ABL)(Ph+) and the $11 \mathrm{q} 23$ rearrangement of the MLL gene are associated with aggressive disease and increased drug resistance ${ }^{63}$. Genetic lesions such as deletions or mutations in the IKZF1 gene or activating mutations in JAK tyrosine kinase have also been linked to drug 
resistance and high risk ALL disease ${ }^{63}$. In addition to these well-documented mutations, BCL6 protein (B-cell CLL/lymphoma 6, zinc finger protein 51) expression has recently been shown to promote drug resistance in $A L L^{64}$.

BCL6 or LAZ3 was first characterized in 1993 by two groups as a gene associated with 3q27 chromosomal translocations in B-cell lymphomas ${ }^{65,66}$. Soon after its initial characterization BCL6 was found to also be important in normal germinal center biology and B-cell development ${ }^{67,68}$. More recently BCL6 has become recognized as an important transcription factor in a variety of normal and malignant cell contexts. BCL6 is a $95 \mathrm{kDa}$ protein that functions as a sequence specific repressor of transcription ${ }^{69}$. BCL6 contains three distinct domains, the N-terminal BTB/POZ domain, a central PEST domain, and 6 C-terminus zinc finger DNA-binding motifs (Figure 3$)^{69}$. The N-terminal BTB/POZ domain is critical to BCL6's function as a transcriptional repressor, as this domain is responsible for recruitment and binding of histone deacetylase complexes and co-repressors ${ }^{69}$. Through this domain BCL6 is able to directly recruit class I and II histone deacetylases (HDAC) ${ }^{69-71}$. In addition, BCL6's BTB domain is able to recruit and bind multiple corepressors such as; NCOR1, NCOR2, BCOR, and CTBP1 all of which promote BCL6 function as a transcriptional repressor $69,70,72-76$. The $\mathrm{POZ}$ portion of this domain can also bind to other zinc finger proteins such as Miz-1, which was shown by Phan et al to increase the number of DNA sequences BCL6 could affect through use of the Miz-1 specific zinc finger DNA binding sites $^{77}$. The central PEST domain is also responsible for recruitment of co-repressors and like the BTB domain, it binds to CTBP1, but can also recruit co-repressor MTA3 ${ }^{69,76,78}$. Moreover, this domain regulates stability of BCL6 serving as a site for 
phosphorylation and acetylation ${ }^{69}$. ATM and MAPK pathway activation can result in phosphorylation of serine 333 or 343 within the PEST domain leading to BCL6 degradation through the ubiquitin-proteasome pathway ${ }^{79,80}$. Additionally, FBXO11 has also been reported to bind BCL6 and subsequently lead to ubiquitination and proteasomal degradation ${ }^{81}$. Acetylation of the PEST domain results in a functional inactivation of BCL6 by preventing recruitment of co-repressors ${ }^{82}$. The C-terminus zinc finger DNA-binding motifs are critical to BCL6's transcriptional activity through direct binding to sequence specific sites ${ }^{83-86}$. A few key examples of targeted binding of BCL6 through its zinc finger motifs are repression of $p 53$, TGF- $\beta$ receptors, STAT family members, a number of CD markers, as well as, key components of BCR, CD40, MAPK, and NF- $\varkappa$ B pathways ${ }^{69}$. Together these domains allow BCL6 to exert its transcriptional repression on a large number of targets through direct and indirect DNA binding, as well as recruitment of co-repressors. This positions BCL6 to regulate critical cellular programs such as survival, proliferation, and differentiation.

Classically, BCL6 has been studied for its role in germinal center biology and its impact on diffuse large B-cell lymphoma (DLBCL). In normal B-cell development, BCL6 expression is associated with B-cells of the dark zone of the germinal center ${ }^{87,88}$. Fukuda et al showed that nascent pre-germinal center B-cells upregulated BCL6 as a requirement for migration to the follicular area and initiation of germinal center formation ${ }^{89}$. Consistent with the earlier discussion of overlap in bone marrow regulation of normal hematopoiesis and dysregulation that results in ALL, many critical regulators have roles in both circumstances. BCL6 expression in the germinal center context promotes B-cell proliferation and allows for tolerance to DNA damage associated with 
gene rearrangement through repression of $p 53^{68,90-92}$. Additionally, BCL6 modulation is an important component of plasmacytic differentiation ${ }^{78,93}$. Overall, BCL6 regulation and its functions are essential to normal maturation of B-cells. Also, this likely explains why disruption to normal BCL6 physiology is a major factor in the lymphogenesis seen in DLBCL cases. In the case of DLBCL, BCL6 is often constitutively overexpressed due to translocation or mutations in the BCL6 locus ${ }^{66,94-96}$. In this context, BCL6 acts in much the same way it does in normal B-cell development promoting proliferation and tolerance to DNA damaging stress, thus resulting in B-cell lymphoma ${ }^{94,97-105 .}$

More recently BCL6 has been discovered to play a role in malignancies of immature B-cells in addition to the role described above for DLBCL, as well as other forms of hematologic diseases ${ }^{64,106-108}$. Sarsotti et al. identified a group of B-cell chronic lymphocytic leukemias with BCL6 mutations and observed that these patients had a higher risk of disease progression than those without BCL6 mutations ${ }^{109}$. BCL6 has also been reported to be critical for leukemic stem cell survival in chronic myeloid leukemia $(\mathrm{CML})$ through its repression of $\mathrm{p} 53^{108}$. Additionally, through generation of a $\mathrm{Ph}^{+}$pre- B-cell ALL model, Duy et al. found that BCL6 was also important to ALL leukemic stem cells ${ }^{64}$. This group also discovered that BCL6 was upregulated in response to tyrosine kinase inhibition, and in part promoted survival through TKI resistance via inhibition of $p 53^{64}$. Collectively, BCL6 is a well-defined factor in the development of both normal and malignant B-cells that regulates differentiation, proliferation, and survival. 


\section{Summary}

ALL was once a devastating disease with few treatment options and little chance of survival. Advances in our understanding of this disease, as well as synthesis of a variety of chemotherapy agents allowed for the first breakthroughs in the treatment of ALL. Moreover, modern combination treatments have resulted in some of the highest response rates seen in all forms of cancer. However, relapse of disease remains a persistent problem in the long term survival of patients with ALL and relapse events commonly still result in aggressive and drug resistant disease leading to poor outcomes.

One major contributor to relapse of disease is the frequency with which ALL cells persist in the bone marrow niche and contributes to refractory disease that is inevitably aggressive. This clinical challenge provides the rational for the projects described herein, in which our laboratory aims to establish an efficient and accurate in vitro, preclinical representation of the most drug resistant ALL populations supported through BMM interactions. In the manuscript Slone and Moses et al., we provide instruction and representative results of our in vitro model of $A L L$ and the BMM, in which we establish and recover a chemotherapy resistant ALL population (Chapter 2$)^{40}$. This is followed by our report in which the BMM supported in vitro ALL chemotherapy resistant population is further characterized (Chapter 3$)^{39}$. In addition to the promotion of chemotherapy resistance through BMM interaction, upregulation of the proto-onco gene BCL6 is known to support ALL drug resistance ${ }^{64}$. However, a major gap in the field is an understanding of how the BMM influences ALL levels of BCL6. This gap, as well as potential interventions surrounding BMM modulation of ALL BCL6 abundance, is discussed in Chapter 4. Collectively, the goal of this project is to provide a better in vitro 
platform in which to test hypotheses centered on ALL and BMM interactions that lead to resistant disease. Additionally, through use of these models, we aim to better understand the impact of the BMM on ALL BCL6 levels and use this information to further progress current chemotherapy regimens, so that refractory disease may be reduced and relapse of ALL prevented. While preventing relapse is the unifying goal of these studies, observations that contribute to reduced need for intense and repeated chemotherapy exposure in children is also an important consideration given the long term consequences including the generation of secondary malignancies. Together, these concerns underpin the following studies. 


\section{References}

1. Inaba $\mathrm{H}$, Greaves M, Mullighan CG. Acute lymphoblastic leukaemia. The Lancet. 2013;381(9881):1943-1955.

2. Howlader N, Noone A, Krapcho M, et al. SEER Cancer Statistics Review, 1975-2012, National Cancer Institute. Bethesda, MD, http://seer.cancer.gov/csr/1975_2012/, based on November 2014 SEER data submission, posted to the SEER web site, April 2015. 2014;

3. Bassan R, Hoelzer D. Modern therapy of acute lymphoblastic leukemia. J. Clin. Oncol. Off. J. Am. Soc. Clin. Oncol. 2011;29(5):532-543.

4. Piller GJ. Leukaemia - a brief historical review from ancient times to 1950. Br. J. Haematol. 2001;112(2):282-292.

5. Thomas X. First contributors in the history of leukemia. World J. Hematol. 2013;2(3):62.

6. Gilman A, Philips FS. The Biological Actions and Therapeutic Applications of the BChloroethyl Amines and Sulfides. Science. 1946;103(2675):409-436.

7. Farber S. Some observations on the effect of folic acid antagonists on acute leukemia and other forms of incurable cancer. Blood. 1949;4(2):160-167.

8. Franklin AL, Stokstad ELR. Biochemical experiments with a synthetic preparation having an action antagonistic to that of pteroylglutamic acid. J. Biol. Chem. 1947;169(2):427-435.

9. Farber S, Diamond LK. Temporary remissions in acute leukemia in children produced by folic acid antagonist, 4-aminopteroyl-glutamic acid. N. Engl. J. Med. 1948;238(23):787-793.

10. Pui C-H, Evans WE. A 50-Year Journey to Cure Childhood Acute Lymphoblastic Leukemia. Semin. Hematol. 2013;50(3):185-196.

11. Seibel NL. Acute Lymphoblastic Leukemia: An Historical Perspective. ASH Educ. Program Book. 2008;2008(1):365-365.

12. Pinkel D. Flve-year follow-up of "total therapy" of childhood lymphocytic leukemia. JAMA. 1971;216(4):648-652. 
13. Aur RJA, Simone J, Hustu HO, et al. Central Nervous System Therapy and Combination Chemotherapy of Childhood Lymphocytic Leukemia. Blood. 1971;37(3):272-281.

14. Gökbuget N, Hoelzer D. Treatment of Adult Acute Lymphoblastic Leukemia. Semin. Hematol. 2009;46(1):64-75.

15. Szczepanek J, Styczyński J, Haus O, Tretyn A, Wysocki M. Relapse of Acute Lymphoblastic Leukemia in Children in the Context of Microarray Analyses. Arch. Immunol. Ther. Exp. (Warsz.). 2011;59(1):61-68.

16. Gökbuget N, Stanze D, Beck J, et al. Outcome of relapsed adult lymphoblastic leukemia depends on response to salvage chemotherapy, prognostic factors, and performance of stem cell transplantation. Blood. 2012;120(10):2032-2041.

17. Choi S, Henderson MJ, Kwan E, et al. Relapse in children with acute lymphoblastic leukemia involving selection of a preexisting drug-resistant subclone. Blood. 2007;110(2):632639.

18. Pui C-H, Campana D, Evans WE. Childhood acute lymphoblastic leukaemia - current status and future perspectives. Lancet Oncol. 2001;2(10):597-607.

19. Pui C-H, Relling MV, Downing JR. Acute Lymphoblastic Leukemia. N. Engl. J. Med. 2004;350(15):1535-1548.

20. Gaynon PS, Qu RP, Chappell RJ, et al. Survival after relapse in childhood acute lymphoblastic leukemia: impact of site and time to first relapse--the Children's Cancer Group Experience. Cancer. 1998;82(7):1387-1395.

21. Chessells JM, Veys P, Kempski H, et al. Long-term follow-up of relapsed childhood acute lymphoblastic leukaemia. Br. J. Haematol. 2003;123(3):396-405.

22. Pui C-H, Robison LL, Look AT. Acute lymphoblastic leukaemia. The Lancet. 2008;371(9617):1030-1043.

23. Nguyen K, Devidas M, Cheng S-C, et al. Factors Influencing Survival After Relapse From Acute Lymphoblastic Leukemia: A Children's Oncology Group Study. Leuk. Off. J. Leuk. Soc. Am. Leuk. Res. Fund UK. 2008;22(12):2142-2150.

24. Cooper B. The origins of bone marrow as the seedbed of our blood: from antiquity to the time of Osler. Proc. Bayl. Univ. Med. Cent. 2011;24(2):115-118. 
25. Chiarini F, Lonetti A, Evangelisti C, et al. Advances in understanding the acute lymphoblastic leukemia bone marrow microenvironment: From biology to therapeutic targeting. Biochim. Biophys. Acta BBA - Mol. Cell Res. 2016;1863(3):449-463.

26. Boulais PE, Frenette PS. Making sense of hematopoietic stem cell niches. Blood. 2015;125(17):2621-2629.

27. Raggatt LJ, Partridge NC. Cellular and Molecular Mechanisms of Bone Remodeling. J. Biol. Chem. 2010;285(33):25103-25108.

28. Sims NA, Martin TJ. Coupling the activities of bone formation and resorption: a multitude of signals within the basic multicellular unit. BoneKEy Rep. 2014;3:481.

29. Taichman RS, Emerson SG. Human osteoblasts support hematopoiesis through the production of granulocyte colony-stimulating factor. J. Exp. Med. 1994;179(5):1677-1682.

30. Taichman RS, Reilly MJ, Emerson SG. Human osteoblasts support human hematopoietic progenitor cells in vitro bone marrow cultures. Blood. 1996;87(2):518-524.

31. Calvi LM, Adams GB, Weibrecht KW, et al. Osteoblastic cells regulate the haematopoietic stem cell niche. Nature. 2003;425(6960):841-846.

32. Zhang J, Niu C, Ye L, et al. Identification of the haematopoietic stem cell niche and control of the niche size. Nature. 2003;425(6960):836-841.

33. Evans AG, Calvi LM. Notch signaling in the malignant bone marrow microenvironment: implications for a niche-based model of oncogenesis. Ann. N. Y. Acad. Sci. 2015;1335(1):6377.

34. Visnjic D, Kalajzic Z, Rowe DW, et al. Hematopoiesis is severely altered in mice with an induced osteoblast deficiency. Blood. 2004;103(9):3258-3264.

35. Arai F, Hirao A, Ohmura M, et al. Tie2/Angiopoietin-1 Signaling Regulates Hematopoietic Stem Cell Quiescence in the Bone Marrow Niche. Cell. 2004;118(2):149-161.

36. Stier S, Ko Y, Forkert R, et al. Osteopontin is a hematopoietic stem cell niche component that negatively regulates stem cell pool size. J. Exp. Med. 2005;201(11):1781-1791.

37. Nilsson SK, Johnston HM, Whitty GA, et al. Osteopontin, a key component of the hematopoietic stem cell niche and regulator of primitive hematopoietic progenitor cells. Blood. 
2005;106(4):1232-1239.

38. Boyerinas B, Zafrir M, Yesilkanal AE, et al. Adhesion to osteopontin in the bone marrow niche regulates lymphoblastic leukemia cell dormancy. Blood. 2013;121(24):4821-4831.

39. Moses BS, Slone WL, Thomas P, et al. Bone marrow microenvironment modulation of acute lymphoblastic leukemia phenotype. Exp. Hematol. 2016;44(1):50-59.e2.

40. Slone WL, Moses BS, Evans R, et al. Modeling Chemotherapy Resistant Leukemia In Vitro. J. Vis. Exp. JoVE. 2016;(108.):

41. Dong-Feng Z, Ting L, Yong Z, et al. The TPO/c-MPL pathway in the bone marrow may protect leukemia cells from chemotherapy in AML Patients. Pathol. Oncol. Res. POR. 2014;20(2):309-317.

42. Saito $\mathrm{Y}$, Uchida N, Tanaka S, et al. Induction of cell cycle entry eliminates human leukemia stem cells in a mouse model of AML. Nat. Biotechnol. 2010;28(3):275-280.

43. Yamazaki S, Ema H, Karlsson G, et al. Nonmyelinating Schwann cells maintain hematopoietic stem cell hibernation in the bone marrow niche. Cell. 2011;147(5):1146-1158.

44. Yamazaki S, Iwama A, Takayanagi S, et al. TGF- $\beta$ as a candidate bone marrow niche signal to induce hematopoietic stem cell hibernation. Blood. 2009;113(6):1250-1256.

45. Butler JM, Nolan DJ, Vertes EL, et al. Endothelial cells are essential for the self-renewal and repopulation of Notch-dependent hematopoietic stem cells. Cell Stem Cell. 2010;6(3):251264.

46. Kunisaki Y, Bruns I, Scheiermann C, et al. Arteriolar niches maintain haematopoietic stem cell quiescence. Nature. 2013;502(7473):637-643.

47. Jing D, Fonseca A-V, Alakel N, et al. Hematopoietic stem cells in co-culture with mesenchymal stromal cells--modeling the niche compartments in vitro. Haematologica. 2010;95(4):542-550.

48. Krause DS, Scadden DT, Preffer FI. The hematopoietic stem cell niche-home for friend and foe? Cytometry B Clin. Cytom. 2013;84B(1):7-20.

49. Nakamura-Ishizu A, Suda T. Hematopoietic stem cell niche: An interplay among a repertoire of multiple functional niches. Biochim. Biophys. Acta BBA - Gen. Subj. 
2013;1830(2):2404-2409.

50. Suda T, Arai F, Hirao A. Hematopoietic stem cells and their niche. Trends Immunol. 2005;26(8):426-433.

51. Ding L, Morrison SJ. Haematopoietic stem cells and early lymphoid progenitors occupy distinct bone marrow niches. Nature. 2013;495(7440):231-235.

52. Ding L, Saunders TL, Enikolopov G, Morrison SJ. Endothelial and perivascular cells maintain haematopoietic stem cells. Nature. 2012;481(7382):457-462.

53. Chiaretti S, Foà R. T-cell acute lymphoblastic leukemia. Haematologica. 2009;94(2):160-162.

54. Wei J, Wunderlich M, Fox C, et al. Microenvironment determines lineage fate in a human model of MLL-AF9 leukemia. Cancer Cell. 2008;13(6):483-495.

55. Mudry RE, Fortney JE, York T, Hall BM, Gibson LF. Stromal cells regulate survival of Blineage leukemic cells during chemotherapy. Blood. 2000;96(5):1926-1932.

56. Iwamoto S, Mihara K, Downing JR, Pui C-H, Campana D. Mesenchymal cells regulate the response of acute lymphoblastic leukemia cells to asparaginase. J. Clin. Invest. 2007;117(4):1049-1057.

57. Meads MB, Hazlehurst LA, Dalton WS. The Bone Marrow Microenvironment as a Tumor Sanctuary and Contributor to Drug Resistance. Clin. Cancer Res. 2008;14(9):2519-2526.

58. Tesfai Y, Ford J, Carter KW, et al. Interactions between acute lymphoblastic leukemia and bone marrow stromal cells influence response to therapy. Leuk. Res. 2012;36(3):299-306.

59. Hazlehurst LA, Argilagos RF, Dalton WS. Beta1 integrin mediated adhesion increases Bim protein degradation and contributes to drug resistance in leukaemia cells. Br. J. Haematol. 2007;136(2):269-275.

60. Dührsen U, Hossfeld DK. Stromal abnormalities in neoplastic bone marrow diseases. Ann. Hematol. 1996;73(2):53-70.

61. Colmone A, Amorim M, Pontier AL, et al. Leukemic Cells Create Bone Marrow Niches That Disrupt the Behavior of Normal Hematopoietic Progenitor Cells. Science. 
2008;322(5909):1861-1865.

62. Duan C-W, Shi J, Chen J, et al. Leukemia propagating cells rebuild an evolving niche in response to therapy. Cancer Cell. 2014;25(6):778-793.

63. Bhojwani D, Howard SC, Pui C-H. High-risk childhood acute lymphoblastic leukemia. Clin. Lymphoma Myeloma. 2009;9 Suppl 3:S222-230.

64. Duy C, Hurtz C, Shojaee S, et al. BCL6 enables $\mathrm{Ph}+$ acute lymphoblastic leukaemia cells to survive BCR-ABL1 kinase inhibition. Nature. 2011;473(7347):384-388.

65. Baron BW, Nucifora G, McCabe N, et al. Identification of the gene associated with the recurring chromosomal translocations $\mathrm{t}(3 ; 14)(\mathrm{q} 27 ; \mathrm{q} 32)$ and $\mathrm{t}(3 ; 22)(\mathrm{q} 27 ; \mathrm{q} 11)$ in B-cell lymphomas. Proc. Natl. Acad. Sci. U. S. A. 1993;90(11):5262-5266.

66. Kerckaert JP, Deweindt C, Tilly H, et al. LAZ3, a novel zinc-finger encoding gene, is disrupted by recurring chromosome $3 q 27$ translocations in human lymphomas. Nat. Genet. 1993;5(1):66-70.

67. Cattoretti G, Chang CC, Cechova K, et al. BCL-6 protein is expressed in germinal-center B cells. Blood. 1995;86(1):45-53.

68. Shaffer AL, Yu X, He Y, et al. BCL-6 represses genes that function in lymphocyte differentiation, inflammation, and cell cycle control. Immunity. 2000;13(2):199-212.

69. Basso K, Dalla-Favera R. Roles of BCL6 in normal and transformed germinal center B cells. Immunol. Rev. 2012;247(1):172-183.

70. Wong CW, Privalsky ML. Components of the SMRT corepressor complex exhibit distinctive interactions with the POZ domain oncoproteins PLZF, PLZF-RARalpha, and BCL-6. J. Biol. Chem. 1998;273(42):27695-27702.

71. Lemercier C, Brocard M-P, Puvion-Dutilleul F, et al. Class II histone deacetylases are directly recruited by BCL6 transcriptional repressor. J. Biol. Chem. 2002;277(24):22045-22052.

72. Huynh KD, Bardwell VJ. The BCL-6 POZ domain and other POZ domains interact with the co-repressors N-CoR and SMRT. Oncogene. 1998;17(19):2473-2484. 
73. Huynh KD, Fischle W, Verdin E, Bardwell VJ. BCoR, a novel corepressor involved in BCL-6 repression. Genes Dev. 2000;14(14):1810-1823.

74. Dhordain P, Albagli O, Lin RJ, et al. Corepressor SMRT binds the BTB/POZ repressing domain of the LAZ3/BCL6 oncoprotein. Proc. Natt. Acad. Sci. U. S. A. 1997;94(20):1076210767.

75. Ahmad KF, Melnick A, Lax S, et al. Mechanism of SMRT corepressor recruitment by the BCL6 BTB domain. Mol. Cell. 2003;12(6):1551-1564.

76. Mendez LM, Polo JM, Yu JJ, et al. CtBP is an essential corepressor for BCL6 autoregulation. Mol. Cell. Biol. 2008;28(7):2175-2186.

77. Phan RT, Saito M, Basso K, Niu H, Dalla-Favera R. BCL6 interacts with the transcription factor Miz-1 to suppress the cyclin-dependent kinase inhibitor p21 and cell cycle arrest in germinal center B cells. Nat. Immunol. 2005;6(10):1054-1060.

78. Fujita N, Jaye DL, Geigerman C, et al. MTA3 and the Mi-2/NuRD complex regulate cell fate during B lymphocyte differentiation. Cell. 2004;119(1):75-86.

79. Phan RT, Saito M, Kitagawa Y, Means AR, Dalla-Favera R. Genotoxic stress regulates expression of the proto-oncogene Bcl6 in germinal center B cells. Nat. Immunol. 2007;8(10):1132-1139.

80. Niu H, Ye BH, Dalla-Favera R. Antigen receptor signaling induces MAP kinase-mediated phosphorylation and degradation of the BCL-6 transcription factor. Genes Dev. 1998;12(13):1953-1961.

81. Duan S, Cermak L, Pagan JK, et al. FBXO11 targets BCL6 for degradation and is inactivated in diffuse large B-cell lymphomas. Nature. 2012;481(7379):90-93.

82. Bereshchenko OR, Gu W, Dalla-Favera R. Acetylation inactivates the transcriptional repressor BCL6. Nat. Genet. 2002;32(4):606-613.

83. Basso K, Saito M, Sumazin P, et al. Integrated biochemical and computational approach identifies BCL6 direct target genes controlling multiple pathways in normal germinal-center B cells. Blood. 2009;

84. Chang CC, Ye BH, Chaganti RS, Dalla-Favera R. BCL-6, a POZ/zinc-finger protein, is a sequence-specific transcriptional repressor. Proc. Natl. Acad. Sci. 1996;93(14):6947-6952. 
85. Kawamata N, Miki T, Ohashi K, et al. Recognition DNA sequence of a novel putative transcription factor, BCL6. Biochem. Biophys. Res. Commun. 1994;204(1):366-374.

86. Ci W, Polo JM, Cerchietti L, et al. The BCL6 transcriptional program features repression of multiple oncogenes in primary B cells and is deregulated in DLBCL. Blood.

2009;113(22):5536-5548.

87. Onizuka T, Moriyama M, Yamochi T, et al. BCL-6 gene product, a 92- to 98-kD nuclear phosphoprotein, is highly expressed in germinal center B cells and their neoplastic counterparts. Blood. 1995;86(1):28-37.

88. Allman D, Jain A, Dent A, et al. BCL-6 expression during B-cell activation. Blood. 1996;87(12):5257-5268.

89. Fukuda T, Yoshida T, Okada S, et al. Disruption of the Bcl6 gene results in an impaired germinal center formation. J. Exp. Med. 1997;186(3):439-448.

90. Phan RT, Dalla-Favera R. The BCL6 proto-oncogene suppresses p53 expression in germinal-centre B cells. Nature. 2004;432(7017):635-639.

91. Ranuncolo SM, Polo JM, Melnick A. BCL6 represses CHEK1 and suppresses DNA damage pathways in normal and malignant B-cells. Blood Cells. Mol. Dis. 2008;41(1):95-99.

92. Ranuncolo SM, Polo JM, Dierov J, et al. Bcl-6 mediates the germinal center B cell phenotype and lymphomagenesis through transcriptional repression of the DNA-damage sensor ATR. Nat. Immunol. 2007;8(7):705-714.

93. Tunyaplin C, Shaffer AL, Angelin-Duclos CD, et al. Direct repression of prdm1 by Bcl-6 inhibits plasmacytic differentiation. J. Immunol. Baltim. Md 1950. 2004;173(2):1158-1165.

94. Baron BW, Anastasi J, Montag A, et al. The human BCL6 transgene promotes the development of lymphomas in the mouse. Proc. Natl. Acad. Sci. U. S. A. 2004;101(39):1419814203.

95. Ye BH, Chaganti S, Chang CC, et al. Chromosomal translocations cause deregulated BCL6 expression by promoter substitution in B cell lymphoma. EMBO J. 1995;14(24):62096217.

96. Ye BH, Lista F, Coco F Lo, et al. Alterations of a zinc finger-encoding gene, BCL-6, in diffuse large-cell lymphoma. Science. 1993;262(5134):747-750. 
97. Bai M, Agnantis NJ, Skyrlas A, et al. Increased Expression of the bcl6 and CD10 Proteins Is Associated with Increased Apoptosis and Proliferation in Diffuse Large B-Cell Lymphomas. Mod. Pathol. 2003;16(5):471-480.

98. Bertolo C, Roa S, Sagardoy A, et al. LITAF, a BCL6 target gene, regulates autophagy in mature B-cell lymphomas. Br. J. Haematol. 2013;162(5):621-630.

99. Brunn A, Nagel I, Montesinos-Rongen M, et al. Frequent triple-hit expression of MYC, BCL2, and BCL6 in primary lymphoma of the central nervous system and absence of a favorable MYC(low)BCL2 (low) subgroup may underlie the inferior prognosis as compared to systemic diffuse large B cell lymphomas. Acta Neuropathol. (Berl.). 2013;126(4):603-605.

100. Cattoretti G, Pasqualucci L, Ballon G, et al. Deregulated BCL6 expression recapitulates the pathogenesis of human diffuse large B cell lymphomas in mice. Cancer Cell. 2005;7(5):445455.

101. Cerchietti LC, Hatzi K, Caldas-Lopes E, et al. BCL6 repression of EP300 in human diffuse large B cell lymphoma cells provides a basis for rational combinatorial therapy. J. Clin. Invest. 2010;120(12):4569-4582.

102. Cristina Bertolo SR. LITAF, a BCL6 target gene, regulates autophagy in mature B-cell lymphomas. Br. J. Haematol. 2013;

103. Gu X, Booth CJ, Liu Z, Strout MP. AID-associated DNA repair pathways regulate malignant transformation in a murine model of BCL6-driven diffuse large B-cell lymphoma. Blood. 2016;127(1):102-112.

104. Parekh S, Polo JM, Shaknovich R, et al. BCL6 programs lymphoma cells for survival and differentiation through distinct biochemical mechanisms. Blood. 2007;110(6):2067-2074.

105. Saito M, Gao J, Basso K, et al. A signaling pathway mediating downregulation of BCL6 in germinal center B cells is blocked by BCL6 gene alterations in B cell lymphoma. Cancer Cell. 2007;12(3):280-292.

106. Hideshima T, Mitsiades $\mathrm{C}$, Ikeda $\mathrm{H}$, et al. A proto-oncogene BCL6 is up-regulated in the bone marrow microenvironment in multiple myeloma cells. Blood. 2010;115(18):3772-3775.

107. Geng H, Hurtz C, Lenz KB, et al. Self-Enforcing Feedback Activation between BCL6 and Pre-B Cell Receptor Signaling Defines a Distinct Subtype of Acute Lymphoblastic Leukemia. Cancer Cell. 2015;27(3):409-425. 
108. Hurtz C, Hatzi K, Cerchietti L, et al. BCL6-mediated repression of p53 is critical for leukemia stem cell survival in chronic myeloid leukemia. J. Exp. Med. 2011;208(11):2163-2174.

109. Sarsotti E, Marugan I, Benet I, et al. Bcl-6 mutation status provides clinically valuable information in early-stage B-cell chronic lymphocytic leukemia. Leukemia. 2004;18(4):743-746. 


\section{Figures}

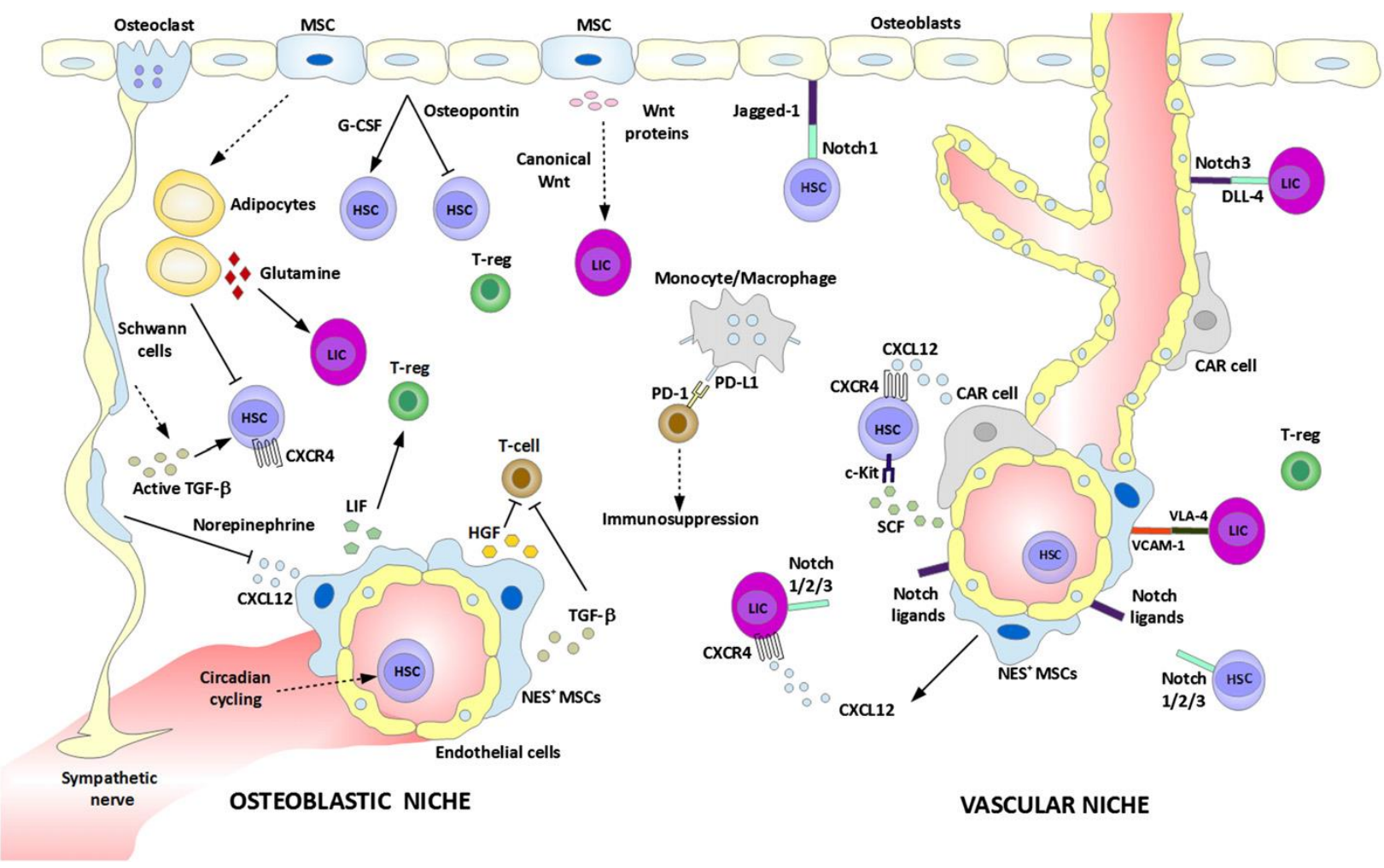

Figure 1. Mechanisms involved in HSCs and LICs maintenance in osteoblastic and vascular niches.

Chiarini F, Lonetti A, Evangelisti C, et al. Advances in understanding the acute lymphoblastic leukemia bone marrow microenvironment: From biology to therapeutic targeting. Biochim. Biophys. Acta BBA - Mol. Cell Res. 2016;1863(3):449-463. Permission license number: 3825990660594 


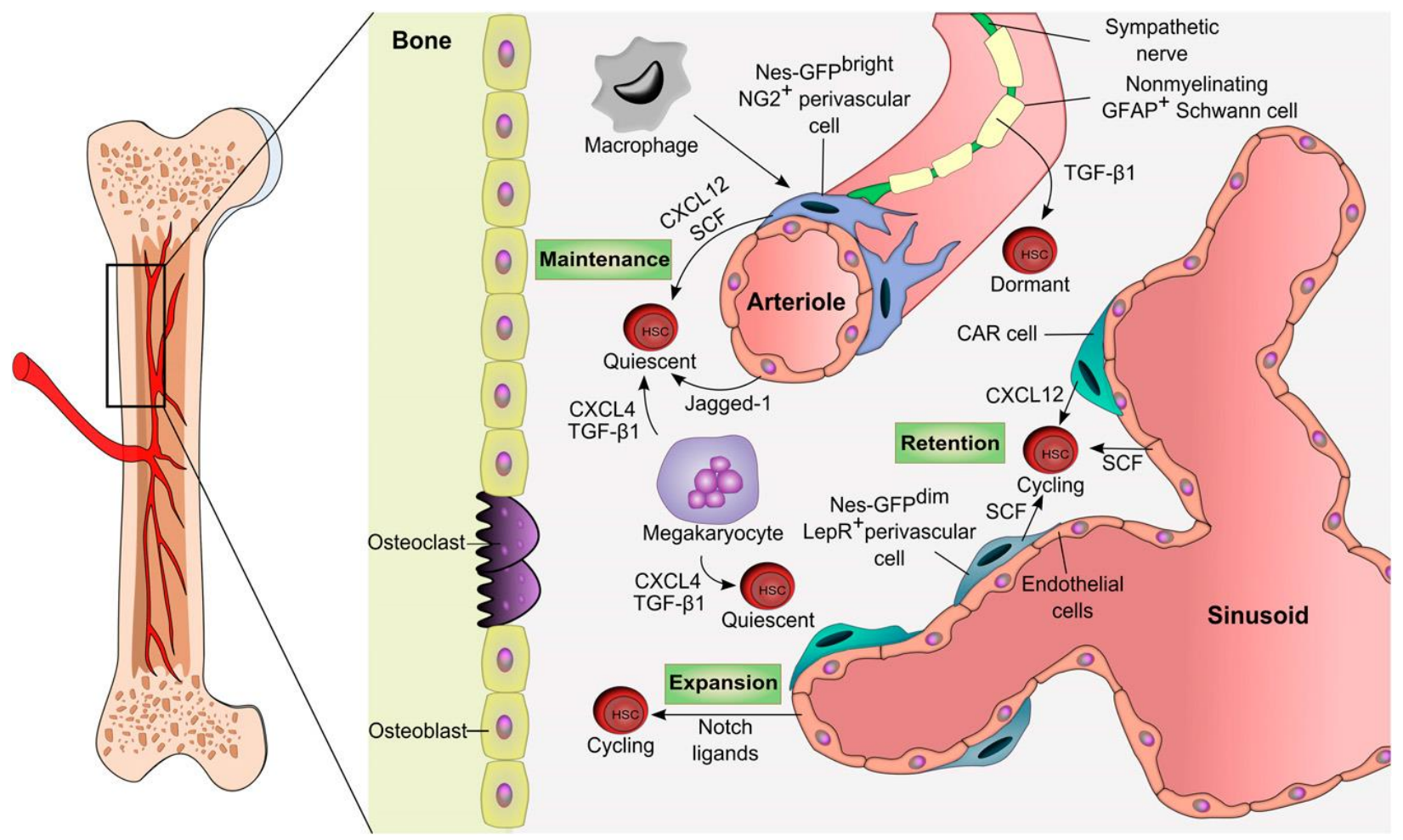

Figure 2. The adult bone marrow HSC niche.

Boulais PE, Frenette PS. Making sense of hematopoietic stem cell niches. Blood. 2015;125(17):2621-2629. 


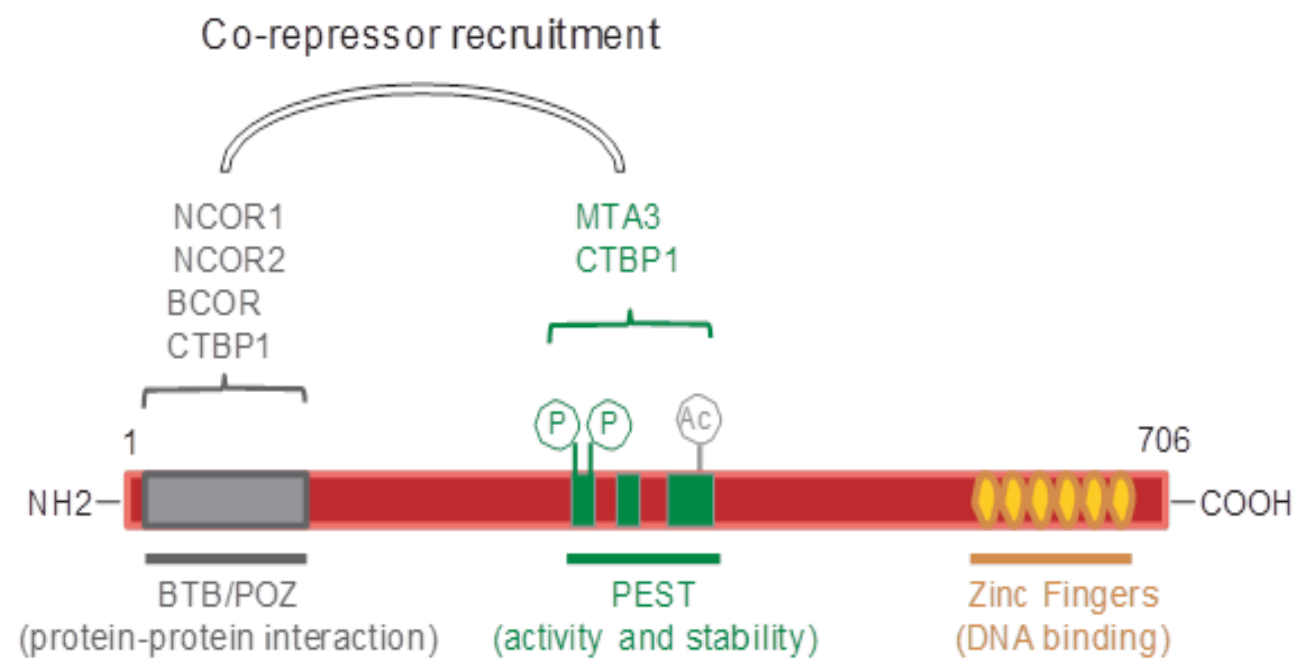

Figure 3. Schematic representation of BCL6 illustrating its key domains and binding partners.

Adapted from: Basso K, Dalla-Favera R. Roles of BCL6 in normal and transformed germinal center B cells. Immunol. Rev. 2012;247(1):172-183. 


\section{Chapter 2}

\section{Modeling chemotherapy resistant leukemia in vitro}

Slone, William L. ${ }^{1, \dagger}$, Moses, Blake S. ${ }^{1, \dagger}$, Evans, Rebecca ${ }^{1}$, Piktel, Debbie ${ }^{1}$, Martin, Karen H. ${ }^{1,2}$, Petros, William ${ }^{1}$, Craig, Michael ${ }^{1}$, and Gibson, Laura F. ${ }^{1,3}$

†These authors contributed equally to this work

${ }^{1}$ Alexander B. Osborn Hematopoietic Malignancy and Transplantation Program of the Mary Babb Randolph Cancer Center, ${ }^{2}$ Department of Neurobiology and Anatomy and ${ }^{3}$ Department of Microbiology, Immunology and Cell Biology, Robert C. Byrd Health Sciences Center, West Virginia University School of Medicine, USA

KEYWORDS: Leukemia, Chemotherapy, Microenvironment, Resistance, Niche, Marrow

This work has been published as a manuscript in Jove:

Slone WL, Moses BS, Evans R, Piktel D, Martin KH, Petros W, Craig M, Gibson LF. Modeling Chemotherapy Resistant Leukemia In Vitro. J Vis Exp JoVE 2016.

\section{Video protocol can be found at:}

http://www.jove.com/video/53645/modeling-chemotherapy-resistant-leukemia-invitro 
SHORT ABSTRACT: The current report summarizes a protocol that can be utilized to model the influence of the bone marrow microenvironment niche on leukemic cells with emphasis placed on enrichment of the most chemoresistant subpopulation.

LONG ABSTRACT: It is well established that the bone marrow microenvironment provides a unique site of sanctuary for hematopoietic diseases that both initiate and progress in this site. The model presented in the current report utilizes human primary bone marrow stromal cells and osteoblasts as two representative cell types from the marrow niche that influence tumor cell phenotype. The in vitro co-culture conditions described for human leukemic cells with these primary niche components support the generation of a chemoresistant subpopulation of tumor cells that can be efficiently recovered from culture for analysis by diverse techniques. A strict feeding schedule to prevent nutrient fluxes followed by gel type 10 cross-linked dextran (G10) particles recovery of the population of tumor cells that have migrated beneath the adherent bone marrow stromal cells (BMSC) or osteoblasts (OB) generating a "phase dim" (PD) population of tumor cells, provides a consistent source of purified therapy resistant leukemic cells. This clinically relevant population of tumor cells can be evaluated by standard methods to investigate apoptotic, metabolic, and cell cycle regulatory pathways as well as providing a more rigorous target in which to test novel therapeutic strategies prior to pre-clinical investigations targeted at minimal residual disease. 
INTRODUCTION: The overall goal of the method described is to provide an efficient, cost-effective in vitro approach that supports investigation of the mechanisms that underlie bone marrow supported survival of leukemic cells during chemotherapy exposure. It is well documented that surviving residual tumor cells that persist after treatment contribute to relapse of disease that is often more aggressive than that at diagnosis and is often less effectively treated ${ }^{1-8}$. Models that include leukemic cells in isolation, such as those limited to culture of cells in media alone, for testing of therapeutic approaches do not factor in these critical signals, or the heterogeneity of disease that occurs in response to availability of niche derived cues in which tumor cell subpopulations with very specific interactions with niche cells derive enhanced protection. Standard 2D co-culture models that co-culture bone marrow derived stromal cells and leukemic cells have somewhat addressed the contribution of the marrow niche and have shown that interaction with bone marrow microenvironment cells increases their resistance to chemotherapy and alters their growth characteristics ${ }^{9-14}$. These models however often fail to recapitulate long term survival of tumor cells and do not accurately inform the outcomes associated with the most resistant leukemic cell populations that contribute to MRD. In vivo models remain critical and define the "gold standard" for investigation of innovative therapies prior to clinical trials but they are often challenged by the time and cost required to test hypotheses related to resistant tumors and relapse of disease. As such, development of more informative 2D models would be of benefit for pilot investigations to better inform the design of subsequent murine based pre-clinical design. 
The $2 \mathrm{D}$ in vitro model presented in this report lacks the complexity of the true in vivo microenvironment, but provides a cost effective and reproducible means to interrogate tumor interactions with the microenvironment that lends itself specifically to enrichment of the chemoresistant subpopulation of tumor cells. This distinction is valuable as evaluation of the entire population of tumor cells may mask the phenotype of a minor group of therapy resistant tumor cells that comprise the most important target. An additional advantage is the scalability of the model to fit the analysis of interest. Bulk cultures can be established for those analyses requiring significant recovery of tumor cells, while small scale co-cultures in multi-well plates can be utilized for PCR based analysis or microscopy based evaluations.

Based on this need we developed an in vitro model to address the heterogeneity of disease that is characteristic of B-lineage acute lymphoblastic leukemia (ALL). We demonstrate that ALL cells, which share many characteristics in common with their healthy counterparts, localize to distinct compartments of BMSC or OB co-culture. Three populations of tumor cells are generated that have distinct phenotypes that are valuable for investigation of therapeutic response. Specifically, we demonstrate that (ALL) cells recovered from the "phase dim" (PD) population of co-culture are consistently refractory to therapy with survival that approximates tumor cells that have not been exposed to cytotoxic agents. These ALL cells, from either established cell lines or primary patient samples, migrate beneath adherent stromal cells or osteoblast layers but can be captured following trypsinization of cultures and separation of cell types by utilization of gel type 10 cross-linked dextran (G10) particle columns ${ }^{15}$. 
Here we present a setup of a $2 \mathrm{D}$ co-culture that can be employed to model interactions between bone marrow microenvironment stromal cells (BMSC/OB) and leukemic cells. Of particular importance is the observation that leukemic cells form three spatial subpopulations relative to the stromal cell monolayer and that the PD population represents a chemotherapy resistant tumor population due to its interaction with the BMSC or OB. Furthermore, we demonstrate how to effectively isolate the leukemic cell populations by $\mathrm{G} 10$ columns. Of note, we have found that isolation of these subpopulations allows for downstream analysis of the most resistant PD population to determine potential modes of resistance that are conferred to these cells due to their interaction with the bone marrow microenvironment stromal cells or osteoblasts. Techniques that we have utilized downstream of this co-culture and isolation model include flow cytometric evaluation, proteomic analysis and targeted protein expression evaluation as well as more recently developed laser ablation electrospray ionization (LAESI) and Seahorse analysis to evaluate metabolic profiles. Through use of this model in combination with the techniques above we have found that the PD population of leukemic cells has a chemotherapy resistant phenotype that is unique when compared to leukemic cells cultured in media alone or those recovered from the other subpopulations in the same co-culture. As such, this model lends itself to more rigorous evaluation to test strategies targeting the most chemotherapy resistant leukemic cells which derive their resistant phenotype through interaction with the bone marrow microenvironment. 


\section{Protocol:}

\section{Advanced preparation}

1.1) Preparing G10 particles.

1.1.1) Prepare $\mathrm{G} 10$ slurry by adding $50 \mathrm{ml} 1 \mathrm{x}$ PBS to $10 \mathrm{~g} \mathrm{G} 10$ particles. Mix by inversion and allow $\mathrm{G} 10$ to settle out of phosphate buffered saline (PBS) at $4^{\circ} \mathrm{C}$ overnight.

1.1.2) The day of G10 column separation, aspirate PBS from settled $\mathrm{G} 10$ particles and add $50 \mathrm{ml}$ fresh PBS. Mix by inversion. Repeat twice, adding $50 \mathrm{ml}$ fresh PBS to settled $\mathrm{G} 10$ particles and store at $4^{\circ} \mathrm{C}$ until ready to use.

1.2) Culturing BMSC and OB.

1.2.1) Both $\mathrm{BMSC}$ or $\mathrm{OB}$ are maintained at $37^{\circ} \mathrm{C}$ in $6 \% \mathrm{CO}_{2}$ and grown on $10 \mathrm{~cm}$ tissue culture plates until $90 \%$ confluency is reached.

1.2.2) BMSC or OB cells are trypsinized and split $1: 2$ onto new $10 \mathrm{~cm}$ plates. The cells are grown to these standards until needed for leukemic co-culturing.

\section{Establishing and maintaining co-culture}

2.1) Add $5-20 \times 10^{6}$ leukemic cells in $10 \mathrm{ml}$ of tumor specific culture media onto an $80-90 \%$ confluent BMSC or OB plate.

NOTE: Our lab maintains co-cultures at $37{ }^{\circ} \mathrm{C}$ in $5 \% \mathrm{O}_{2}$ to better recapitulate the bone marrow microenvironment which has been shown to range from 1 to $7 \%^{16-18}$. However, maintaining co-cultures at this oxygen tension is not critical for the establishment of the three leukemic subpopulations and is at the discretion of the lab.

2.2) Every $4^{\text {th }}$ day remove all but $1 \mathrm{ml}$ of media (including leukemic cells in suspension) and replace with $9 \mathrm{ml}$ fresh leukemic culture media.

NOTE: When removing $9 \mathrm{ml}$ of media from plate, be careful not to disturb the BMSC or $\mathrm{OB}$ adherent layer. Remove media by tilting plate to the side and aspirate media in the corner of the plate. Additionally, when adding fresh media, be sure to add drop wise in the corner of the plate against the sidewall to ensure minimal disruption of the BMSC or OB adherent layer.

2.3) After the $12^{\text {th }}$ day of co-culture, rinse leukemic cells from BMSC or OB layer by pipetting culture media from dish up and down gently over the dish approximately 5 to 10 times and then collect in $15 \mathrm{ml}$ conical tube. Reseed onto new $80-90 \%$ confluent BMSC or OB plate as described in step 2.1. 
NOTE: The gentle rinsing of the co-culture as described in step 2.3 will remove $S$ and PB leukemic cells without disrupting the BMSC or OB monolayer. This allows only tumor cells to be transferred to the next co-culture plate. This 12 day cycle can be repeated as many times as needed based on user needs.

\section{Preparing G10 bead columns}

NOTE: If sterile downstream analysis or culturing is required following G10 column separation the following steps should be carried out using sterile technique and G10 columns should be setup in a sterile biological hood.

3.1) Pre-warm cell culture media to $37^{\circ} \mathrm{C}$ in water bath ( $30 \mathrm{ml}$ per column).

3.2) Using a $10 \mathrm{ml}$ disposable syringe, remove and discard plunger.

3.3) Add glass wool to syringe.

3.3.1) Using tweezers, pull apart glass wool into thin loose strands. Add multiple layers of lightly packed glass wool to the syringe until $2 / 3$ of the syringe is filled with glass wool.

NOTE: The glass wool is crucial to prevent loose G10 particles from contaminating the leukemic cell collection. Make sure glass wool is packed enough to support the G10 particles, but not too densely packed to block media flow through the column.

3.4) Attach 1-way stopcock to the tip of the syringe in the closed position.

3.5) Clamp syringe column to ring stand high enough so a $50 \mathrm{ml}$ conical tube (collection tube) can be placed underneath stopcock. Place collection tube under syringe column.

3.6) Using a $10 \mathrm{ml}$ pipette add, drop-wise, G10 particles resuspended in PBS to the column on top of the glass wool. Continue adding G10 particles until a 2 ml pellet (as measured by graduations on syringe) of G10 particles forms on top of the glass wool.

3.7) Equilibrate the G10 column with pre-warmed media.

3.7.1) Add $2 \mathrm{ml}$ of pre-warmed media to column. Open stopcock valve slowly so that media flows out of the column drop-wise.

3.7.2) Repeat step 3.7.1 until a total of $10 \mathrm{ml}$ of pre-warmed media have been ran across the column.

NOTE: If G10 particles are seen in the flow through in the collection tube, either 1) add more G10 particles to maintain $2 \mathrm{ml}$ pellet making sure no additional G10 
particles escape from the column or 2) replace column with an unused one and repeat steps 3.5-3.7.1.

3.7.4) Once the pre-warmed media drains from the column, close the stopcock and discard collection tube with flow through.

3.7.5) Add new collection tube under column. Column is ready to be loaded with media + cell mixture.

NOTE: Columns should be used immediately and not allowed to dry.

\section{Separating 3 subpopulations within co-culture}

4.1) Collection of suspension (S) tumor subpopulation.

4.1.1) Aspirate media from co-culture plate with pipette and gently reapply the same media to rinse the plate and collect media containing leukemic cells in a $15 \mathrm{ml}$ conical tube. The leukemic cells collected are the S subpopulation.

4.2) Collection of Phase Bright (PB) tumor subpopulation.

4.2.1) Add $10 \mathrm{ml}$ fresh media back onto co-culture plate. Rinse vigorously by pipetting added media up and down approximately 5 times to remove adherent leukemic cells but not hard enough to dislodge adherent BMSC/OB component.

4.2.2) Aspirate with pipette and collect media in a $15 \mathrm{ml}$ conical tube. The collected cells are the PB subpopulation.

4.3) Collection of Phase Dim (PD) tumor subpopulation.

4.3.1) Rinse plate with $1 \mathrm{ml}$ PBS to remove remaining media. Trypsinize co-culture plate with $3 \mathrm{ml}$ trypsin and place into $37^{\circ} \mathrm{C}$ incubator for $5 \mathrm{~min}$.

4.3.2) Remove plate out of incubator and gently tap sides of the plate to dislodge adherent BMSC/OB.

4.3.3) Add $1 \mathrm{ml}$ fetal bovine serum (FBS) and pipette up and down 3-5 times to break apart large cell aggregates.

4.3.4) Collect media with cells in a $15 \mathrm{ml}$ conical tube. These cells are the unpurified PD subpopulation with BMSC/OB as well.

4.4) Centrifuge 3 isolated subpopulations at $400 \mathrm{xg}$ for $7 \mathrm{~min}$. Aspirate and discard supernatant then individually resuspend pellets in $1 \mathrm{ml}$ pre-warmed media. Cells are ready to be loaded onto a G10 column.

\section{Loading co-culture cells onto G10 column}


NOTE: Make sure stopcock is completely closed before adding media containing cells to G10 column. Also, each subpopulation must be ran over a separate G10 column so not to introduce any bias between populations in downstream analysis.

5.1) Using a $1000 \mu \mathrm{l}$ pipette, add $1 \mathrm{ml}$ of each cell subpopulation in pre-warmed media to a separate G10 column drop-wise. The media containing the cells should remain on top or within $\mathrm{G} 10$ pellet.

5.2) Allow cells to incubate on $\mathrm{G} 10$ pellet for $20 \mathrm{~min}$ at RT.

NOTE: Stopcock remains closed for duration of incubation.

\section{Collecting leukemic cells from G10 column}

6.1) Add 1-3 ml pre-warmed media to each G10 column.

6.2) Open stopcock valve and allow media to slowly exit the column drop-wise.

NOTE: It is crucial to maintain a slow flow rate from the column or the G10 pellet containing BMSC/OB can wash out of the column and contaminate the isolated leukemic cells.

6.3) Continue to add pre-warmed media in small increments (1-2 $\mathrm{ml}$ ) to $\mathrm{G} 10$ column until a total of 15 to $20 \mathrm{ml}$ has run through column and has been collected. Close stopcock valve and cap collection tube.

NOTE: If a G10 particle pellet is seen at the bottom of collection tube, gently remove media from the tube leaving G10 particle pellet undisturbed and transfer to new tube.

6.4) Centrifuge collected media at $400 \mathrm{xg}$ for $7 \mathrm{~min}$ at RT.

6.5) Remove supernatant and resuspend cell pellet in buffer appropriate for downstream application.

6.6) Cells are now a pure population of leukemic cells free of BMSC or OB contamination and are ready to be applied to downstream applications at user discretion.

NOTE: Leukemic cell viability should remain unchanged when passing cells through G10 columns. 
Representative results: Successful setup and culture of this co-culture model will result in the establishment of 3 subpopulations of leukemic cells relative to the adherent BMSC or OB monolayer. Figure 1 shows how ALL cells seeded into a BMSC monolayer initially appear as only a single population of suspended leukemic cells. Over the course of 4 days leukemic cells interact with the BMSC to form 3 spatial subpopulations of leukemic cells (suspended (S), phase bright (PB), and phase dim (PD)). While the 3 subpopulations of tumor cells can commonly be seen after 24 hours of co-culture with BMSC or OB we co-culture the cells for 4 days to allow the full dynamics and interactions between the leukemic cells and BMSC/OB cells to take place before any manipulation or experimentation takes place (Figure 1). Also, note that we maintain the co-cultures at an oxygen tension of $5 \%$ to recapitulate bone marrow physiology, which has been reported to range from $1-7 \%{ }^{16-18}$.

A vast majority of downstream analysis requires the separation of the leukemic cells from the BMSC or OB. To achieve this we use G10 columns to harvest a pure population of leukemic cells (Figure 2A). Following trypsinization of BMSC and PD REH cells a mixed population is seen by two distinct forward/side populations by flow cytometry (Figure 2B, top panel). Following G10 separation a pure population of only REH ALL cells is recovered, which was confirmed by forward/side scatter flow cytometry (Figure2B, bottom panel).

Use of this co-culture model and the ability to isolate leukemic cells from 3 subpopulations when in co-culture with BMSC or OB allows for interrogation of leukemic cell phenotype with relation to its spatial location relative to the adherent BMSC or OB monolayer. Of particular interest, is that ALL cells recovered from the PD population of a 
BMSC or OB co-culture have little to no cell death following exposure to cytotoxic chemotherapy (Figure $3 \mathbf{A}, \mathbf{B}$ ). 
Discussion: Minimal residual disease (MRD) which contributes to relapse of disease continues to be a major clinical challenge in the treatment of aggressive refractory ALL, as well as, a host of other hematological malignancies. The bone marrow microenvironment is the most common site of relapse in $A L L^{3,8}$. As such, models that model the bone marrow microenvironment are vital tools to test hypotheses related to leukemic tumor cell survival and maintenance of MRD during chemotherapy exposure. While mouse models define the gold standard for testing questions related to drug efficacy, 2D co-culture continues to be a cost effective methodology for testing hypotheses and drug strategies related to bone morrow microenvironment support of leukemic cell survival. Many groups have shown that co-culture of leukemic cells with BMSC or OB provides a survival advantage when challenged with chemotherapy agents $^{9,10,12-14,19-21}$. Work modeling normal immature CD34+ hematopoietic cells in coculture with mesenchymal stem cells (MSC) revealed that hematopoietic cells will interact with the adherent monolayer of MSCs to form three distinct spatial populations of hematopoietic cells ${ }^{22,23}$. Proliferation and differentiation of the CD34+ cells was effected relative to their location within the co-culture ${ }^{22}$. We have expanded on this observation to test questions related to bone marrow microenvironment stromal cell support of a resistant population of tumor cells within a 2D co-culture and its isolation for downstream analysis.

Unlike standard 2D co-culture models which typically sample leukemic cells by removal of the suspended tumor, our model shows that co-culture represents a more dynamic interaction in which leukemic cells in co-culture with BMSC or OB form three subpopulations relative to the BMSC or OB monolayer (Figure 1). The tumor 
subpopulations that form are suspended (S) tumor, which is freely floating in the media; phase bright (PB) that is adhered to the surface of the BMSC or OB; and the phase dim (PD) which have buried beneath the BMSC or OB monolayer (Figure 1). In this model, we found that a strict feeding and reseeding schedule is important to achieve consistent results in a co-culture model and therefore we feed the co-cultures at 4 day intervals and transfer tumor to new BMSC or OB monolayers every 12 days. This may require modification for alternative tumor types as needed. The number of tumor cells that will migrate below the BMSC or OB to form the PD population may vary between different leukemic cells. This can be a limitation of the model, when the number of PD tumor cells are low making it difficult to collect enough cells for downstream analysis. In some cases this problem can be overcome by establishing replicate co-cultures to allow for pooling of the three individual subpopulations.

As this model relies on tumor cell interaction with the BMSC or OB it is important to have an effective method to remove stromal cell contamination to address specific biology of the leukemic cells. To accomplish this separation of tumor cells from stroma we use G10 columns. Proper setup and use of these columns is crucial for isolation of pure tumor populations for downstream analysis. As highlighted in Figure 2B, proper execution of the G10 column separation results in recovery of tumor cells at greater than $99 \%$ purity. This allows for downstream analysis of the leukemic cells without complication of interpretation of results that would result from stromal cell contamination. It is important to note that all leukemic cell types whether cell lines or primary patient samples will vary slightly in their ability to pass through the G10 columns. Before use in large scale experiments users should determine the number of 
leukemic cells they must input to recover the desired amount needed for their specific downstream needs. In addition, the amount of wash media ran over the G10 column post incubation can be increased to try and increase the number of cells recovered. Care should be taken to insure that the additional washes do not cause stromal cell contamination which can be determined post wash by cell counts or flow cytometry analysis of flow through.

In establishing this model, we observed that leukemic cells recovered from the PD population have increased viability compared to leukemic cells grown in media alone, as well as to those recovered from the S or PB populations in the same co-culture when exposed to cytotoxic chemotherapy (Figure $3 a-b)$. This is significant because it represents a population of leukemic cells in vitro that derive pronounced protection from chemotherapy. This provides a useful tool to test treatment strategies aimed at targeting the most resistant tumor population, which is supported by the bone marrow microenvironment. Furthermore, because these leukemic cells are so well protected by the $\mathrm{BMSC}$ or $\mathrm{OB}$ co-culture it is amenable to in vitro combination treatment strategies, that in media alone or standard co-culture models would appear to or would completely kill the tumor which is not always representative of effects seen in resistant microenvironment supported leukemic populations.

Finally, we believe that use of this model can provide valuable insight into the interactions between $\mathrm{BMSC} / \mathrm{OB}$, and leukemic cells that are responsible for resistance to chemotherapy treatment, lead to MRD, and subsequently relapse. This model provides an in vitro platform to design experiments which will better inform downstream pre-clinical models. Though we show use of this model to test interactions between 
bone marrow stromal cells and ALL derived leukemic cells, we are hopeful that future directions and applications of this model will be useful in a variety of malignancies in which the bone marrow microenvironment provides a site of sanctuary for tumors during chemotherapeutic intervention.

Acknowledgments: Supported by National Institutes of Health (NHLBI) R01 HL056888 (LFG), National Cancer Institute (NCI) RO1 CA134573NIH (LFG), P30 GM103488 (LFG), WV CTR-IDEA NIH 1U54 GM104942, the Alexander B. Osborn Hematopoietic Malignancy and Transplantation Program, and the WV Research Trust Fund. We are grateful for the support of Dr. Kathy Brundage and the West Virginia University Flow Cytometry Core Facility, supported by NIH S10-OD016165 and the Institutional Development Award (IDeA) from the NIH Institute of General Medical Sciences of the National Institutes of Health (CoBRE P30GM103488 and INBRE P20GM103434).

Disclosures: The authors have no competing financial interests. 


\section{References:}

1. Ayala, F., Dewar, R., Kieran, M. \& Kalluri, R. Contribution of bone microenvironment to leukemogenesis and leukemia progression. Leukemia 23, (12) 2233-2241 (2009).

doi:10.1038/leu.2009.175

2. Coustan-Smith, E., Sancho, J., et al. Clinical importance of minimal residual disease in childhood acute lymphoblastic leukemia. Blood 96, (8) 2691-2696 (2000).

3. Gaynon, P. S., Qu, R. P., et al. Survival after relapse in childhood acute lymphoblastic leukemia. Cancer 82, (7) 1387-1395 (1998). doi:10.1002/(SICI)10970142(19980401)82:7<1387::AID-CNCR24>3.0.CO;2-1

4. Kikuchi, M., Tanaka, J., et al. Clinical significance of minimal residual disease in adult acute lymphoblastic leukemia. Int. J. Hematol. 92, (3) 481-489 (2010). doi:10.1007/s12185-0100670-1

5. Krause, D. S., Scadden, D. T. \& Preffer, F. I. The hematopoietic stem cell niche-home for friend and foe? Cytometry B Clin. Cytom. 84B, (1) 7-20 (2013). doi:10.1002/cyto.b.21066

6. Meads, M. B., Hazlehurst, L. A. \& Dalton, W. S. The Bone Marrow Microenvironment as a Tumor Sanctuary and Contributor to Drug Resistance. Clin. Cancer Res. 14, (9) 2519-2526 (2008). doi:10.1158/1078-0432.CCR-07-2223

7. Nguyen, K., Devidas, M., et al. Factors Influencing Survival After Relapse From Acute Lymphoblastic Leukemia: A Children's Oncology Group Study. Leuk. Off. J. Leuk. Soc. Am. Leuk. Res. Fund UK 22, (12) 2142-2150 (2008). doi:10.1038/leu.2008.251

8. Szczepanek, J., Styczyński, J., Haus, O., Tretyn, A. \& Wysocki, M. Relapse of Acute Lymphoblastic Leukemia in Children in the Context of Microarray Analyses. Arch. Immunol. Ther. Exp. (Warsz.) 59, (1) 61-68 (2011). doi:10.1007/s00005-010-0110-1

9. Boyerinas, B., Zafrir, M., Yesilkanal, A. E., Price, T. T., Hyjek, E. M. \& Sipkins, D. A. Adhesion to osteopontin in the bone marrow niche regulates lymphoblastic leukemia cell dormancy. Blood 121, (24) 4821-4831 (2013). doi:10.1182/blood-2012-12-475483

10. Bradstock, K., Bianchi, A., Makrynikola, V., Filshie, R. \& Gottlieb, D. Long-term survival and proliferation of precursor-B acute lymphoblastic leukemia cells on human bone marrow stroma. Leukemia 10, (5) 813-820 (1996).

11. Clutter, S. D., Fortney, J. \& Gibson, L. F. MMP-2 is required for bone marrow stromal cell support of pro-B-cell chemotaxis. Exp. Hematol. 33, (10) 1192-1200 (2005). doi:10.1016/j.exphem.2005.06.022

12. Manabe, A., Murti, K. G., et al. Adhesion-dependent survival of normal and leukemic human B lymphoblasts on bone marrow stromal cells. Blood 83, (3) 758-766 (1994). 
13. Mudry, R. E., Fortney, J. E., York, T., Hall, B. M. \& Gibson, L. F. Stromal cells regulate survival of B-lineage leukemic cells during chemotherapy. Blood 96, (5) 1926-1932 (2000).

14. Tesfai, Y., Ford, J., et al. Interactions between acute lymphoblastic leukemia and bone marrow stromal cells influence response to therapy. Leuk. Res. 36, (3) 299-306 (2012). doi:10.1016/j.leukres.2011.08.001

15. Hathcock, K. S. Depletion of Accessory Cells by Adherence to Sephadex G-10. Curr. Protoc. Immunol. (2001).at <http://onlinelibrary.wiley.com/doi/10.1002/0471142735.im0306s08/abstract>

16. Berniakovich, I. \& Giorgio, M. Low oxygen tension maintains multipotency, whereas normoxia increases differentiation of mouse bone marrow stromal cells. Int. J. Mol. Sci. 14, (1) 2119-2134 (2013). doi:10.3390/ijms14012119

17. Chow, D. C., Wenning, L. A., Miller, W. M. \& Papoutsakis, E. T. Modeling pO(2) distributions in the bone marrow hematopoietic compartment. II. Modified Kroghian models. Biophys. J. 81, (2) 685-696 (2001). doi:10.1016/S0006-3495(01)75733-5

18. Holzwarth, C., Vaegler, M., et al. Low physiologic oxygen tensions reduce proliferation and differentiation of human multipotent mesenchymal stromal cells. BMC Cell Biol. 11, 11 (2010). doi:10.1186/1471-2121-11-11

19. O'Leary, H., Akers, S. M., et al. VE-cadherin Regulates Philadelphia Chromosome Positive Acute Lymphoblastic Leukemia Sensitivity to Apoptosis. Cancer Microenviron. Off. J. Int. Cancer Microenviron. Soc. 3, (1) 67-81 (2010). doi:10.1007/s12307-010-0035-6

20. Wang, L., Chen, L., Benincosa, J., Fortney, J. \& Gibson, L. F. VEGF-induced phosphorylation of Bcl-2 influences $B$ lineage leukemic cell response to apoptotic stimuli. Leukemia 19, (3) 344-353 (2005). doi:10.1038/sj.leu.2403643

21. Wang, L., Coad, J. E., Fortney, J. M. \& Gibson, L. F. VEGF-induced survival of chronic lymphocytic leukemia is independent of Bcl-2 phosphorylation. Leukemia 19, (8) 1486-1487 (2005). doi:10.1038/sj.leu.2403837

22. Jing, D., Fonseca, A.-V., et al. Hematopoietic stem cells in co-culture with mesenchymal stromal cells--modeling the niche compartments in vitro. Haematologica 95, (4) 542-550 (2010). doi:10.3324/haematol.2009.010736

23. Jing, D., Wobus, M., Poitz, D. M., Bornhäuser, M., Ehninger, G. \& Ordemann, R. Oxygen tension plays a critical role in the hematopoietic microenvironment in vitro. Haematologica 97 , (3) 331-339 (2012). doi:10.3324/haematol.2011.050815 


\section{Figure legends}

Figure 1: ALL cells in co-culture with BMSC or OB form three spatial populations. Our lab uses an in vitro co-culture system to model leukemic cell interactions with bone marrow microenvironment derived stromal cells (BMSC or OB). To establish co-culture, leukemic cells (Red) are seeded onto an $80-90 \%$ confluent monolayer of BMSC or OB (Blue), which is denoted as 'Time $0^{\prime}$ '. Co-cultures are maintained at $37^{\circ} \mathrm{C}$ at $5 \%$ oxygen to approximate conditions of the bone marrow microenvironment. Leukemic cells will begin to form 3 subpopulations as early as 24 hours, but to allow for complete interactions to form we allow co-cultures 4 days to establish before utilizing leukemic cells for experiments. By day 4 (right panels), three subpopulations of leukemic cells will form in relation to the adherent monolayer. The schematic (top right) and the phase contrast microscopy (bottom right) show the suspended (S) leukemic cells freely floating in the media; phase bright (PB) leukemic cells which are adhered to the surface of the BMSC or OB monolayer; and the phase dim (PD) leukemic cells that have migrated beneath the BMSC or OB monolayer. Scale bar represents 10 microns.

Figure 2: Use of G10 columns allows for separation of ALL cells from BMSC/OB. (A) Demonstration of the process of using a G10 column to separate ALL cells from BMSC/OB co-culture to achieve a pure population of tumor cells for downstream analysis. From left to right, a mixture of ALL cells and BMSC/OB cells is added to the top of the G10 column; (Center) cell mixture will settle in the G10 slurry and should be incubated at RT for 20 min (Note: Stopcock is in the closed position throughout first two steps); (right) leukemic cells are recovered by opening the stopcock and rinsing column with pre-warmed media. (B) Top panel shows before G10 separation 
that there is a mixed population of cells containing BMSC (blue gate) and REH ALL cells (red gate) by evaluating forward (FSC) and side scatter (SSC) analysis. Bottom panel, following G10 separation only the pure population of REH ALL cells (red gate) remain with less than $1 \%$ stromal cell contamination (blue gate).

Figure 3: PD leukemic cells have increased resistance to chemotherapy exposure. SD-1 leukemic cells recovered from the PD population of a BMSC co-culture (A) do not display reduced viability following a 4 day exposure to Ara-C $[1 \mu \mathrm{M}]$, MTX $[50 \mu \mathrm{M}]$, or VCR $[25 \mu \mathrm{M}]$, similar to untreated controls (note that a second dose of Ara-C added at 48 hours to account for any drug loss due to stability). Leukemic cells from the media alone, S, and PB populations have significantly reduced viability as determined by trypan blue exclusion. SD-1 leukemic cells co-cultured with OB cells display similar trends in viability (B). Results are expressed as mean \pm SEM. $\left({ }^{*}\right)$ denotes $p<0.05$, unpaired t-test relative to untreated controls. 
Figures

\section{Time 0}

\section{Day 4}
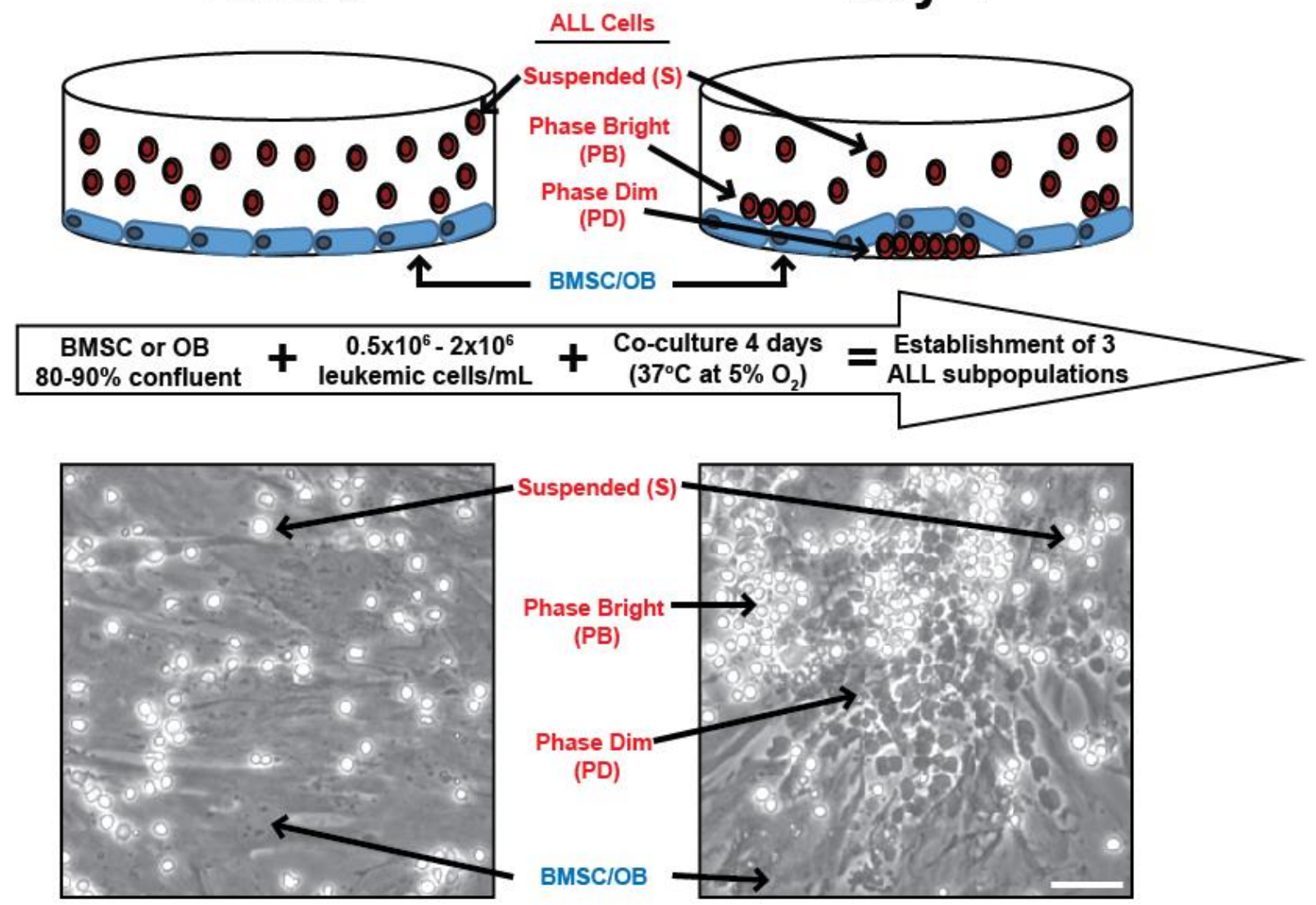

Figure 1: ALL cells in co-culture with BMSC or OB form three spatial populations. 

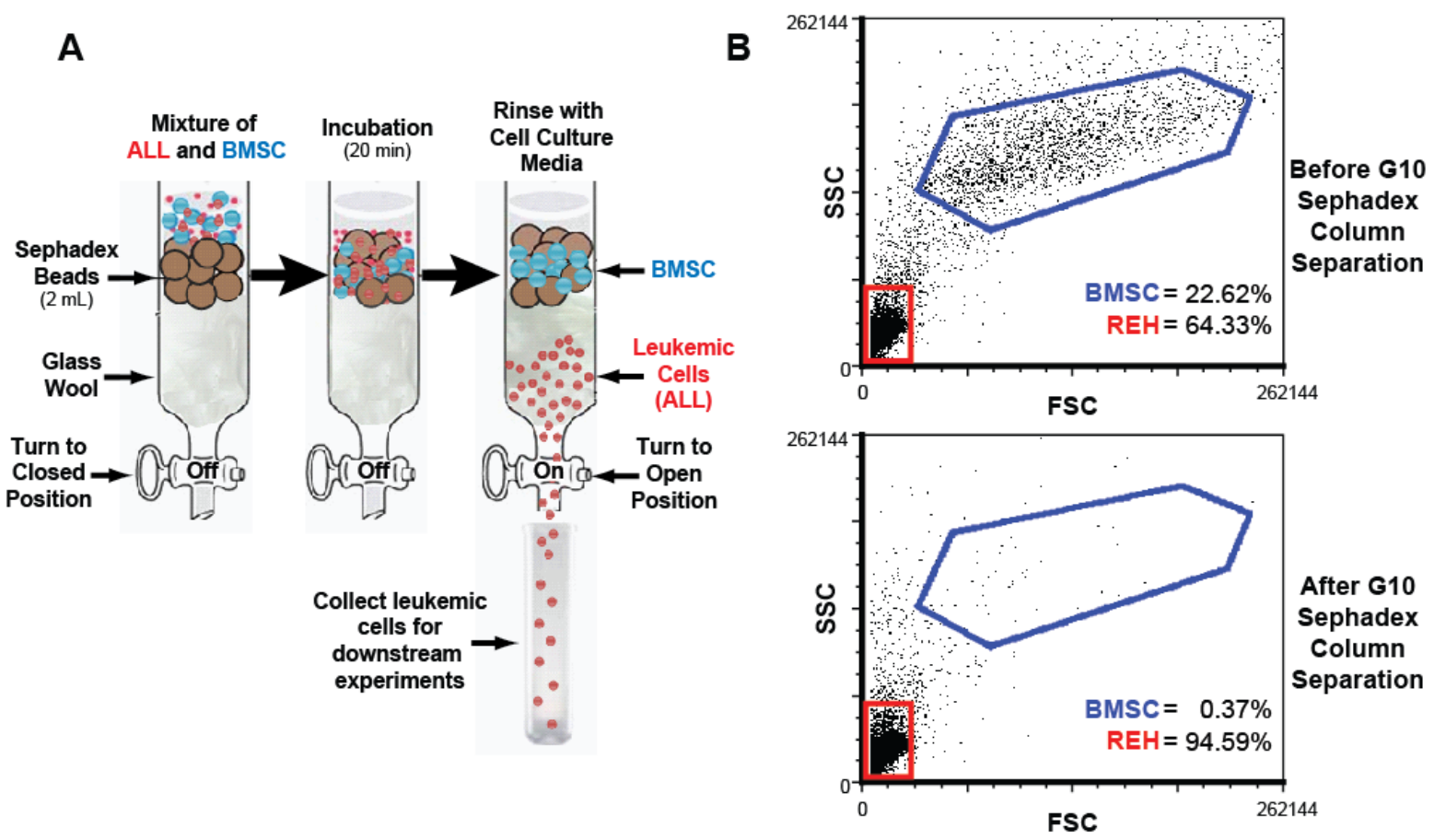

Figure 2: Use of G10 columns allows for separation of ALL cells from BMSC/OB. 

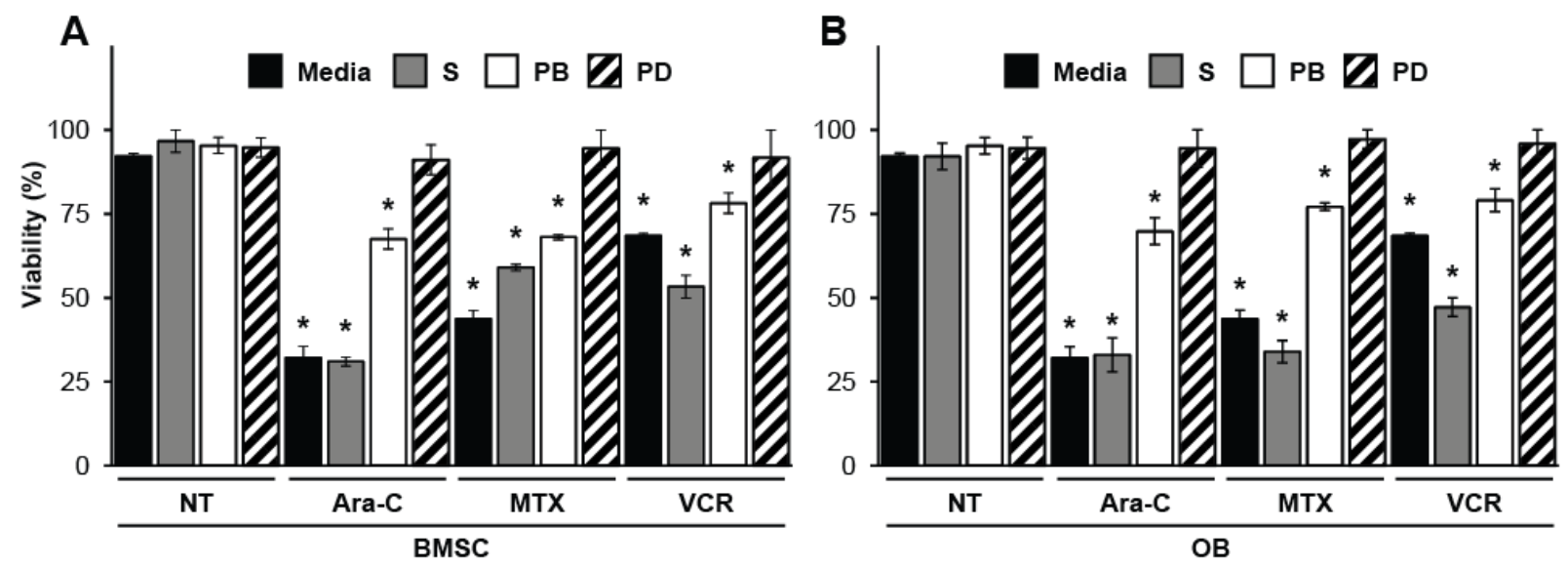

Figure 3: PD leukemic cells have increased resistance to chemotherapy exposure. 


\section{Chapter 3}

\section{Bone Marrow Microenvironment Modulation of \\ Acute Lymphoblastic Leukemia Phenotype}

Blake S Moses ${ }^{1, \dagger}$, William L Slone ${ }^{1, \dagger}$, Patrick Thomas ${ }^{1}$, Rebecca Evans ${ }^{1}$, Debbie Piktel ${ }^{1}$, Peggi M Angel ${ }^{2}$, Callee M Walsh², Pamela S Cantrell ${ }^{2}$, Stephanie L Rellick ${ }^{3}$, Karen H Martin $^{1,4}$, James W Simpkins ${ }^{3,5,6}$ and Laura F Gibson ${ }^{1,7, *}$

tThese authors contributed equally to this work

${ }^{1}$ Alexander B. Osborn Hematopoietic Malignancy and Transplantation Program of the Mary Babb Randolph Cancer Center, Robert C. Byrd Health Sciences Center, West Virginia University School of Medicine, USA; ${ }^{2}$ Protea Bioscience, Morgantown West Virginia, USA; ${ }^{3}$ Department of Physiology \& Pharmacology, West Virginia University School of Medicine, Morgantown, West Virginia, USA; ${ }^{4}$ Department of Neurobiology and Anatomy, West Virginia University School of Medicine, Morgantown, West Virginia, USA; ${ }^{5}$ Center for Basic and Translational Stroke Research, West Virginia University School of Medicine, Morgantown, West Virginia, USA; ${ }^{6}$ Center for Neuroscience, West Virginia University School of Medicine, Morgantown, West Virginia, USA; ${ }^{7}$ Department of Microbiology, Immunology and Cell Biology, Robert C. Byrd Health Sciences Center, West Virginia University School of Medicine, USA

Key Words: Model, Bone Marrow Microenvironment, Leukemia, Chemoresistance, Coculture

This work has been published as a manuscript in Experimental Hematology:

Moses BS, Slone WL, Thomas P, Evans R, Piktel D, Angel PM et al. Bone marrow microenvironment modulation of acute lymphoblastic leukemia phenotype. Exp Hematol 2016; 44: 50-59.e2. 


\section{Abstract}

Acute lymphoblastic leukemia (ALL) treatment regimens have dramatically improved the survival of ALL patients. However, chemoresistant minimal residual disease (MRD) that persists following cessation of therapy contributes to aggressive relapse. The bone marrow microenvironment (BMM) is an established "site of sanctuary" for ALL as well as myeloid lineage hematopoietic disease, with signals in this unique anatomical location contributing to drug resistance. Several models have been developed to recapitulate the interactions between the BMM and ALL cells. However, many in vitro models fail to accurately reflect the level of protection afforded to the most resistant sub-set of leukemic cells during co-culture with BMM elements. Pre-clinical in vivo models have advantages, but can be costly, and are often not fully informed by optimal in vitro studies. In the current report we describe an innovative extension of 2D co-culture wherein ALL cells uniquely interact with bone marrow derived stromal cells. Tumor cells in this model bury beneath primary human bone marrow derived stromal cells or osteoblasts, termed "phase dim" (PD) ALL, and exhibit a unique phenotype characterized by altered metabolism, distinct protein expression profiles, increased quiescence, and pronounced chemotherapy resistance. Investigation focused on the PD subpopulation may more efficiently inform pre-clinical design and investigation of MRD and relapse that arises from BMM supported leukemic tumor cells. 


\section{Introduction}

The bone marrow microenvironment (BMM) is a well-established "site of sanctuary" in a host of malignancies, with the most common being of hematopoietic origin[1-8]. In leukemia, the BMM serves as the site of initiation and progression of disease. The BMM is also the most common site of relapse, where leukemic cells respond to signals that are critical for the support of "healthy" steady-state hematopoiesis[2,9,10]. Quiescence, metabolism, and survival pathways are all influenced by the BMM and are pathways known to be co-opted by leukemic cells in the marrow niche to promote treatment resistance[5,7,11]. Studies from many laboratories have furthered our understanding of the interplay between leukemic cells and the BMM, however, relapse of disease continues to be a clinical challenge.

A number of models have been employed to recapitulate the interactions between the bone marrow niche and leukemic cells. In vivo murine models have provided insight and have become standard pre-clinical models in which to test novel therapeutic strategies[12-14]. While in vivo models define the gold standard they are labor intensive, time consuming, and costly to test hypotheses related to relapse of disease. Also, while the BMM can be effectively imaged during disease progression or treatment response, sequential sampling of tumor recovered from the niche is only achievable upon termination of experiments, resulting in evaluation of snapshots in time. Often, ongoing analyses are limited to peripheral circulating tumor that does not reflect the most treatment-resistant subpopulation of interest. Standard 2D in vitro models, while lacking the complexity of the in vivo microenvironment, provide an alternative means to interrogate tumor interactions with the microenvironment. Several groups have 
demonstrated that 2D co-culture with primary human bone marrow stromal cells (BMSC) and osteoblasts (HOB) protect human leukemic cells from chemotherapy induced death[2,6,8,11,15]. However, standard in vitro models lack the ability to predict long term survival of sub-sets of resistant leukemic cells, and as a result, are not ideal for evaluation of mechanisms that underlie MRD.

Studies including co-culture of healthy hematopoietic stem cells with mesenchymal stromal cells (MSC) revealed that co-culture models exhibit a more dynamic nature than was previously appreciated. Hematopoietic cells interacted with MSCs in three distinct spatial compartments[16]. The subpopulations included uniquely identifiable suspended $(\mathrm{S})$, phase bright $(\mathrm{PB})$, or phase dim (PD) tumor cells when evaluated by light microscopy. Differences in the hematopoietic stem cell phenotype correlated with location of the hematopoietic cell relative to adherent MSC. Of particular relevance to the current study was the observation that the "phase dim" (PD) population of hematopoietic cells that buried beneath the MSC monolayer was immature and quiescent, two characteristics that have been associated with chemotherapy resistance[16,17]. In addition, it has previously been described that tumor cells closely associated with BMSC or HOB niches in vivo are more resistant to chemotherapyinduced apoptosis[11,18].

Based on previous works we sought to determine whether B- lineage acute lymphoblastic leukemia (ALL) cells, which share many common characteristics with their healthy pre- and pro-B cell counterparts, would localize to distinct compartments of BMSC or $\mathrm{HOB}$ co-culture resulting in distinct subpopulations for investigation of therapeutic resistance. We demonstrate that ALL cells recovered from the PD 
population of co-culture are phenotypically distinct, and exhibit many characteristics of refractory disease described in vivo. PD derived tumor cells are resistant to therapy with survival that approximates tumor cells that have not been exposed to cytotoxic agents. When compared to the other subpopulations recovered from the same co-culture, PD leukemic cells, in addition to their marked survival during chemotherapy exposure, were characterized by increased quiescence and elevated glycolytic activity. Our observations suggest that a biologically relevant model of minimal residual disease can be utilized in vitro that benefits from the inclusion of relevant human derived BMM constituents and targeted evaluation of the most resistant component of ALL. The PD leukemic cells in this model lend themselves to more rigorous drug screening than can be achieved when total leukemic populations are evaluated. Importantly, this novel approach of focus on the PD tumor cells may also more efficiently inform pre-clinical design to investigate MRD and relapse, with specific consideration of resistant subpopulations supported by the BMM.

\section{Materials and Methods}

\section{Cell lines and culture conditions}

Bcr;Abl (Ph+) lymphoblastic cell lines Tom-1 (DSMZ-ACC 578), Nalm-27 (Fujisaki Cancer Center), Nalm-30 (Fujisaki Cancer Center), and Sup-B15 (ATCC-CRL-1929) and (Ph-) REH (ATCC-CRL-8286) and Nalm-6 (ATCC-CRL-1567) were utilized. Deidentified primary bone marrow stromal cells (BMSC) were provided by the Mary Babb Randolph Cancer Center (MBRCC) Biospecimen Processing Core and the West Virginia University Department of Pathology Tissue Bank. BMSC cultures were established as previously described[19]. Human osteoblasts (HOB) were purchased 
(PromoCell, Heidelberg, Germany), and cultured according to the supplier's

recommendations. Co-cultures were established by seeding leukemic cells onto $80-90 \%$ confluent BMSC or HOB monolayers. Cultures were fed every 4 days and tumor cells collected for inclusion in experiments with remaining leukemic cells moved to new primary BMSC or $\mathrm{HOB}$ adherent layers every 12 days. Cultures were maintained in $5 \%$ $\mathrm{O}_{2}$ to model normal bone marrow oxygen tension, reported to range from $1-7 \%[20-22]$. Suspended (S) leukemic cells floating freely in the media were removed by gentle pipetting. Phase bright (PB) tumor cells, that were loosely adherent to the top of BMSC or HOB, were harvested by vigorous pipetting. Phase dim (PD) leukemic cells that were buried firmly beneath adherent BMSC or HOB were recovered by trypsinization of the adherent layer and PD tumor. The S, PB, and PD tumor populations were separated from BMSC/HOB by size exclusion with G10 Sephadex (Sigma, St Louis, MO, USA) column separation[23,24].

\section{Microscopy}

Phase contrast images were acquired using a Leica DMIL LED microscope and processed by Leica application suite version 4.0 software (Buffalo Grove, IL, USA). Confocal images were acquired using an upright LSM 510 Zeiss microscope and processed using Zen2009 software (Thornwood, NY, USA). Fluorescence intensity for image acquisition was only altered when fluorescence intensities were not compared between samples.

\section{Subpopulation tracking}

The three ALL subpopulations were isolated from co-culture as described above. Each subpopulation (S, PB and PD) was individually stained with CellTracker ${ }^{\text {TM }}$ Green, 
CellTracker ${ }^{\mathrm{TM}}$ Violet, or CellTracker ${ }^{\mathrm{TM}}$ Deep Red (Life Technologies, Grand Island, NY, USA) following the manufacturer's protocol. An equal number of cells from each population was combined and cultured on coverslips with confluent BMSC or HOB for 1 , 4 and 48 hours. Coverslips were extensively washed with PBS to remove S and PB subpopulations, fixed with $4 \%$ paraformaldehyde, and stained with phalloidin-TRITC (Sigma). Slides were mounted with Prolong® Gold anti-fade (Life Technologies), and evaluated by confocal microscopy.

\section{Chemotherapeutic agents}

Cytarabine (Ara-C) (Selleckchem, Houston, TX, USA; Cat \# S1648), Methotrexate (MTX) (Selleckchem, Cat \# S1210) and Vincristine (VCR) (Selleckchem, Cat \# S1241) were stored per manufacturer recommendations, and diluted in base media immediately

prior to use. Experimental concentrations of Ara-C [1 $\mu \mathrm{M}]$, MTX [50 $\mu \mathrm{M}]$, or VCR [25 $\mu \mathrm{M}]$ were used to approximate clinically relevant doses in ALL[25-29].

\section{Evaluation of leukemic cell viability}

ALL cells were cultured in media alone, or co-cultured with BMSC or HOB for 4 days to establish S, PB, and PD tumor populations. At day 4, cultures were provided fresh media and exposed to Ara-C, MTX, or VCR for 4 days. Cells treated with Ara-C were exposed to a second dose at 48 hours. Viability was evaluated by trypan blue exclusion in triplicate samples.

\section{Annexin V/PI staining}

Cell culture and chemotherapy exposure were completed as described above. Following drug exposure ALL cells were stained using an Annexin V (FITC)/ propidium 
iodide (PI) apoptosis detection kit (Trevigen, Gaithersburg, MD, USA; Cat \# 4830-01-K) according to the recommended protocol of the manufacturer. Collection and analysis were performed in triplicate using the LSRFortessa (Becton Dickenson, San Jose, CA, USA).

\section{Co-culture of tumor cells with non-bone marrow derived adherent cells}

ALL cells were cultured in media alone, or co-cultured with sheep choroid plexus epithelial cells (SCP) (ATCC-CRL-1700), 3T3 mouse embryonic fibroblasts (3T3) (ATCC-CRL-1658), mouse embryonic fibroblasts (MEF) (ATCC-CRL-2991), human embryonic kidney cells (293T) (ATCC-CRL-3216), or HT-1080 human fibrosarcoma derived cells (HT) (ATCC-CCL-121). Leukemic cells were cultured with adherent layers for 4 days to establish S, PB, and PD tumor populations comparable to those established with human BMSC/HOB. At day 4, cultures were exposed to Ara-C and evaluated for viability by trypan blue exclusion in triplicate as described above.

\section{In vitro relapse model}

ALL cells were grown in co-culture with BMSC or HOB for 4 days. At day 4, cultures were provided fresh media and exposed to Ara-C for 72 hours. Following Ara-C exposure, S and PB ALL cell subpopulations were harvested as previously described and viability enumerated by trypan blue exclusion. Co-cultures, in which PD tumor cells remained buried beneath adherent $\mathrm{BMSC} / \mathrm{HOB}$, were rinsed to remove residual Ara-C and subsequently repopulation was monitored. ALL cells that comprised the regenerated $S$ and $\mathrm{PB}$ fractions were enumerated at 5 day intervals at which time fresh media was provided. Cultures were maintained until tumor burden compromised BMSC or HOB monolayers. 


\section{Western blot analysis}

Specific targets of glycolytic regulation were detected by rabbit mAb Hexokinase 1 (Cell Signaling Technologies, Danvers, MA, USA; C35C4; Cat \# 2024) and rabbit mAb Hexokinase 2 (C64G5; Cat \# 2867). Following incubation with horseradish peroxidaseconjugated secondary antibodies, signal was visualized using enhanced chemiluminescence (Amersham, Piscataway, NJ, USA). Densitometry was quantified by ImageJ with signal normalized to GAPDH.

\section{Ki-67 staining}

ALL subpopulations were either cytospun following G10 Sephadex purification following co-culture or analysis was completed on ALL cells during co-culture with BMSC or HOB grown on coverslips. Cells were fixed with $4 \%$ paraformaldehyde, washed with PBS, permeabilized with $0.1 \%$ Triton X-100 (Sigma) in PBS, and incubated with rabbit anti-Ki67 followed by Alexa 488 anti-rabbit. Phalloidin-TRITC was used to visualize the actin cytoskeleton. Cells were washed with PBS and mounted to glass slides (coverslip staining) or coverslips (cytospins) with Prolong® Gold anti-fade/DAPI. Images were acquired by confocal microscopy and a minimum of 50 cells were counted to quantitate percent positive Ki-67 cells in triplicate.

\section{Cell cycle analysis}

Go accumulation of ALL cells was investigated by evaluation of the DNA/RNA content quantitated by Hoechst33342/Pyronin Y (H/PY) (Sigma) double staining as previously described.[30] To evaluate the overall cell cycle profile of ALL cells, leukemic cells were collected from media or the PD population of co-culture after 12 days. ALL cells were fixed in $70 \%$ ethanol, treated with RNase (Sigma), and stained with PI for DNA analysis. 
All samples were performed in triplicate and processed on a FACSFortessia flow cytometer, and analyzed by FCS Express 4 software.

\section{Oxygen consumption and Extracellular Acidification analysis}

Leukemic cells $(800,000$ cells/well) were collected from media alone or isolated from $\mathrm{BMSC} / \mathrm{HOB}$ co-culture and incubated in an $\mathrm{XF}^{\mathrm{e}} 96$ cell culture microplate coated with Cell-Tak (BD Biosciences). The XFe 96 Analyzer with XF Assay Media containing sodium pyruvate and glucose was used to determine Oxygen Consumption Rate [OCR] measurements, or with XF Base Media with L-glutamine to determine Extracellular Acidification Rate [ECAR] measurements. The XF plate was calibrated overnight with $\mathrm{XF}$ Calibrant at $37^{\circ} \mathrm{C}$. On the day of the measurements, tumor cells were plated directly in XF media, and basal measurements (OCR or ECAR) were collected at three time points. All analysis was performed using XFe 96 Analyzer (Seahorse Bioscience, North Billerica, MA, USA)

\section{Laser Ablation Electrospray lonization (LAESI) and LC-MS/MS}

Leukemic cells cultured in medium alone or harvested from the PD population of BMSC or HOB co-culture were analyzed by LAESI-MS for metabolic profiling. Quantitative proteomic LC-MS/MS analyses were performed on the following cell treatments: leukemic cells grown in media alone and co-culture with $\mathrm{BMSC}, \mathrm{BMSC} / \mathrm{HOB}$, and $\mathrm{HOB}$ (Protea Biosciences, Morgantown, WV, USA). Detailed methodology and statistical analyses are included in Supplementary Materials and Methods. 


\section{Statistical analysis}

Results are expressed as mean \pm SEM. An unpaired t-test was performed to analyze results of cell viability data, H/PY, and KI67 quantitation (Graph Pad Software, La Jolla, CA, USA). Results of basal ECAR and OCR rates were analyzed by One-way ANOVA with Dunnett's post hoc (Sigma Plot, San Jose, CA, USA). A p value of $<0.05$ was considered statistically significant as detailed in figure legends. Error bars throughout figures are represent standard error (SEM).

\section{Results}

\section{ALL cells in co-culture with BMSC or HOB form three distinct spatial compartments.}

A panel of ALL cell lines formed three spatially and phenotypically distinct populations during co-culture with BMSC (Figure 1) or HOB (DNS). ALL cells were separated into suspended tumor (S), which are not in physical contact with BMSC/HOB, phase bright (PB) that are loosely adherent to BMSC/HOB and phase dim (PD) subpopulations which bury beneath the BMSC or HOB monolayer (Figure 1). Each individual subpopulation re-establishes the PD subpopulation when collected and placed into subsequent co-cultures. When individual ALL subpopulations ( $\mathrm{S}, \mathrm{PB}$, and PD) were removed from BMSC or $\mathrm{HOB}$ co-culture, stained with distinct dyes and re-plated for 148h of interaction with BMM, no unique affinity was observed within any group of ALL cells to repopulate the PD compartment (Figure 2). 


\section{ALL cells located in the PD population of BMSC or HOB co-culture demonstrate pronounced resistance to chemotherapy-induced death.}

PD ALL cells in BMSC/HOB co-culture have pronounced protection from chemotherapyinduced death when compared to media alone, S, or PB tumor cells following exposure to Ara-C, methotrexate (MTX), or vincristine (VCR) (Figure 3A-B and DNS). ALL cells readily establish three subpopulations (S, PB and PD) when co-cultured with several types of adherent layers established from sites other than the bone marrow, however, the PD population is not protected from Ara-C induced cell death (Figure $3 C$ ).

Furthermore, we determined if surviving PD tumor cells from human BMSC or HOB coculture could reconstitute the culture upon conclusion of chemotherapy exposure to simulate a purposefully simplified "in vitro relapse". Following a quiescent period of approximately 15 to 20 days, ALL cells from the chemotherapy resistant PD population migrated from beneath the stromal layers and initiated proliferation to re-populate the cultures (Figure 3D).

\section{ALL cells influenced by BMM have altered cell cycle distribution and quiescence.}

PD ALL cells have an increased $G_{0} / G_{1}$ fraction compared to media alone ALL cells (Figure $4 A$ ). The $G_{0} / G_{1}$ combined fraction was further investigated to determine the subset of PD ALL cells that are specifically in the $G_{0}$ (quiescent) phase by H/PY double staining. Corresponding to the increase in $G_{0} / G_{1}, P D$ cells have an increase in the percentage of cells in $\mathrm{G}_{0}$ compared to ALL cells in media alone (Figure 4B). Ki-67 staining was completed for analysis of the PD ALL population (Figure 4C) with PD ALL cells consistently having diminished Ki-67 staining when compared to media controls 
(Figure 4C-D). In addition to cell cycle analysis and Ki-67 expression alterations, global proteomic analysis was performed. As shown in Figure 5, proteins involved in cell cycle progression and DNA accessibility were altered in the leukemic cells influenced by the BMM. For a select group of histone-related proteins, alterations were seen in SUP-B15 ALL cells co-cultured with BMSC versus those co-cultured with HOB.

\section{BMSC/HOB cues alter ALL metabolic profiles.}

PD ALL cells have an increased level of glycolytic activity reflected by increased extracellular acidification rate (ECAR) when compared to ALL cells in media alone (Figure 6A). In agreement with increased basal glycolytic activity, PD ALL cells also have increased Hexokinase 1 and 2 protein levels (Figure 6B). While glycolytic activity was increased in the PD population, basal levels of oxidative phosphorylation are significantly diminished in leukemic cells in co-culture (Figure 6C). Metabolomic analysis

was completed to compare global changes between leukemic cells in the presence (PD) or absence (media alone) of microenvironment cues with clustering of $\mathrm{m} / \mathrm{z}$ according to expression level reflecting distinct metabolic profiles (Figure 6D).

\section{Discussion}

In this study, using an extension of 2D co-culture techniques we have demonstrated that a panel of ALL cell lines when in co-culture with BMSC or HOB form three distinct spatial compartments: S, PB, and PD. Of these, the PD population is the most resistant and quiescent subpopulation generated by BMM interactions in vitro, and provides a valuable tool that can be applied for studying aggressive, resistant leukemia for targeted intervention. To evaluate whether the three individual groups of ALL cells had specific 
affinity for the location from which they were isolated, cell tracking experiments were completed. Leukemic cells in our model behave stochastically, and did not preferentially reconstitute the location from which they were isolated (Figure 2). S, PB or PD derived ALL cells readily buried under BMSC or HOB ("became PD"). This observation suggests a very dynamic phenotype, driven by the specific cues in distinct locations, versus a sustained phenotypic alteration or ALL cell "memory".

Our laboratory has previously shown that in general BMSC provide chemotherapy protection to leukemic cells via soluble factors[32,33] and adhesion interactions in standard 2D co-cultures[15,34-36]. When the attention was directed to the PD subpopulation, they were shown to be the most resistant to chemotherapy exposure. Protection was specific to interactions with BMM-derived BMSC, HOB or NSG derived BMSC (Figure 3A-C, DNS). The value of our model approach is the observation that, with inclusion of just one niche component, either BMSC or $\mathrm{HOB}$, a distinct group of tumor cells can be isolated that have altered cell cycle profiles, metabolic signatures and cytotoxic agent response. Future work can expand upon this model, increasing its complexity through methodical addition of other key bone marrow microenvironment components, such as endothelial cells[36], to better recapitulate the resistant leukemic niche in vitro to answer specific, clinically relevant questions with emphasis on interruption of signals that influence ALL cell quiescence, metabolic activity, and apoptosis.

Tumor cells that are in a quiescent state have been described by other groups to be drug resistant[37]. We observed that PD cells accumulate in the $\mathrm{G}_{0} / \mathrm{G}_{1}$ phase of cell cycle with a reduction in S phase (Figure 4A). Coincident with induction of quiescence, 
PD cells had increased p27 suggesting this may be one mechanism by which the cells are arrested in a Go state (DNS; figure 4B). The PD population does not demonstrate $100 \%$ accumulation in $\mathrm{G}_{0}$ indicating that cell cycle interruption does not explain the entire escape from S phase specific drug-induced apoptosis. Even within the purified PD subpopulation multiple pathways are likely influenced by niche cells that converge on blunting apoptosis. PD ALL cells also had a reduced proliferation index measured by Ki-67 staining (Figure 4C-D), again consistent with the assertion that the BMM alters ALL proliferation, which may be one contributing factor to increased chemotherapy resistance (Figures 3-4). Future studies will be important to evaluate a broader range of drugs in this model, including those that are not S phase specific, to expand our understanding of the resistant subpopulation.

Diverse protein pathways were altered in leukemic cells during co-culture with BMM cells evaluated by MS/MS analysis (Figure 5). Key pathways with significant alteration in ALL cells were those associated with cell cycle progression and DNA accessibility. Interestingly, differences were not only seen in ALL cells from BMM niche co-culture compared to media alone, but also in histone related protein expression between ALL cells influenced by BMSC compared to HOB. Although both cell types are derived from the bone marrow, it is not surprising that they influence ALL gene expression differently based the uniqueness of the endosteal and perivascular niches[38,39]. This reflects the complexity of the marrow niche and compartmentalization of function that is critical for regulated development of healthy hematopoietic cells through controlled differentiation, proliferation, survival and eventual egress to the periphery. 
We further characterized the metabolomic profiles of the PD subpopulation compared to tumor cells grown in media alone utilizing LAESI-MS. The metabolic signatures of leukemic cells provided microenvironment cues were notably distinct from ALL cells deprived of these signals (Figure 6). This global evaluation was not intended to identify specific targets but rather to determine if overall metabolite patterns were shifted (Figure 6D). The cellular metabolism of this subpopulation of leukemic cells has been altered by the bone marrow microenvironment interactions, resulting in quiescent cells with high glycolytic potential (Figure 6A-B). This has been previously observed in quiescent fibroblasts[40], and the notion that the PD cells are "primed" for proliferation when they are released from quiescent constraints is a characteristic previously reported in activated dormant $\mathrm{T}$ cells[41].

A particular concern that remains in ALL is the aggressive treatment strategies required to treat relapse in children with the marked potential of late effects and secondary malignancies. Against this backdrop, it is essential to expand the knowledge we obtain in vitro for efficient translation to pre-clinical modeling, subsequent novel drug trials, and generation of new treatment paradigms for patients. Clearly limitations are significant in modeling a complex and dynamic disease such as ALL in vitro. The unique leukemic co-culture model described with an emphasis on a functionally distinct, quiescent and chemoresistant PD subpopulation provides a valuable tool for future analysis. Further dissection of the molecular pathways regulated by the BMM and the "sanctuary" that is created for leukemic cells to generate refractory disease still needs to be extensively studied in order to achieve a higher percentage of disease free survival in leukemia patients. 


\section{Acknowledgements}

The authors thank Dr. Michael Craig for his assistance in acquiring primary patient ALL samples and lan Hare for manuscript editing. We are grateful for the support of Dr.

Kathy Brundage and the West Virginia University Flow Cytometry Core Facility, supported by NIH S10-OD016165 and the Institutional Development Award (IDeA) from the NIH Institute of General Medical Sciences of the National Institutes of Health (CoBRE P30GM103488 and INBRE P20GM103434). Imaging experiments were performed in the West Virginia University Microscope Imaging Facility, supported by the Mary Babb Randolph Cancer Center and NIH grants P20 RR016440, P30 GM103488 and P20 GM103434.

Funding Source: NIH NHLBI R01 HL056888 (LFG), NIH NCI R01 CA134573NIH (LFG), P30 GM103488 (LFG), WV CTR-IDEA NIH 1U54 GM104942, the Alexander B. Osborn Hematopoietic Malignancy and Transplantation Program, and the WV Research Trust Fund.

Conflict of Interest: Angel PM, Walsh CM, and Cantrell PS receive compensation as employees of Protea Biosciences. 


\section{References}

1. Barcellos-de-Souza P, Gori V, Bambi F, Chiarugi P. Tumor microenvironment: Bone marrow-mesenchymal stem cells as key players. Biochim Biophys Acta BBA - Rev Cancer. 2013 Dec;1836(2):321-35.

2. Bradstock K, Bianchi A, Makrynikola V, Filshie R, Gottlieb D. Long-term survival and proliferation of precursor-B acute lymphoblastic leukemia cells on human bone marrow stroma. Leukemia. 1996 May;10(5):813-20.

3. Duan C-W, Shi J, Chen J, Wang B, Yu Y-H, Qin X, et al. Leukemia Propagating Cells Rebuild an Evolving Niche in Response to Therapy. Cancer Cell. 2014 Jun 16;25(6):778-93.

4. Ghajar CM, Peinado H, Mori H, Matei IR, Evason KJ, Brazier H, et al. The perivascular niche regulates breast tumour dormancy. Nat Cell Biol. 2013 Jul;15(7):807-17.

5. Krause DS, Scadden DT, Preffer FI. The hematopoietic stem cell niche-home for friend and foe? Cytometry B Clin Cytom. 2013;84B(1):7-20.

6. Manabe A, Murti KG, Coustan-Smith E, Kumagai M, Behm FG, Raimondi SC, et al. Adhesion-dependent survival of normal and leukemic human $B$ lymphoblasts on bone marrow stromal cells. Blood. 1994 Feb 1;83(3):758-66.

7. Meads MB, Hazlehurst LA, Dalton WS. The Bone Marrow Microenvironment as a Tumor Sanctuary and Contributor to Drug Resistance. Clin Cancer Res. 2008 May 1;14(9):2519-26.

8. Tesfai Y, Ford J, Carter KW, Firth MJ, O'Leary RA, Gottardo NG, et al. Interactions between acute lymphoblastic leukemia and bone marrow stromal cells influence response to therapy. Leuk Res. 2012 Mar;36(3):299-306.

9. Szczepanek J, Styczyński J, Haus O, Tretyn A, Wysocki M. Relapse of Acute Lymphoblastic Leukemia in Children in the Context of Microarray Analyses. Arch Immunol Ther Exp (Warsz). 2011 Feb 1;59(1):61-8.

10. Colmone A, Amorim M, Pontier AL, Wang S, Jablonski E, Sipkins DA. Leukemic Cells Create Bone Marrow Niches That Disrupt the Behavior of Normal Hematopoietic Progenitor Cells. Science. 2008 Dec 19;322(5909):1861-5.

11. Boyerinas B, Zafrir M, Yesilkanal AE, Price TT, Hyjek EM, Sipkins DA. Adhesion to osteopontin in the bone marrow niche regulates lymphoblastic leukemia cell dormancy. Blood. 2013 Jun 13;121(24):4821-31.

12. Jacoby E, Chien CD, Fry TJ. Murine Models of Acute Leukemia: Important Tools in Current Pediatric Leukemia Research. Front Oncol [Internet]. 2014 May 7 [cited 2014 Jul 28];4. Available from: http://www.ncbi.nlm.nih.gov/pmc/articles/PMC4019869/

13. Liem NLM, Papa RA, Milross CG, Schmid MA, Tajbakhsh M, Choi S, et al. Characterization of childhood acute lymphoblastic leukemia xenograft models for the preclinical evaluation of new therapies. Blood. 2004 May 15;103(10):3905-14. 
14. Samuels AL, Beesley AH, Yadav BD, Papa RA, Sutton R, Anderson D, et al. A preclinical model of resistance to induction therapy in pediatric acute lymphoblastic leukemia. Blood Cancer J. 2014 Aug 1;4(8):e232.

15. Mudry RE, Fortney JE, York T, Hall BM, Gibson LF. Stromal cells regulate survival of Blineage leukemic cells during chemotherapy. Blood. 2000 Sep 1;96(5):1926-32.

16. Jing D, Fonseca A-V, Alakel N, Fierro FA, Muller K, Bornhauser M, et al. Hematopoietic stem cells in co-culture with mesenchymal stromal cells--modeling the niche compartments in vitro. Haematologica. 2010 Apr;95(4):542-50.

17. Moore N, Lyle S. Quiescent, Slow-Cycling Stem Cell Populations in Cancer: A Review of the Evidence and Discussion of Significance. J Oncol [Internet]. 2010 Sep 29 [cited 2013 May 29];2011. Available from: http://www.hindawi.com/journals/jo/2011/396076/abs/

18. Saito Y, Uchida N, Tanaka S, Suzuki N, Tomizawa-Murasawa M, Sone A, et al. Induction of cell cycle entry eliminates human leukemia stem cells in a mouse model of AML. Nat Biotechnol. 2010 Mar;28(3):275-80.

19. Gibson LF, Fortney J, Landreth KS, Piktel D, Ericson SG, Lynch JP. Disruption of bone marrow stromal cell function by etoposide. Biol Blood Marrow Transplant J Am Soc Blood Marrow Transplant. 1997 Aug;3(3):122-32.

20. Berniakovich I, Giorgio M. Low oxygen tension maintains multipotency, whereas normoxia increases differentiation of mouse bone marrow stromal cells. Int J Mol Sci. 2013;14(1):2119-34.

21. Chow DC, Wenning LA, Miller WM, Papoutsakis ET. Modeling $\mathrm{pO}(2)$ distributions in the bone marrow hematopoietic compartment. II. Modified Kroghian models. Biophys J. 2001 Aug;81(2):685-96.

22. Holzwarth C, Vaegler M, Gieseke F, Pfister SM, Handgretinger R, Kerst G, et al. Low physiologic oxygen tensions reduce proliferation and differentiation of human multipotent mesenchymal stromal cells. BMC Cell Biol. 2010;11:11.

23. Hathcock KS. Depletion of Accessory Cells by Adherence to Sephadex G-10. In: Current Protocols in Immunology [Internet]. John Wiley \& Sons, Inc.; 2001 [cited 2015 Apr 16]. Available from: http://onlinelibrary.wiley.com/doi/10.1002/0471142735.im0306s08/abstract

24. Slone WS, Moses BS, Evans R, Piktel D, Martin KH, Petros W, et al. Modeling chemotherapy resistant leukemia in vitro. J Vis Exp. In press.

25. Liedtke M, Dunn T, Dinner S, Coutré SE, Berube C, Gotlib J, et al. Salvage therapy with mitoxantrone, etoposide and cytarabine in relapsed or refractory acute lymphoblastic leukemia. Leuk Res. 2014 Dec;38(12):1441-5.

26. Weinstein HJ, Griffin TW, Feeney J, Cohen HJ, Propper RD, Sallan SE. Pharmacokinetics of continuous intravenous and subcutaneous infusions of cytosine arabinoside. Blood. 1982 Jun;59(6):1351-3. 
27. Joannon P, Oviedo I, Campbell M, Tordecilla J. High-dose methotrexate therapy of childhood acute lymphoblastic leukemia: lack of relation between serum methotrexate concentration and creatinine clearance. Pediatr Blood Cancer. 2004 Jul;43(1):17-22.

28. Bhojwani D, Sabin ND, Pei D, Yang JJ, Khan RB, Panetta JC, et al. Methotrexateinduced neurotoxicity and leukoencephalopathy in childhood acute lymphoblastic leukemia. $J$ Clin Oncol Off J Am Soc Clin Oncol. 2014 Mar 20;32(9):949-59.

29. Van den Berg HW, Desai ZR, Wilson R, Kennedy G, Bridges JM, Shanks RG. The pharmacokinetics of vincristine in man: reduced drug clearance associated with raised serum alkaline phosphatase and dose-limited elimination. Cancer Chemother Pharmacol. 1982;8(2):215-9.

30. Shen $\mathrm{H}$, Boyer M, Cheng T. Flow cytometry-based cell cycle measurement of mouse hematopoietic stem and progenitor cells. Methods Mol Biol Clifton NJ. 2008;430:77-86.

31. Wang L, Clutter S, Benincosa J, Fortney J, Gibson LF. Activation of transforming growth factor-beta1/p38/Smad3 signaling in stromal cells requires reactive oxygen species-mediated MMP-2 activity during bone marrow damage. Stem Cells Dayt Ohio. 2005 Sep;23(8):1122-34.

32. Clutter SD, Fortney J, Gibson LF. MMP-2 is required for bone marrow stromal cell support of pro-B-cell chemotaxis. Exp Hematol. 2005 Oct;33(10):1192-200.

33. O'Leary H, Akers SM, Piktel D, Walton C, Fortney JE, Martin KH, et al. VE-cadherin Regulates Philadelphia Chromosome Positive Acute Lymphoblastic Leukemia Sensitivity to Apoptosis. Cancer Microenviron Off J Int Cancer Microenviron Soc. 2010;3(1):67-81.

34. Wang L, Coad JE, Fortney JM, Gibson LF. VEGF-induced survival of chronic lymphocytic leukemia is independent of Bcl-2 phosphorylation. Leukemia. 2005 Aug;19(8):1486-7.

35. Wang L, Chen L, Benincosa J, Fortney J, Gibson LF. VEGF-induced phosphorylation of Bcl-2 influences B lineage leukemic cell response to apoptotic stimuli. Leukemia. 2005 Mar;19(3):344-53.

36. Ayala F, Dewar R, Kieran M, Kalluri R. Contribution of bone microenvironment to leukemogenesis and leukemia progression. Leukemia. 2009 Sep 3;23(12):2233-41.

37. Li L, Bhatia R. Stem Cell Quiescence. Clin Cancer Res. 2011 Aug 1;17(15):4936-41.

38. Morrison SJ, Scadden DT. The bone marrow niche for haematopoietic stem cells. Nature. 2014 Jan 16;505(7483):327-34.

39. Mendelson A, Frenette PS. Hematopoietic stem cell niche maintenance during homeostasis and regeneration. Nat Med. 2014 Aug;20(8):833-46.

40. Lemons JMS, Feng X-J, Bennett BD, Legesse-Miller A, Johnson EL, Raitman I, et al. Quiescent Fibroblasts Exhibit High Metabolic Activity. PLoS Biol. 2010 Oct 19;8(10):e1000514.

41. Krauss S, Brand MD, Buttgereit F. Signaling Takes a Breath - New Quantitative Perspectives on Bioenergetics and Signal Transduction. Immunity. 2001 Oct;15(4):497-502. 


\section{Supplemental methods:}

\section{Culture conditions}

Co-cultures were established by seeding leukemic cells onto $80-90 \%$ confluent BMSC or HOB monolayers. Cultures were fed every 4 days and tumor cells collected for inclusion in experiments with remaining leukemic cells moved to new primary BMSC or $\mathrm{HOB}$ adherent layers every 12 days. Cultures were maintained in $5 \% \mathrm{O}_{2}$ to model normal bone marrow oxygen tension, reported to range from 1-7\%[1-3]. Suspended (S) leukemic cells floating freely in the media were removed by gentle pipetting. Phase bright (PB) tumor cells, that were loosely adherent to the top of BMSC or HOB, were harvested by vigorous pipetting. Phase dim (PD) leukemic cells that were buried firmly beneath adherent BMSC or HOB were recovered by trypsinization of the adherent layer and PD tumor. The S, PB, and PD tumor populations were separated from BMSC/HOB by size exclusion with G10 Sephadex (Sigma, St Louis, MO, USA) column separation[4].

\section{Microscopy}

Phase contrast images were acquired using a Leica DMIL LED microscope and processed by Leica application suite version 4.0 software (Buffalo Grove, IL, USA). Confocal images were acquired using an upright LSM 510 Zeiss microscope and processed using Zen2009 software (Thornwood, NY, USA). Fluorescence intensity for image acquisition was only altered when fluorescence intensities were not compared between samples. 


\section{Co-culture of tumor cells with non-bone marrow derived adherent cells}

ALL cells were cultured in media alone, or co-cultured with sheep choroid plexus epithelial cells (SCP) (ATCC-CRL-1700), 3T3 mouse embryonic fibroblasts (3T3) (ATCC-CRL-1658), mouse embryonic fibroblasts (MEF) (ATCC-CRL-2991), human embryonic kidney cells (293T) (ATCC-CRL-3216), or HT-1080 human fibrosarcoma derived cells (HT) (ATCC-CCL-121). Leukemic cells were cultured with adherent layers for 4 days to establish S, PB, and PD tumor populations comparable to those established with human BMSC/HOB. At day 4, cultures were exposed to Ara-C and evaluated for viability by trypan blue exclusion in triplicate.

\section{In vitro relapse model}

ALL cells were grown in co-culture with BMSC or HOB for 4 days. At day 4, cultures were provided fresh media and exposed to Ara-C for 72 hours. Following Ara-C exposure, S and PB ALL cell subpopulations were harvested as previously described and viability enumerated by trypan blue exclusion. Co-cultures, in which PD tumor cells remained buried beneath adherent $\mathrm{BMSC} / \mathrm{HOB}$, were rinsed to remove residual Ara-C and subsequently repopulation was monitored. ALL cells that comprised the regenerated $S$ and $P B$ fractions were enumerated at 5 day intervals at which time fresh media was provided. Cultures were maintained until tumor burden compromised BMSC or HOB monolayers.

\section{Western blot analysis}

Specific targets of glycolytic regulation were detected by rabbit mAb Hexokinase 1 (Cell Signaling Technologies, Danvers, MA, USA; C35C4; Cat \# 2024) and rabbit mAb 
Hexokinase 2 (C64G5; Cat \# 2867). Following incubation with horseradish peroxidaseconjugated secondary antibodies, signal was visualized using enhanced

chemiluminescence (Amersham, Piscataway, NJ, USA). Densitometry was quantified by ImageJ with signal normalized to GAPDH.

\section{Ki-67 staining}

ALL subpopulations were either cytospun following G10 Sephadex purification following co-culture or analysis was completed on ALL cells during co-culture with BMSC or HOB grown on coverslips. Cells were fixed with $4 \%$ paraformaldehyde, washed with PBS,

permeabilized with $0.1 \%$ Triton X-100 (Sigma) in PBS, and incubated with rabbit anti-Ki67 followed by Alexa 488 anti-rabbit. Phalloidin-TRITC was used to visualize the actin cytoskeleton. Cells were washed with PBS and mounted to glass slides (coverslip staining) or coverslips (cytospins) with Prolong® Gold anti-fade/DAPI. Images were acquired by confocal microscopy and a minimum of 50 cells were counted to quantitate percent positive Ki-67 cells in triplicate.

\section{Seahorse analysis}

Leukemic cells $(800,000$ cells/well) were collected from media alone or isolated from BMSC/HOB co-culture and incubated in an XFe96 cell culture microplate coated with Cell-Tak (BD Biosciences). The XFe 96 Analyzer with XF Assay Media containing sodium pyruvate and glucose was used to determine Oxygen Consumption Rate [OCR] measurements, or with XF Base Media with L-glutamine to determine Extracellular Acidification Rate [ECAR] measurements. The XF plate was calibrated overnight with XF Calibrant at $37^{\circ} \mathrm{C}$. On the day of the measurements, tumor cells were plated directly 
in XF media, and basal measurements (OCR or ECAR) were collected at three time points.

\section{Laser Ablation Electrospray lonization (LAESI)}

Prior to direct analysis by laser ablation electrospray ionization (LAESI-MS) each cell pellet $\left(5 \times 10^{6}\right.$ cells) was centrifuged at $1,000 \times g$ for 2 minutes at $4^{\circ} \mathrm{C}$. The entire pellet $(\sim 3 \mu \mathrm{L})$ was dispensed onto a glass microscope slide for LAESI-MS analyses. In vivo molecular profiling was performed on the cells with a LAESI DP-1000 Direct lonization source interfaced with a Thermo QExactive mass spectrometer (Thermo Scientific). Electrospray solution (50\% methanol/0.1\% acetic acid) flowed at $1 \mu \mathrm{L} / \mathrm{min}$ through a stainless steel emitter tip (320 $\mu \mathrm{m}$ OD and $100 \mu \mathrm{m}$ ID; New Objective, Woburn, MA) at an electrospray voltage $4 \mathrm{kV}$. Three technical replicates $(250$ laser pulses at $10 \mathrm{~Hz}$ with

a laser energy $600 \mu \mathrm{J}$ ) were performed per three biological replicates. The LAESI peltier stage was cooled to $4^{\circ} \mathrm{C}$. Full scan mass spectrometer profiles were collected over a mass range of $\mathrm{m} / \mathrm{z} 50$ to 750 at 35,000 mass resolution with $\mathrm{m} / \mathrm{z} 37[5] .1012$ selected for real-time mass accuracy lockmass correction.

\section{Post-analysis Processing and Multivariate Statistics}

Post LAESI-MS acquisition, the spectra were averaged across each technical replicate per biological replicate (approximately 175 scans). Multivariate statistics were applied in order to compare media treatment to BMSC and $\mathrm{HOB}$, respectively. Mass Profiler Professional (Agilent, version 13 build 211261) was used to determine significantly altered $\mathrm{m} / \mathrm{z}$ using a Benjamini Hochberg false discovery rate corrected $\mathrm{p}$-value $<0.01$ from ANOVA testing1. Putatively altered $\mathrm{m} / \mathrm{z}$ visualized using the heatmap function. 


\section{Proteomics}

\section{iTRAQ Sample Preparation}

Cell pellets were lysed $150 \mu \mathrm{L}$ of $0.1 \mathrm{M}$ TEAB with $2 \%$ SDS, vortexed and sonicated for 20 minutes in an ice bath, followed by centrifugation at $12,000 \mathrm{~g}$ for 10 minutes. Supernatant was quantified by BCA, and $200 \mu \mathrm{g}$ of protein from each cell type was precipitated using cold acetone in a $6: 1$ acetone to sample ratio, chilling at $-20^{\circ} \mathrm{C}$ overnight. Proteins were reduced and alkylated, and trypsin digested overnight. The iTRAQ labeling (Applied Biosciences) was performed according to manufacturer's instructions, labeling for two hours, followed by adding an excess $350 \mu \mathrm{L}$ of water and incubating for 30 minutes to stop the labeling reaction. Samples Media, BMSC, $\mathrm{BMSC} / \mathrm{HOB}$, and $\mathrm{HOB}$ samples were labeled with tagged with the $115,1116,117,118$ reagents, respectively. Samples were frozen to $-80^{\circ} \mathrm{C}$ followed by overnight lyophilization, and cleaned up using strong cation exchange (SCX) SpinTips (Protea Biosciences). Samples were lyophilized after cleanup, and reconstituted in $40 \mu \mathrm{L}$ of $0.1 \%$ formic acid $/ 5 \%$ acetonitrile.

\section{LC-MS/MS}

Samples were separated by reverse phase chromatography using a Shimadzue LC20AD HPLC system eluting over 90 minutes using a C18 column (Kinetex $100 \times 2.1 \mathrm{~mm}$ C18, Phenomenex). Gradient was 0-3 minutes 2\% B, 3-70 minutes 2-40\%B, 70-80 minutes $90 \%$ B followed by a column wash $80-85$ minutes $90 \%$ B using a flow rate of $200 \mu \mathrm{L} /$ minute. Mobile phase $\mathrm{A}$ was $0.1 \%$ formic acid in water, mobile phase $\mathrm{B}$ was $0.1 \%$ formic acid in acetonitrile. Peptides were eluted with a positive ion mode applied 
voltage of $3.5 \mathrm{kV}$ into a QTrap 5500 (AB Sciex). Using data independent acquisition, the 3 most intense multiply charged ions with ion intensities above a threshold of 50000 in each regular MS scan were subjected to MS/MS analyses.

\section{Data Analysis}

MS/MS data were searched against the Swissprot human database downloaded January 7, 2015. Data were searched with the Paragon search algorithm (Applied Biosciences) through the ProteinPilot software using trypsin as the enzyme, statics modifications of Cysteine and MMTS (Methylthio, the labeling reagent), dynamic modifications of deamidation $(\mathrm{N}, \mathrm{Q})$ and oxidation $(\mathrm{M})$. Autobias was applied for quantification using GAPDH as a control to evaluate quantification. Altered proteins were designated as those with $p$-value $<0.05$ relative to Media. The web applications ToppCluster and WebGestalt were used for enrichment analysis and graphical representation of biological processes and pathways $[6,7]$.

\section{Statistical analysis}

Results are expressed as triplicate mean \pm SEM. An unpaired t-test were performed for viability, H/PY, and KI67 quantitation (Graph Pad Software, La Jolla, CA, USA). Seahorse results were analyzed by One-way ANOVA with Dunnett's post hoc (Sigma Plot, San Jose, CA, USA). $p$ value of $<0.05$ was considered statistically significant. 


\section{Supplemental References}

1. Berniakovich I, Giorgio M. Low oxygen tension maintains multipotency, whereas normoxia increases differentiation of mouse bone marrow stromal cells. Int J Mol Sci. 2013;14(1):2119-34.

2. Chow DC, Wenning LA, Miller WM, Papoutsakis ET. Modeling $\mathrm{pO}(2)$ distributions in the bone marrow hematopoietic compartment. II. Modified Kroghian models. Biophys J. 2001 Aug;81(2):685-96.

3. Holzwarth C, Vaegler M, Gieseke F, Pfister SM, Handgretinger R, Kerst G, et al. Low physiologic oxygen tensions reduce proliferation and differentiation of human multipotent mesenchymal stromal cells. BMC Cell Biol. 2010;11:11.

4. Hathcock KS. Depletion of Accessory Cells by Adherence to Sephadex G-10. Current Protocols in Immunology [Internet]. John Wiley \& Sons, Inc.; 2001 [cited 2015 Apr 16]. Available from: http://onlinelibrary.wiley.com/doi/10.1002/0471142735.im0306s08/abstract

5. Benjamini Y, Hochberg Y. Controlling the False Discovery Rate: A Practical and Powerful Approach to Multiple Testing. J R Stat Soc Ser B Methodol. 1995 Jan 1;57(1):289_ 300.

6. Kaimal V, Bardes EE, Tabar SC, Jegga AG, Aronow BJ. ToppCluster: a multiple gene list feature analyzer for comparative enrichment clustering and network-based dissection of biological systems. Nucleic Acids Res. 2010 Jul;38(Web Server issue):W96-102.

7. Zhang B, Kirov S, Snoddy J. WebGestalt: an integrated system for exploring gene sets in various biological contexts. Nucleic Acids Res. 2005 Jul 1;33(Web Server issue):W741-8. 


\section{Figure legends}

Figure 1. Human acute lymphoblastic leukemia cells (ALL) occupy three functionally distinct spatial compartments during co-culture with BMSC. The left panels show suspended ALL tumor cells from representative cell lines (REH, Nalm-27 or Tom-1) grown in media alone. Right panels demonstrate co-culture dynamics with leukemic cells forming three functionally distinct populations in relation to the BMSC monolayer. Cells were co-cultured for 48 to $72 \mathrm{~h}$ prior to acquiring images. The three ALL populations include suspended (S) cells which refract light, appear bright and are freely floating in culture media; phase bright (PB) tumor cells that are loosely attached to the surface of the adherent BMSC monolayer; and phase dim (PD) tumor cells which are beneath the BMSC monolayer and appear as phase dim cells upon light microscopy. Arrows highlight the PD subpopulation of ALL cells in co-culture with BMSC, which are enlarged in the inset for more detailed visualization. Scale bar $=10 \mu \mathrm{m}$.

Figure 2. Each subpopulation of Nalm-27 ALL cells re-established the PD fraction when provided BMM niche cells. The S, PB and PD ALL subpopulations were collected from co-culture and individually stained with blue, far red and green fluorophores for visualization, respectively. Each subpopulation associated with BMSC (top panel) and HOB (bottom panel) observed after 48h. Co-cultures were vigorously rinsed to remove $\mathrm{S}$ and PB tumor cells to visualize only PD tumor cells shown in the representative images. Actin was visualized by Phalloidin-TRITC staining. Levels including gamma were adjusted and a median filter was applied for image clarity with no comparison of intensity. Scale bar $=10 \mu \mathrm{m}$. 
Figure 3. PD leukemic cells have pronounced resistance to chemotherapy induced death. (A) Leukemic cells recovered from the PD population of an $\mathrm{HOB}$ co-culture have significantly increased viability following exposure to Ara-C [1 $\mu \mathrm{M}]$, MTX [50 $\mu \mathrm{M}]$, or VCR $[25 \mu \mathrm{M}]$ determined by trypan blue exclusion or (B) Annexin V-FITC/PI staining when compared to matched controls that are exposed to cytotoxic agents in media alone. (C In contrast to human BMSC or HOB co-culture, leukemic cells recovered from the PD population of non-bone marrow derived adherent layers do not have increased viability compared to untreated controls during exposure to Ara-C. (D) PD leukemic cells undergo a quiescent recovery period following Ara-C exposure, followed by an aggressive period of proliferation to repopulate the S and PB populations. $\left({ }^{*}\right)$ denotes $p$ $<0.05$, unpaired t-test when compared to media alone or untreated controls.

Figure 4. BMM cells influence the PD subpopulation cell cycle profile and increase quiescence. (A) PD cells have a higher percentage of cells in the $\mathrm{G}_{0} / \mathrm{G}_{1}$ phase and a reduction in S phase compared to media alone leukemic cells as measured by PI staining. (B) $H / P Y$ staining revealed the PD cells have a higher percentage of cells in $\mathrm{G}_{0}$ when compared to tumor cells cultured in media alone. (C) Assessing Ki-67 (green) expression by confocal microscopy, the PD cells had a reduction in Ki-67 positive cells. TRITC staining: red, DNA staining: blue, Ki-67: green. Scale bar equal $=10 \mu \mathrm{m} .\left(^{*}\right)$ denotes $p<0.05$, unpaired t-test when compared to media alone. 
Figure 5. BMM alters global protein expression in ALL cells. The heat map shown represents differentially regulated proteins comparing Sup-B15 ALL cells co-cultured with BMSC or $\mathrm{HOB}$ to those grown in media alone. GAPDH was used as a control to normalize expression in all groups. A p-value $<0.05$ for comparisons of co-culture relative to media alone was required for designation of a difference in protein abundance.

Figure 6. PD cells isolated from bone marrow niche co-culture have a distinct metabolic phenotype when compared to ALL cells in the absence of microenvironment signals. (A) REH cells recovered from the PD population have increased basal glycolytic rates compared to tumor in media alone or their S and PB counterparts from the same BMSC or HOB co-culture as indicated by the increase in extracellular acidification rate (ECAR). (B) Western blot analyses indicated increased Hexokinase 1 and Hexokinase 2 protein expression in PD ALL cells compared to tumor cells maintained in media alone. (C) REH cells in co-culture with BMSC or HOB have decreased basal oxygen consumption compared to media alone controls as reflected by diminished oxygen consumption rate (OCR). (D) Laser ablation electrospray ionization mass spectrometry (LAESI-MS) metabolomic analysis of Nalm-27 cells cultured in media alone or recovered from the PD population of BMSC or $\mathrm{HOB}$ co-culture showed global changes of metabolites between ALL cells populations. Heat map represents differentially expressed metabolite ions ( $\mathrm{m} / \mathrm{z}$ values), $\mathrm{p}$-value $<0.01 .\left(^{*}\right)$ denotes $\mathrm{p}<0.05$ by One-way ANOVA with Dunnett's post hoc when compared to media alone. 


\section{Figures}
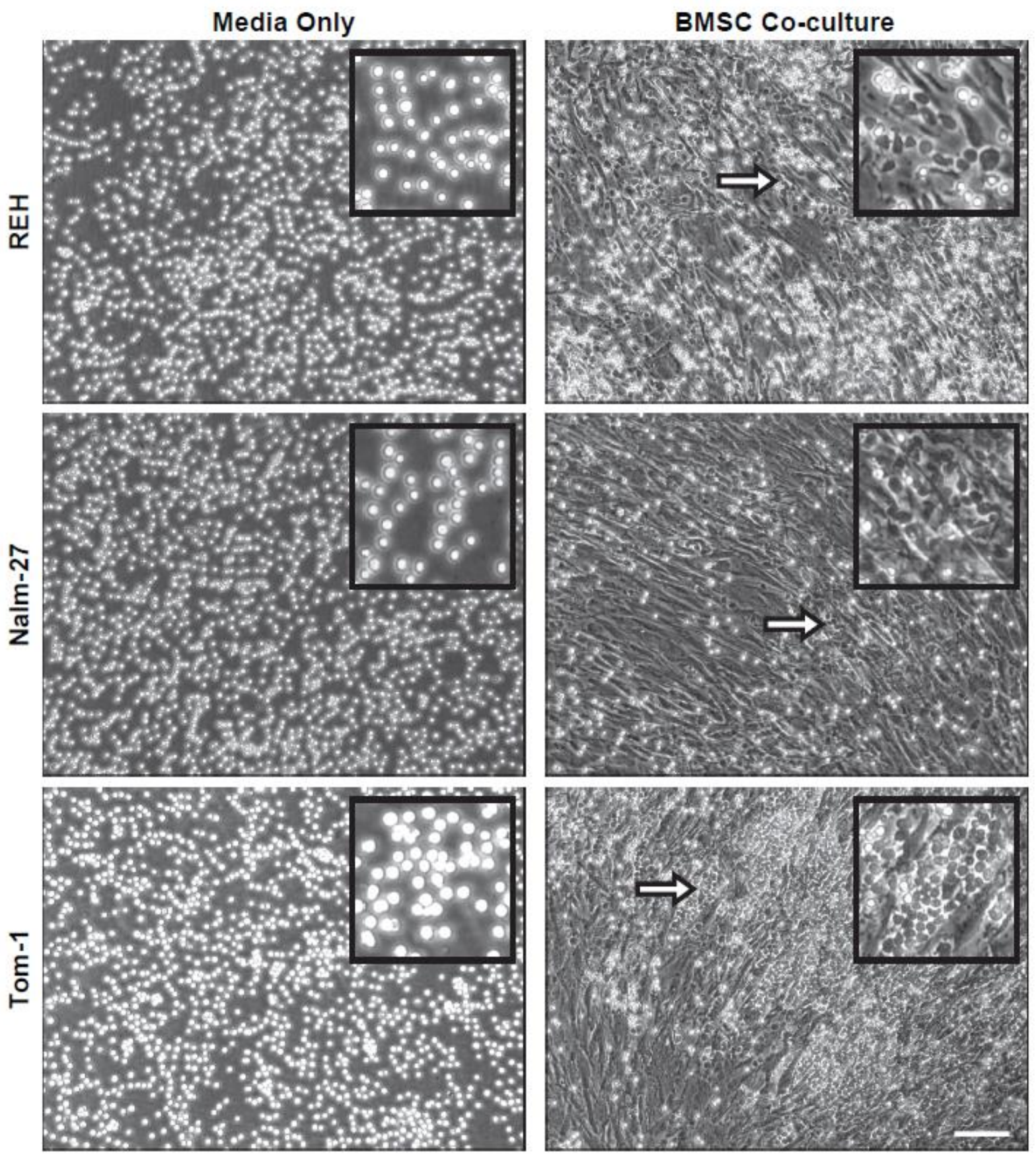

Figure 1. Human acute lymphoblastic leukemia cells (ALL) occupy three functionally distinct spatial compartments during co-culture with BMSC. 

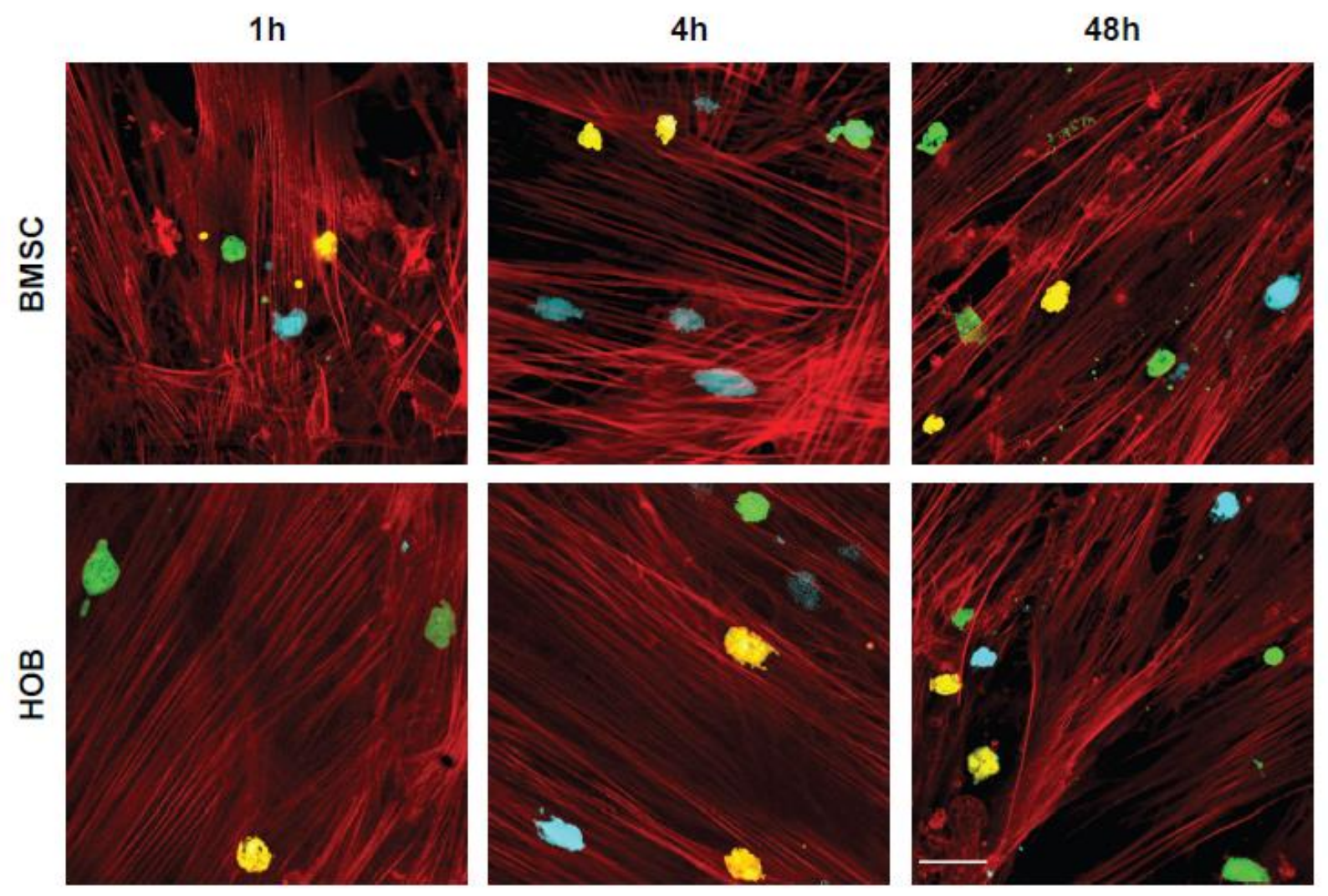

Figure 2. Each subpopulation of Nalm-27 ALL cells re-established the PD fraction when provided BMM niche cells. 

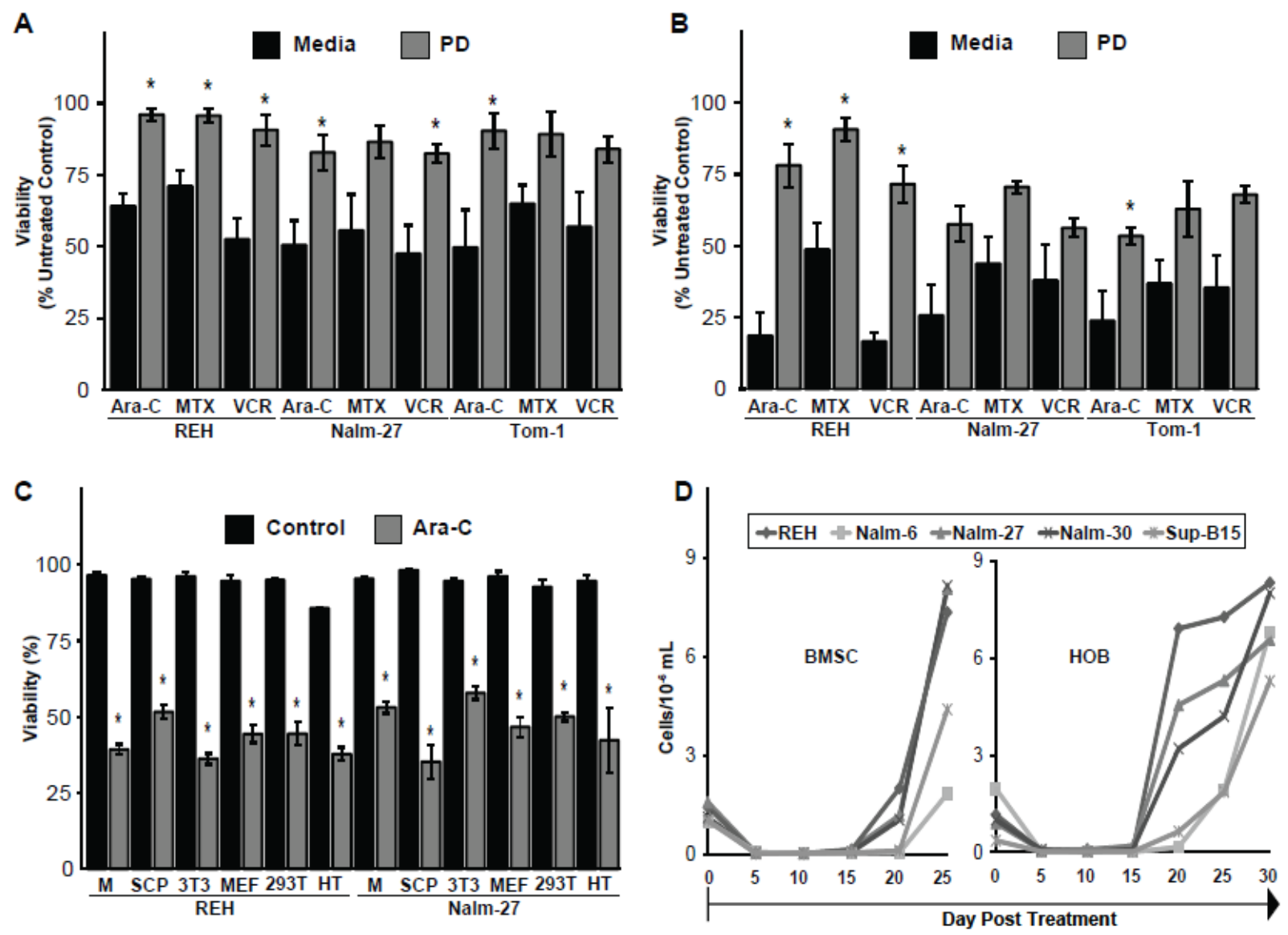

Figure 3. PD leukemic cells have pronounced resistance to chemotherapy induced death. 

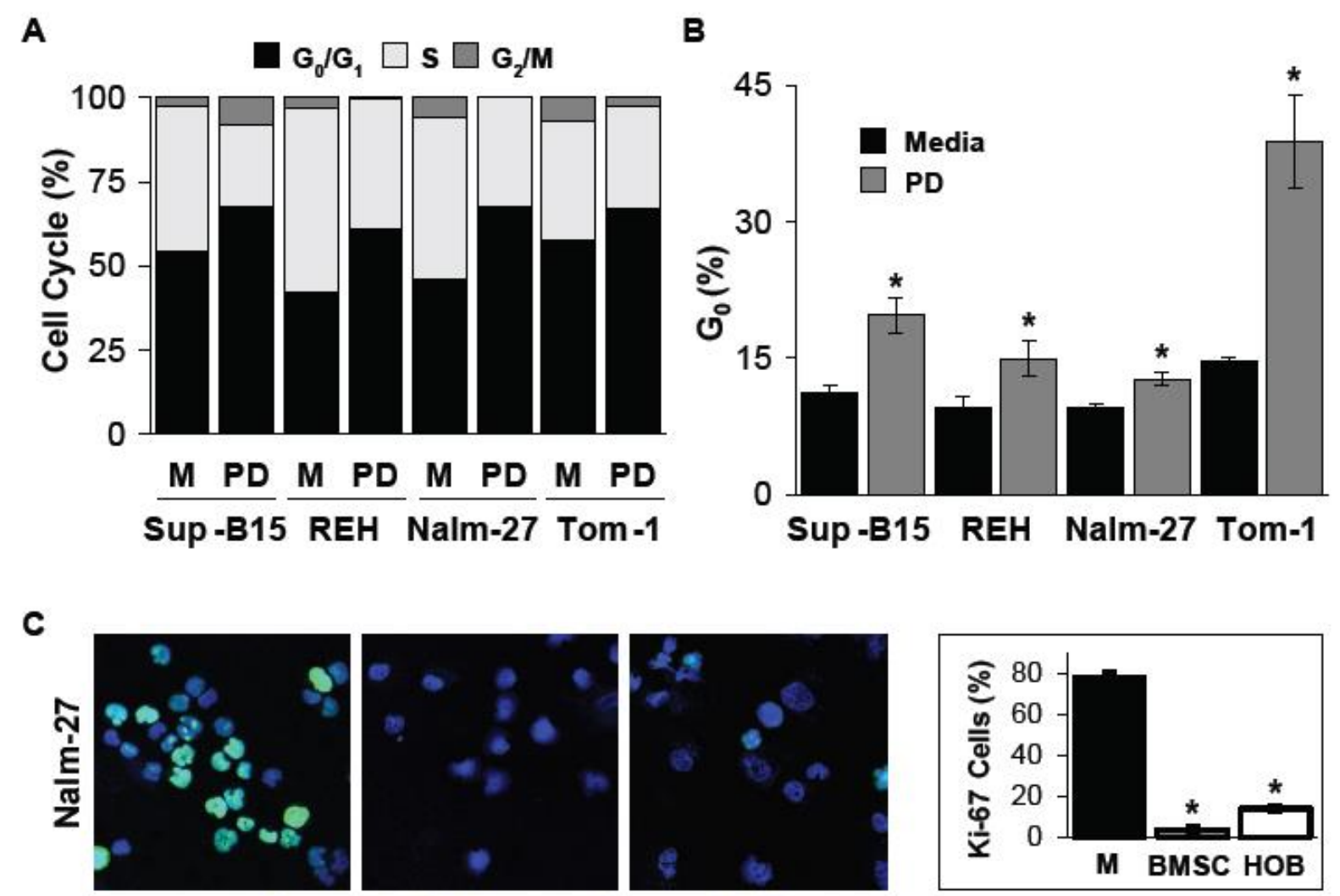

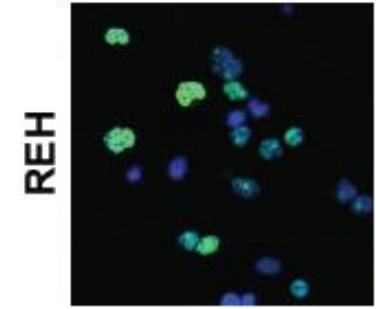

Media

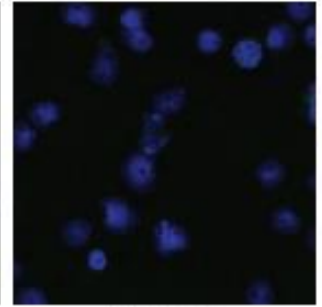

BMSC

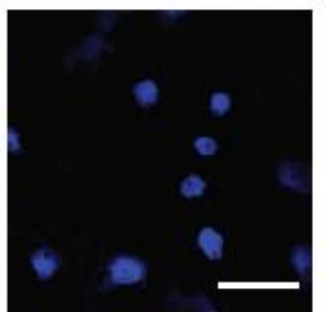

HOB

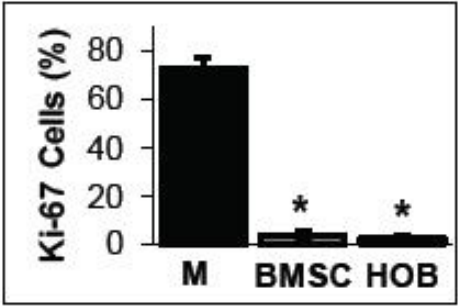

M BMSC нов

Figure 4. BMM cells influence the PD subpopulation cell cycle profile and increase quiescence. 


\section{BMSC:MEDIA HOB:MEDIA}

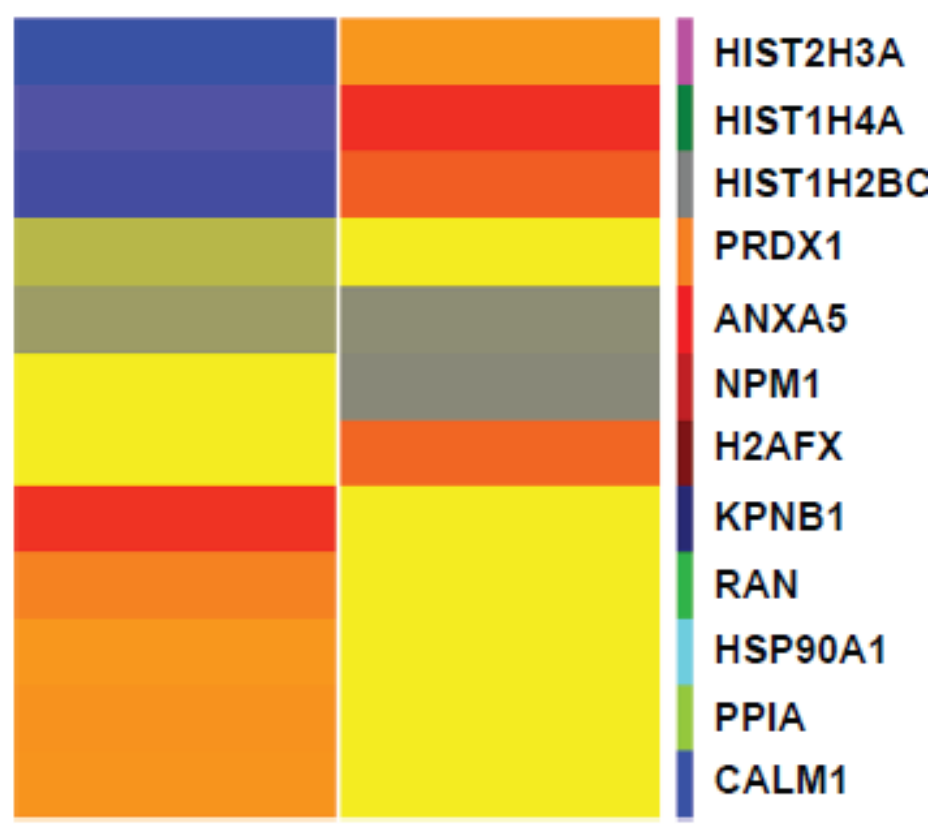

Log2 Intensity Values

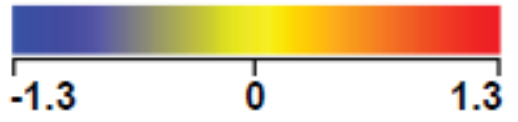

Figure 5. BMM alters global protein expression in ALL cells. 

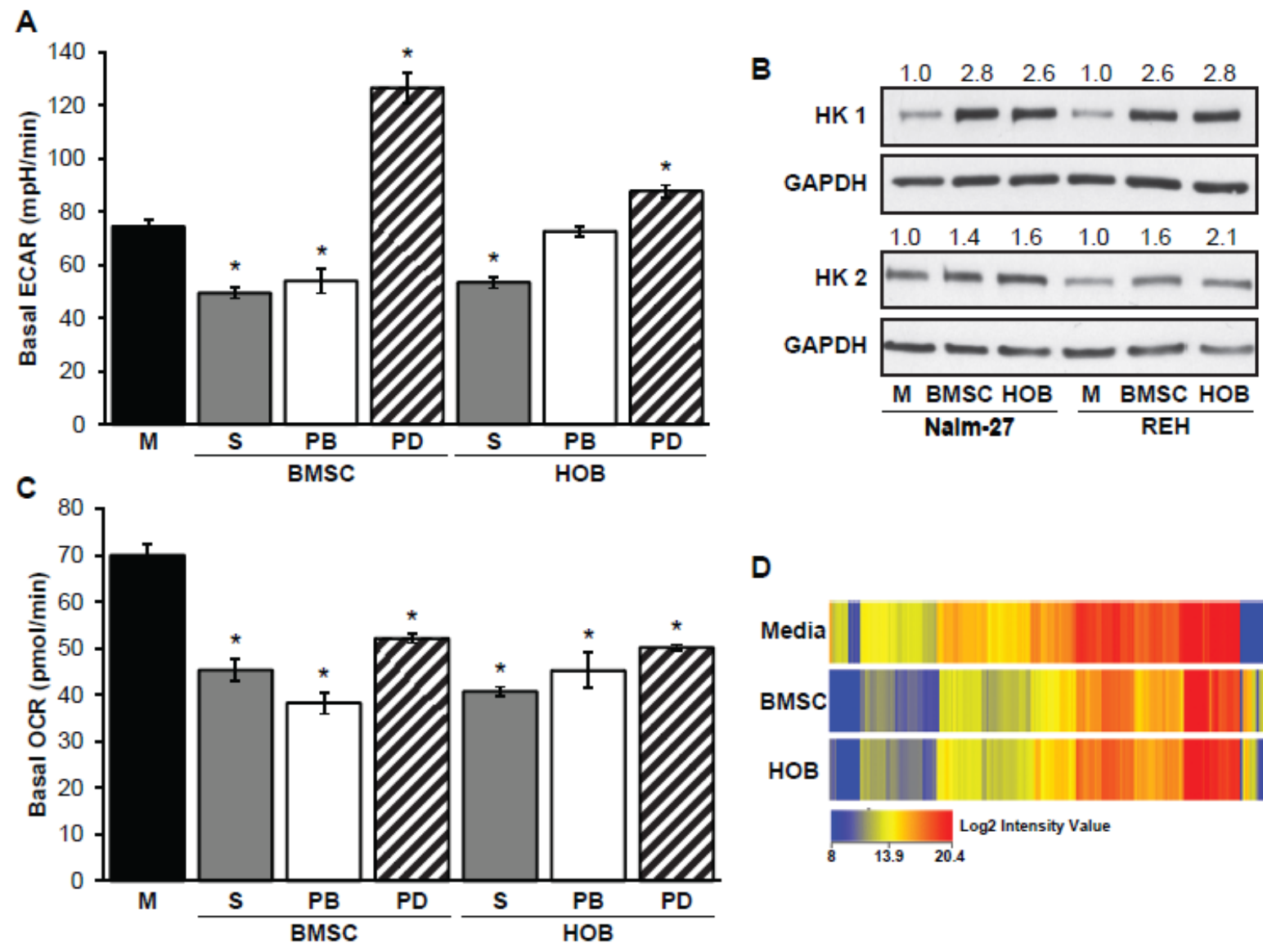

D

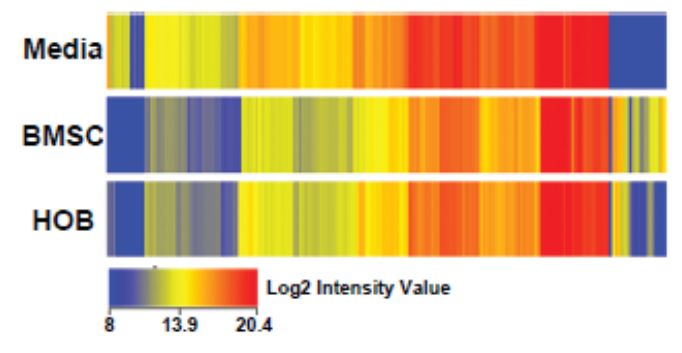

Figure 6. PD cells isolated from bone marrow niche co-culture have a distinct metabolic phenotype when compared to ALL cells in the absence of microenvironment signals. 


\section{Chapter 4}

\section{BCL6 Modulation of Acute Lymphoblastic Leukemia Response to Chemotherapy}

William L Slone ${ }^{1}$, Blake S Moses ${ }^{1}$, Ian Hare ${ }^{1,2}$, Rebecca Evans ${ }^{1}$, Debbie Piktel ${ }^{1}$, and Laura F Gibson ${ }^{1,2,{ }^{*}}$

${ }^{1}$ Alexander B. Osborn Hematopoietic Malignancy and Transplantation Program of the WVU Cancer Institute, Robert C. Byrd Health Sciences Center, West Virginia University School of Medicine, USA; 'Department of Microbiology, Immunology and Cell Biology, Robert C. Byrd Health Sciences Center, West Virginia University School of Medicine, USA

Key Words: Bone marrow microenvironment, Acute Lymphoblastic Leukemia, BCL6, Chemotherapy resistance, ALL

This work has been published as a manuscript in Oncotarget:

Slone WL, Moses BS, Hare I, Et al. BCL6 Modulation of Acute Lymphoblastic Leukemia Response to Chemotherapy. Oncotarget. 2016. doi:10.18632/oncotarget.8273. 


\section{Abstract}

The bone marrow niche has a significant impact on acute lymphoblastic leukemia (ALL) cell phenotype. Of clinical relevance is the frequency with which quiescent leukemic cells, in this niche, survive treatment and contribute to relapse. This study suggests that marrow microenvironment regulation of BCL6 in ALL is one factor that may be involved in the transition between proliferative and quiescent states of ALL cells. Utilizing ALL cell lines, and primary patient tumor cells we observed that tumor cell BCL6 protein abundance is decreased in the presence of primary human bone marrow stromal cells (BMSC) and osteoblasts (HOB). Chemical inhibition, or shRNA knockdown, of BCL6 in ALL cells resulted in diminished ALL proliferation. As many chemotherapy regimens require tumor cell proliferation for optimal efficacy, we investigated the consequences of constitutive BCL6 expression in leukemic cells during co-culture with BMSC or HOB. Forced chronic expression of BCL6 during co-culture with BMSC or HOB sensitized the tumor to chemotherapy induced cell death. Combination treatment of caffeine, which increases BCL6 expression in ALL cells, with chemotherapy extended the event free survival of mice. These data suggest that BCL6 is one factor, modulated by microenvironment derived cues that may contribute to regulation of ALL therapeutic response. 


\section{Introduction}

Acute lymphoblastic leukemia (ALL) is the most common childhood malignancy. While two-thirds of cases present in children, the risk of ALL also increases with age in the adult population [1]. In both populations, relapse of disease is associated with poor prognosis, with relapsed disease often being more aggressive and refractory to treatment $[2,3]$. Risk of relapse has been shown to be linked to the presence of refractory minimal residual disease (MRD) [4-6]. The bone marrow is the most common site of ALL MRD, and consequently, the most common site of relapse [7]. Consistent with relapse in the bone marrow microenvironment (BMM), we and others have shown that bone marrow stromal cells (BMSC) and osteoblasts (HOB) provide protection to leukemic cells during chemotherapy treatment [8- 16]. However, the cell signaling pathways by which the BMM influences tumor cells to provide this protection remains incompletely understood.

While there are many diverse signaling pathways that converge on the phenotype of any tumor in response to microenvironment derived cues, the focus of the current investigation is on the modulation of ALL cell BCL6. BCL6 is a proto-oncogene that has been classically described in the setting of its influence on germinal center Bcells, as well as its role in the progression of diffuse large B-cell lymphoma [17-28]. In these contexts, BCL6 has been well characterized as a regulator of B-cell proliferation, maturation, and resistance to DNA damage [29]. More recent work has highlighted the impact of BCL6 on immature and malignant hematopoietic cells. Increased expression of BCL6 in chronic myelogenous leukemia (CML) and acute lymphoblastic leukemia (ALL) has been shown to protect leukemic cells from chemotherapy induced DNA 
damage through the repression of p53 induced apoptosis [30, 31]. These studies, in addition to earlier work in germinal center biology, reflect the ability of BCL6 to influence leukemic cell phenotype through regulation of survival, differentiation, and cell cycle progression.

To address a fundamental gap that exists in understanding how the BMM impacts leukemic BCL6 we utilized the previously described in vitro model in which phase $\operatorname{dim}(\mathrm{PD})$ ALL cells migrate beneath BMSC or HOB and exhibit a chemotherapyresistant phenotype. Our laboratory has previously characterized this dynamic in vitro model in which ALL cells seeded onto BMSC or HOB transiently migrate beneath the bone marrow stromal layer, generating the "phase dim" population $[13,15]$. This population of ALL cells was characterized by quiescence and chemotherapy resistance while in this in vitro niche. However, removal from beneath the stromal layer results in a return to chemotherapy sensitivity [13]. Furthermore, this PD characteristic was specific to ALL cells co-cultured with BMSCs or HOBs, as PD populations, which readily migrated beneath co-cultures comprised of non-bone marrow derived adherent layers, were not protected from chemotherapy-induced death [13] suggesting the observed effect is not simply physical protection from cytotoxic drugs. Utilizing this co-culture model to represent BMM protected and resistant ALL cells we found that co-culture with BMSC or HOB reduced the abundance of tumor cell BCL6, coincident with increased survival and quiescence of a subset of tumor cells in contact with BMSC or HOB. Furthermore, chronic forced expression of BCL6 in this quiescent tumor cell population resulted in sensitization to chemotherapy. These observations suggest that the BMM influenced leukemic cell BCL6 protein abundance has the potential to contribute to the 
generation of a quiescent, drug resistant population of tumor cells and that strategies aimed at disruption of this pathway may prove to be an effective means by which to diminish MRD and relapse of ALL.

\section{Results}

\section{Co-culture with BMSC or HOB reduces BCL6 in ALL cells.}

Both the BMM in general, and BCL6 specifically, have independently been shown to regulate ALL survival [11- 14, 30, 31]. However, it has not been determined whether there is a functional link between bone marrow niche derived signals and ALL cell abundance of BCL6. To determine whether BMM cells regulate BCL6 protein levels in leukemic cells, ALL cell lines were grown in co-culture with either BMSC or HOB and compared to tumor cultured in media alone. Co-culture derived tumor cells were further sub-divided into distinct populations that included suspended (S), phase bright (PB), and phase dim (PD) leukemic cells based on their spatial location within the co-culture. We have previously observed that in vitro location related to BMSC or HOB stromal cells impacts ALL survival in co-culture during chemotherapy exposure, with the PD population of leukemic cells being the most resistant to chemotherapy exposure $[13,15]$ providing an opportunity to focus studies uniquely on the most resistant subpopulation of tumor cells. In the current study, regardless of the fraction of ALL cells evaluated, decreased BCL6 protein abundance was observed in ALL cells co-cultured with BMSC or $\mathrm{HOB}$, with the most pronounced reduction consistently observed in the PD population (Figure $1 \mathrm{~A}-\mathrm{B}$ ). Of note, under normal culture conditions there is no difference in ALL cell viability between cells cultured in media alone compared to those in the co-culture conditions (DNS) supporting the observation that changes in BCL6 abundance are not 
due to selective pressure of the different culture conditions, but are a result of interactions with the BMSC or HOB. Consistent with western blot observations, flow cytometry and confocal microscopy analysis of REH and Nalm-27 cell lines showed that leukemic cells recovered from the PD population of BMSC or HOB co-culture had reduced BCL6 protein abundance compared to tumor cells cultured in media alone (Figure $1 \mathrm{~B}$ and $\mathrm{D}$ ). Consistent with data derived from cell lines, ALL patient derived cells co-cultured with BMSC or $\mathrm{HOB}$ also had decreased BCL6 protein levels compared to cells grown in media alone (Figure $\mathrm{C}$ and $\mathrm{E}$ ).

\section{Modulation of BCL6 alters ALL cell cycle progression and proliferation rate.}

Based on reports of BCL6 abundance influencing proliferation of B-cells [32-35], we determined the functional consequence of BCL6 downregulation on ALL cell proliferation and cell cycle progression. Inhibition of BCL6 with the small molecule inhibitor 79-6 resulted in a significant decrease in expansion of ALL cells in media alone compared to DMSO solvent controls (Figure 2A) without an effect on tumor cell viability (Figure 2B). Proliferation of ALL cells was reduced by BCL6 inhibition as reflected by a significant reduction in the proliferation index of ALL cells exposed to 79-6 (Figure 2C). Consistent with reduced ALL cell number and proliferation, BCL6 inhibition altered cell cycle progression in ALL cells as shown by an increase in $\mathrm{G}_{0} / \mathrm{G}_{1}$ phases and reduction in $S$ and G2/M phases (Figure 2D). Because there is always concern regarding the potential for non-specific effects when using small molecule inhibitors, we generated lentiviral based shRNA knockdown of BCL6 in REH cells. This more specific targeted approach resulted in diminished proliferation as determined by a decrease in cell density over time relative to vector controls (Figure 2E; left panel). Conversely, 
overexpression of BCL6 in REH cells increased cell density compared to vector controls in a time course assay (Figure 2E; right panel). Knockdown of BCL6 also significantly increased the percentage of $R E H$ tumor cells in $G_{0} / G_{1}$ phases and reduced $G_{2} / M$ phases in line with the observed reduction of cell density in the time course assay (Figure 2F; left panel). Overexpression of BCL6 decreased the fraction of ALL cells in $\mathrm{G}_{0} / \mathrm{G}_{1}$ phases and increased tumor numbers in $\mathrm{S}$ phase (Figure $2 \mathrm{~F}$; right panel), although these changes were not statistically significant their trend is consistent with the cell density assay.

\section{BCL6 expression in ALL cells impacts abundance of cell cycle regulatory protein cyclin D3.}

Cyclin D3 has been shown to be an important cell cycle regulatory protein in germinal center B-cells, which is also a site where BCL6 is actively modulated to promote proliferation [36]. Based on these observations, we investigated whether BCL6 modulation impacts expression of cyclin D3. Consistent with BCL6 protein levels, cyclin D3 protein abundance was decreased in PD REH and Nalm-27 ALL cells compared to tumor cells grown in media alone (Figure 3A). Knockdown of BCL6 in ALL cells reduced the protein abundance of cyclin D3, and BCL6 overexpression increased cyclin D3 protein levels (Figure 3B). In addition, chemical inhibition of BCL6 by 79-6 led to diminished cyclin D3 protein abundance in ALL cells (Figure 3C). 


\section{Chronic overexpression of BCL6 sensitizes the chemotherapy-resistant PD population to chemotherapy.}

Many ALL chemotherapy regimens rely on tumor cell proliferation as a requirement for optimal induction of cell death. Consequently, these strategies tend to be less effective against quiescent tumor cells $[12,37]$. With the observation that reduced BCL6 in PD ALL cells results in a quiescent phenotype, we aimed to investigate strategies that target this chemotherapy-resistant population through modulation of BCL6. REH tumor

cells with constitutive overexpression of BCL6 in the PD population showed a significant reduction in viability when compared to vector controls following exposure to chemotherapy (Figure 4A). PD tumor cells were "rescued" from BCL6 overexpression by BCL6 chemical inhibition, as demonstrated by the increase in PD REH cell viability following 79-6 and chemotherapy exposure relative to the overexpression only cells (Figure 4A). Based on this observation we identified chemical compounds that influence BCL6 protein levels. MG132 and caffeine have been shown to increase BCL6 protein abundance in cells by preventing the degradation of BCL6 [27]. While it is appreciated that neither MG132 or caffeine are specific regulators of BCL6, and that the effects of either could be on an upstream modulator of BCL6, our findings showed that MG132 or caffeine exposure resulted in increased BCL6 protein in ALL cells (Figure 4B). Given that PD cells have less BCL6 and are more resistant to chemotherapy, we investigated whether MG132 or caffeine exposure increased BCL6 in PD ALL cells. Exposure to either MG132 or caffeine increased BCL6 protein abundance in PD ALL cells (Figure 4C). Consistent with our previously published data [13, 15], PD ALL cells in both BMSC and $\mathrm{HOB}$ are protected from chemotherapy exposure relative to their media alone 
counterparts as indicated by significantly increased viability following Ara-C exposure (Figure 4D). However in both REH and Nalm-27 cells, pretreatment with MG132 or caffeine 6 hours prior to Ara-C exposure sensitized the resistant PD ALL cell population to chemotherapy-induced death as shown by a significant reduction in cell viability compared to the group treated with Ara-C alone (Figure 4D).

\section{Forced expression of BCL6 in ALL cells increases chemotherapeutic response.}

Residual tumor cells in the bone marrow following chemotherapy treatment is a prognostic indicator of patient outcome [4-6]. Based this well-established indicator we evaluated tumor burden in the bone marrow of NOD-SCID gamma (NSG) mice following treatment with chemotherapy (Figure 5A). Although not statistically significant mice injected with ALL cells overexpressing BCL6 had a lower median percentage $(45.6 \% \mathrm{GFP}+)$ of human tumor cells compared to those injected with vector control cells $(54.1 \% \mathrm{GFP}+) 24$ hours after the conclusion of Ara-C treatment (Figure 5B). Because MG132 and caffeine sensitized the chemotherapy-resistant PD ALL cells to chemotherapy in vitro (Figure 4D), we investigated whether MG132 or caffeine could increase event free survival in a NSG model of ALL disease (Figure 5C). Corresponding to the in vitro observations, mice pretreated with caffeine 6 hours prior to Ara-C treatment had significantly increased event free survival time compared to mice treated with Ara-C only (Figure 5D).

\section{Discussion}

In the current study, we investigated the role that bone marrow stromal cells and osteoblasts have on the modulation of BCL6 levels in ALL, and the influence of BCL6 
on resistance to chemotherapy. While there are numerous established BMM interactions that regulate ALL proliferation and chemotherapy resistance, to our knowledge this work represents the first time microenvironment regulation of ALL BCL6 abundance has been explored. Utilizing BMSC and HOB as just two representative elements of the protective BMM niche, we observed that co-culture reduces tumor cell BCL6 expression compared to ALL cells cultured in media alone (Figure 1) and that removal of ALL cells from the PD "niche" buried beneath BMSC or HOB to media alone results in increased BCL6 protein abundance (DNS). The reduction of BCL6 in ALL cells that are in co-culture with bone marrow derived adherent stromal cells or osteoblasts is most pronounced in the PD sub-population of ALL cells, which we have previously reported as the most quiescent and refractory to chemotherapy $[13,15]$. The quiescent phenotype appears to be regulated, in part, through BCL6 impact on ALL cell cycle progression. Both chemical inhibition and targeted knockdown of BCL6 in ALL cells resulted in diminished proliferation and accumulation of cells in the $\mathrm{G}_{0} / \mathrm{G}_{1}$ phase of cell cycle (Figure 2). Likewise, increased abundance of BCL6 led to sustained proliferation and a higher percentage of cells in S phase (Figure 2) when compared to vector control cells. The ability of BCL6 to regulate the transition of cells between quiescent and proliferative states is reminiscent of its function in germinal center B-cells where elevated BCL6 acts to promote high rates of proliferation [33-35]. Consistent with the broadly recognized complexity of the impact of BCL6 on cell fate, it has been shown that, in contrast to our findings, BCL6 upregulation in some settings promotes a quiescent phenotype [38-40]. These differences are not surprising as BCL6 is known to interact with, and regulate, a variety of cellular programs in a context dependent 
manner [reviewed 41-43] and highlights the importance of investigating BCL6 in the specific setting of microenvironment regulation and to interpret observations with the appropriate model driven limitations in mind. In the current study, we show that BCL6 influences proliferation of ALL cells and that its abundance is influenced by the interaction with elements of the BMM (Figure 1 and 2). In addition, our observations suggest that cyclin D3 protein levels in ALL cells are, in part, regulated by BCL6. Both chemical inhibition and more specific shRNA knockdown of BCL6 in ALL cells reduced cyclin D3 levels with BCL6 overexpression correlated with increased cyclin D3 protein abundance (Figure 3). This observation is significant as cyclin D3 has been reported to be an important regulator of mature and immature B-cell cell cycle progression through $\mathrm{G}_{1}$ phase $[36,44,45]$. While the precise mechanism by which the BMM is regulating BCL6 abundance in ALL cells remains unknown, one possibility that warrants consideration is that BCL6 protein being regulated via niche derived cues that impact on phosphorylation, targeting it for proteasomal degradation. Based on previously described pathways that regulate BCL $6[27,46,47]$ and our observations using proteasome inhibitors (Figure 4), as well as, the lack of significant change in BCL6 mRNA levels in tumor cells co-cultured with BMSC or HOB (DNS), regulation at the protein level is implicated. Future work which focuses investigation on this potential mechanism will be important, however this is beyond the scope of the current study. While additional studies will be required to focus on a greater understanding of the interactions between the BMM and ALL cells that drive the reduction in BCL6, our results suggest that the quiescent phenotype exhibited by ALL cells in the BMM niche is 
in part modulated through microenvironment regulation of ALL cell BCL6 protein. This in turn appears to regulate cell cycle progression, potentially through control of cyclin D3.

In both normal and malignant B-cells, increased expression of BCL6 has been shown to promote cell survival through inhibition of the p53 pathway, which allows for tolerance to DNA damage within cells [20, 30, 31]. In ALL cells, increased expression of BCL6 results in a tolerance to DNA damage and subsequently increased survival during BCR-ABL1 kinase inhibition [30]. Conversely, our observations suggest that decreased abundance of BCL6 subsequent to interaction of leukemic cells with BMSC or HOB can also protect ALL cells from death through induction of a quiescent phenotype.

Furthermore, chronic overexpression of BCL6 appears to sensitize tumor cells to chemotherapy exposure coincident with increased ALL cell proliferation and blunted tumor cell quiescence (Figure 2 and 4). We speculate based on the work of others, as well as these observations that dynamic regulation of BCL6 in ALL regulates survival when challenged by stress such as chemotherapy. These observations suggest that increased BCL6 protein levels during chemotherapy may allow tolerance of DNA damage, with subsequent downregulation of BCL6 required for cells to enter a quiescent state during which DNA can be repaired. Interference of this dynamic balance, such as that imposed by chronic sustained expression of BCL6, appears one way in which to sensitize BMM protected ALL cells to chemotherapy treatment (Figure 4-5). Due to the complexities of both BMM signaling and BCL6 regulation, additional studies will be needed to determine how these dynamic regulatory pathways affect survival pathways including p53, ATM/ATR, and BCL family proteins within ALL cells and how this may promote resistant disease in the marrow niche. 
Consistent with the in vitro findings, in vivo chronic overexpression of BCL6 during Ara-C treatment resulted in a modest reduction in the tumor burden in femurs of mice when collected 24 hours following the conclusion of Ara-C treatment (Figure 5B). In addition, using a model based on that which was previously described with the readout of event free survival [48-50], we observed that caffeine pre-treatment, shown to increase BCL6 [27], significantly extended event free survival in a NSG mouse model of ALL (Figure 5D). While recognizing that caffeine does not specifically target BCL6 exclusively, it may serve as a safe tool to, at least in part, modulate BCL6 expression. Diminished tumor burden in the bone marrow and event free survival have both been shown to be significant prognostic indicators of patient outcome in response to chemotherapy $[5,7,51]$ and these findings illustrate the significance of the observed increase in event free survival time of mice following combination treatment with caffeine and Ara-C. We also hypothesize that this type of combination treatment strategy might be advantageous during consolidation therapy as a means to "activate" residual quiescent ALL cells to be better targeted by cytotoxic regimens. In this context, caffeine is an attractive treatment strategy due to its long history of safe use in humans [52] and our results which show it can sensitize microenvironment protected ALL cells to chemotherapy treatment (Figure 4-5). As with all models in immunocompromised mice there are limitations to interpretation, however, they serve as an important setting in which to test general concepts and to identify potentially important pathways around which to focus novel intervention strategies.

In summary, the goal of this study was to investigate how BMSC and HOB, components of the protective bone marrow niche, would influence the levels of BCL6 in 
ALL cells. We report that ALL cell lines, as well as primary patient samples, co-cultured with BMSC or $\mathrm{HOB}$, have reduced BCL6 protein. This reduction in BCL6 abundance was most pronounced and consistently observed in leukemic cells recovered from the PD population, which we have previously characterized as a chemotherapy-resistant population representative of resistant tumor populations $[13,15]$. Decreased BCL6 in ALL cells affects the cell cycle profile and promotes a quiescent phenotype. This phenotype appears to be coincident with BCL6 reduction and decreased cyclin D3; a consequence that has been reported to regulate progression through the $\mathrm{G}_{1}$ phase of cell cycle $[36,44,45]$. Chronic overexpression of BCL6, achieved either through overexpression vectors or chemical intervention by MG132 or caffeine, sensitized ALL cells that are generally protected by BMSC or HOB from chemotherapy induced death. Furthermore, combination treatments using caffeine to stabilize BCL6 levels followed by Ara-C exposure significantly increased the event free survival of mice in which ALL had been established. Collectively, these results suggest that strategies which disrupt microenvironmental regulation of BCL6 in ALL cells may be an effective strategy to sensitize quiescent, chemotherapy-resistant leukemic cells to treatment, eliminating MRD in the protective bone marrow niches and reducing the incidence of relapse.

\section{Methods}

\section{Cell lines and culture conditions}

Philadelphia chromosome positive $(\mathrm{Ph}+$ ) lymphoblastic cell lines Nalm-27 (Fujisaki Cancer Center) and Sup-B15 (ATCC-CRL-1929), and Ph- REH (ATCC\#CRL-8286) were utilized. De-identified primary human leukemic cells were acquired from the West Virginia University Health Sciences Center and West Virginia University Cancer Institute 
tissue bank. Primary patient sample $1(\mathrm{P} 1)$ is a MLL rearranged (11q23) B-lineage ALL isolated from a 43 year old female at diagnosis. Primary patient sample $2(\mathrm{P} 2)$ is a ( $\left.\mathrm{Ph}^{-}\right)$ B-cell ALL/LBL isolated from a 65 year old male at diagnosis (45-46, $\mathrm{XY}, \mathrm{t}(4-$ 11)(q21;q23), add (6)(p25), -21, +1-2mar[12]/46, XY[8]). De-identified primary bone marrow stromal cells (BMSC) were provided by the West Virginia University Cancer Institute Biospecimen Processing Core and the West Virginia University Department of Pathology Tissue Bank. BMSC cultures were established as previously described [53]. Human osteoblasts (HOB; PromoCell) were cultured according to the supplier's recommendations. Co-cultures of adherent bone marrow derived supportive cells and ALL cells were established by seeding leukemic cells onto $80-90 \%$ confluent BMSC or HOB monolayers. Cultures were fed every 4 days and tumor cells collected for inclusion in experiments. Remaining leukemic cells were moved to new primary BMSC or $\mathrm{HOB}$ adherent layers every 12 days. Cultures were maintained in $5 \% \mathrm{O}_{2}$ to model normal bone marrow oxygen tension, reported to range from 1-7\% [54, 55]. Suspended (S) leukemic cells floating freely in the media; phase bright (PB) tumor cells, that were loosely adherent to the top of BMSC or HOB; and phase dim (PD) leukemic cells that were buried firmly beneath adherent BMSC or HOB were collected as distinct populations as previously described $[13,15]$. The S, PB, and PD tumor populations were separated from BMSC or HOB by size exclusion with G10 Sephadex (Sigma) column separation as previously described $[13,15,56]$.

\section{Flow Cytometric quantification of BCL6 expression}

REH and Nalm-27 tumor cells were cultured and PD ALL cells were harvested as described above. P1 and P2 were cultured in media alone or co-cultured with BMSC or 
HOB for 2 days prior to analysis to utilize them prior to significant loss in viability. Experiments that included primary tumor cells required collection of all tumor that was in physical contact with the BMSC or HOB (PB + PD) to provide sufficient numbers for analysis. ALL cells were stained using Cell Signaling Technology's recommended protocol for intracellular BCL6 staining using primary antibodies rabbit anti-BCL6 (Cat \# 14895) (1:300) or Rabbit (DA1E) mAb IgG XP isotype control (Cat \# 3900). Cells were washed with $1 \times$ PBS and incubated with secondary antibody goat anti-rabbit Alexa Flour 647 (Invitrogen; Cat \# A21244) [1 $\mu \mathrm{g} / \mathrm{mL}]$. Collection and analysis were performed using the LSRFortessa (Becton Dickenson, San Jose, CA, USA).

\section{Immunofluorescence imaging}

Confocal images were acquired using an upright LSM 510 Zeiss microscope and processed using Zen2009 software and Adobe Photoshop with fluorescence intensity held constant for any experiment in which image acquisition was compared across samples. ALL cells were cytospun on glass slides following G10 Sephadex purification. Cells were fixed with 4\% PFA, blocked in $1 \times$ PBS/ 5\%FBS/ $0.3 \%$ Triton X-100, washed with 1x PBS, and incubated with rabbit anti-BCL6 (Cell Signaling Technology, Cat \# 14895) (1:100) followed by anti-rabbit Alexa 647 (Invitrogen; Cat \# A21244) (1:200). Slides were washed with PBS and mounted to coverslips using Prolong® Gold antifade/DAPI overnight (Life Technologies).

\section{Cell proliferation assay}

ALL cells were labeled using the cell retention dye CellTrace-CFSE Cell Proliferation Kit (Life Technologies, Cat \# C34554) as described by the manufacturer. Cells were then 
cultured under normal growth conditions for 2 days in either media DMSO control or media with 79-6. CellTrace fluorescence intensity was measured by flow cytometry using FACSFortessia. Proliferation indices were calculated using FCS Express4.

\section{Cell cycle analysis}

ALL cells were fixed in $70 \%$ ethanol, treated with RNase (Sigma), and stained with propidium iodide (PI) for DNA analysis. All samples were performed in triplicate, processed on a FACSFortessia flow cytometer and analyzed using FCS Express4 software.

\section{Western blot analysis}

Rabbit polyclonal BCL6 (Cat \# 5650) and Cyclin D3 (Cat \# 2936) were purchased from Cell Signaling Technology and used at 1:1000 dilution. Mouse polyclonal anti-GAPDH was purchased from Fitzgerald Inc. (Cat \# 10R-G109a). Proteins were resolved on SDS-PAGE gels and transferred to nitrocellulose membranes. Membranes were blocked in TBS 5\%/nonfat dry milk $0.05 \%$ Tween-20 and probed with the indicated primary antibodies. After incubation with horseradish peroxidase-conjugated secondary antibodies, signal was visualized using enhanced chemiluminescence reagents (Amersham). Western blots are representative of at least 3 independent experiments. Densitometry quantification is indicated and was completed using ImageJ software.

\section{Drugs and chemotherapeutic reagents}

Cytarabine (Ara-C) (Selleckchem, Cat \# S1648), Methotrexate (MTX) (Selleckchem, Cat \# S1210), Vincristine (VCR) (Selleckchem, Cat \# S1241), MG132 (Selleckchem, cat \# S2619), Caffeine (Sigma-Aldrich, Cat \# C0750), and 79-6 (Calbiochem, Cat \# 197345) 
were diluted and stored per manufacturer recommendations. For in vitro experiments drug stocks were diluted in base media and for in vivo experiments stocks were diluted in saline immediately prior to use. In vitro concentrations of Ara-C [1 $\mu \mathrm{M}]$, MTX [50 $\mu \mathrm{M}]$, VCR [25 $\mu \mathrm{M}$ ], MG-132 [1-5 $\mu \mathrm{M}$ ], caffeine [2.5-10 mM], and 79-6 [125 $\mu \mathrm{M}]$ were used to approximate clinically relevant doses in ALL or published in vitro concentrations [27, 57-63].

\section{Evaluation of leukemic cell concentration and viability}

ALL cells were cultured in media alone or co-cultured with BMSC or HOB for 4 days to establish the PD tumor population. On day 4 cultures were provided fresh media and exposed to Ara-C, MTX, or VCR for 4 additional days. Cells treated with Ara-C were retreated at 48 hours. $79-6$, MG132, or caffeine were added 6 hours prior to chemotherapy in combination experiments. Viability and cell number were evaluated by trypan blue exclusion in triplicate.

\section{BCL6 knockdown and overexpression}

Human TRIPZ lentiviral inducible shRNAmir constructs to BCL6 clone ID numbers V3THs_404721 (KD1) and V2THS_132926 (KD3) were purchased from Thermo Scientific. Viral particles were produced and administered to REH ALL cells according to manufactures protocol. shRNA expression was induced using doxycycline $[1 \mathrm{ug} / \mathrm{mL}]$ and RFP positive cells were sorted by flow cytometry.

BCL6 overexpression vector was generated by removing the BCL6 gene sequence from the MSCV-BCL6-IRES-GFP [40] which was purchased from Addgene (Plasmid 31391). 
BCL6 fragment was then ligated into pLVX-EF1a-IRES-ZsGreen1 plasmid (Clontech Laboratories, Inc. Cat\# 631982).

\section{Mice}

All experimental procedures involving NOD/SCID Gamma (NSG) mice were approved by the West Virginia University Institutional Animal Care and Use Committee. Male NOD/SCID Gamma (NSG) mice age 5-6 weeks were acquired from the West Virginia University NSG colony or purchased from the Jackson Laboratory. To determine whether chronic BCL6 overexpression would sensitize ALL cells to chemotherapy treatment, resulting in reduced tumor burden in the bone marrow, NSG mice were divided into two groups and tail vein injected with $2 \times 10^{6} \mathrm{REH}$ cells expressing BCL6/GFP or vector/GFP control. Peripheral tumor burden was monitored via tail vein draws to collect approximately $30 \mu \mathrm{L}$ of blood. Red blood cells were lysed $(150 \mathrm{mM}$ $\mathrm{NH}_{4} \mathrm{Cl}, 10 \mathrm{mM} \mathrm{NaHCO}_{3}$ and $0.1 \mathrm{mM}$ EDTA in distilled water) and ALL cell frequency was evaluated by flow cytometry analysis of GFP positive human cells relative to total mononuclear cells. Chemotherapy treatment began when the peripheral blood burden of the group reached $1-5 \%$ GFP positive cells which has been previously reported to indicate established leukemic disease [48]. Ara-C treatment was administered by intraperitoneal (IP) injection at a concentration of $100 \mathrm{mg} / \mathrm{kg}$ daily for 3 consecutive days. Mice were euthanized 24 hours after the final Ara-C treatment and bone marrow was collected from femurs to quantify percentage of GFP positive tumor cells in the bone marrow by flow cytometry.

To determine whether combination treatment of mice with the BCL6 modulating agents MG132 or caffeine would sensitize ALL cells to chemotherapy, $2 \times 10^{6} \mathrm{REH}$ cells 
expressing the vector/GFP construct were injected via tail vein to establish leukemic disease. Tumor burden was monitored as previously described. When peripheral blood burden of the group reached an average of $1-5 \%$ GFP positive cells relative to total mononuclear cells, mice were randomly assigned to treatment groups. Treatments included saline control, MG132 [1 mg/kg], Caffeine [50 mg/kg], Ara-C [100 mg/kg], MG132 [1 mg/kg] + Ara-C [100 mg/kg], or Caffeine [50 mg/kg] + Ara-C [100 mg/kg]. All drugs were diluted in saline prior to injection and were administered by IP injection. MG132 and caffeine were given 6 hours before treatment with Ara-C with mice treated for 3 consecutive days. Event free survival (EFS) was calculated from the start of treatment as previously described [48] with an event defined as $25 \%$ GFP positive cells in the peripheral blood by flow cytometric analysis or when mice showed clinical signs of disease (lethargy, weight loss, ruffled fur).

\section{Statistical analysis}

All data are presented as mean \pm standard error and the statistical significances between conditions was determined by the student's t test or 2-way ANOVA with HolmSidak post-hoc test using GraphPad or SigmaPlot software. All in vitro results generated from cell line derived data are representative of at least 3 independent experiments. Experiments with primary patient samples are representative of at least 2 independent experiments. Kaplan-Meier survival curves were generated for event free survival and a fitted Cox model was used to determine p-values. 


\section{Acknowledgements}

The authors thank Dr. Michael Craig, Dr. William Petros, and the West Virginia University Cancer Institute tissue bank for assistance in acquiring primary patient ALL samples. We would also like to thank Emily Ellis and Sarah McLaughlin for their assistance in performing the murine studies. We want to thank Sijin Wen for his assistance with the statistical analysis. We are grateful for the support of Dr. Kathy Brundage and the West Virginia University Flow Cytometry Core Facility, supported by NIH S10-OD016165 and the Institutional Development Award (IDeA) from the NIH Institute of General Medical Sciences of the National Institutes of Health (CoBRE P30GM103488 and INBRE P20GM103434). We would like to thank Dr. Karen Martin and the imaging core for help with imaging experiments which were performed in the West Virginia University Microscope Imaging Facility, supported by the West Virginia University Cancer Institute and NIH grants P20 RR016440, P30 GM103488 and P20 GM103434.

\section{Conflict-of-interest disclosure}

The authors declare no competing financial interests.

\section{Grant Support}

NIH NHLBI R01 HL056888 (LFG), NIH NCI R01 CA134573NIH (LFG), P30 GM103488 (LFG), WV CTR-IDEA NIH 1 U54 GM104942, the Alexander B. Osborn Hematopoietic Malignancy and Transplantation Program, and the WV Research Trust Fund. 


\section{References}

1. Howlader N, Noone A, Krapcho M, Garshell J, Miller D, Altekruse S, Kosary C, Yu M, Ruhl J, Tatalovich Z, Mariotto A, Lewis D, Chen H, et al. SEER Cancer Statistics Review, 19752012, National Cancer Institute. Bethesda, MD, http://seer.cancer.gov/csr/1975_2012/, based on November 2014 SEER data submission, posted to the SEER web site, April 2015. [Internet]. 2014; Available from: http://seer.cancer.gov/csr/1975_2012/

2. Oriol A, Vives S, Hernández-Rivas J-M, Tormo M, Heras I, Rivas C, Bethencourt C, Moscardó F, Bueno J, Grande C, del Potro E, Guardia R, Brunet S, et al. Outcome after relapse of acute lymphoblastic leukemia in adult patients included in four consecutive risk-adapted trials by the PETHEMA Study Group. Haematologica 2010; 95:589-96.

3. Bhojwani D, Pui C-H. Relapsed childhood acute lymphoblastic leukaemia. Lancet Oncol 2013; 14:e205-17.

4. Coustan-Smith E, Sancho J, Hancock ML, Boyett JM, Behm FG, Raimondi SC, Sandlund JT, Rivera GK, Rubnitz JE, Ribeiro RC, Pui C-H, Campana D. Clinical importance of minimal residual disease in childhood acute lymphoblastic leukemia. Blood 2000; 96:2691-6.

5. Nguyen K, Devidas M, Cheng S-C, La M, Raetz EA, Carroll WL, Winick NJ, Hunger SP, Gaynon PS, Loh ML. Factors Influencing Survival After Relapse From Acute Lymphoblastic Leukemia: A Children's Oncology Group Study. Leuk Off J Leuk Soc Am Leuk Res Fund UK 2008; 22:2142-50.

6. Bailey LC, Lange BJ, Rheingold SR, Bunin NJ. Bone-marrow relapse in paediatric acute lymphoblastic leukaemia. Lancet Oncol 2008; 9:873-83.

7. Szczepanek J, Styczyński J, Haus O, Tretyn A, Wysocki M. Relapse of Acute Lymphoblastic Leukemia in Children in the Context of Microarray Analyses. Arch Immunol Ther Exp (Warsz) 2011; 59:61-8.

8. Boyerinas B, Zafrir M, Yesilkanal AE, Price TT, Hyjek EM, Sipkins DA. Adhesion to osteopontin in the bone marrow niche regulates lymphoblastic leukemia cell dormancy. Blood 2013; 121:4821-31.

9. Bradstock K, Bianchi A, Makrynikola V, Filshie R, Gottlieb D. Long-term survival and proliferation of precursor-B acute lymphoblastic leukemia cells on human bone marrow stroma. Leukemia 1996; 10:813-20. 
10. Duan C-W, Shi J, Chen J, Wang B, Yu Y-H, Qin X, Zhou X-C, Cai Y-J, Li Z-Q, Zhang F, Yin M-Z, Tao Y, Mi J-Q, et al. Leukemia propagating cells rebuild an evolving niche in response to therapy. Cancer Cell 2014; 25:778-93.

11. Iwamoto S, Mihara K, Downing JR, Pui C-H, Campana D. Mesenchymal cells regulate the response of acute lymphoblastic leukemia cells to asparaginase. J Clin Invest 2007; 117:1049-57.

12. Meads MB, Hazlehurst LA, Dalton WS. The Bone Marrow Microenvironment as a Tumor Sanctuary and Contributor to Drug Resistance. Clin Cancer Res 2008; 14:2519-26.

13. Moses BS, Slone WL, Thomas P, Evans R, Piktel D, Angel PM, Walsh CM, Cantrell PS, Rellick SL, Martin KH, Simpkins JW, Gibson LF. Bone marrow microenvironment modulation of acute lymphoblastic leukemia phenotype. Exp Hematol 2016; 44:50-9.e2.

14. Mudry RE, Fortney JE, York T, Hall BM, Gibson LF. Stromal cells regulate survival of Blineage leukemic cells during chemotherapy. Blood 2000; 96:1926-32.

15. Slone WL, Moses BS, Evans R, Piktel D, Martin KH, Petros W, Craig M, Gibson LF. Modeling Chemotherapy Resistant Leukemia In Vitro. J Vis Exp JoVE 2016;

16. Wang L, O'Leary H, Fortney J, Gibson LF. Ph+/VE-cadherin+ identifies a stem cell-like population of acute lymphoblastic leukemia sustained by bone marrow niche cells. Blood 2007; 110:3334-44.

17. Bai M, Agnantis NJ, Skyrlas A, Tsanou E, Kamina S, Galani V, Kanavaros P. Increased Expression of the bcl6 and CD10 Proteins Is Associated with Increased Apoptosis and Proliferation in Diffuse Large B-Cell Lymphomas. Mod Pathol 2003; 16:471-80.

18. Baron BW, Anastasi J, Montag A, Huo D, Baron RM, Karrison T, Thirman MJ, Subudhi SK, Chin RK, Felsher DW, Fu Y-X, McKeithan TW, Baron JM. The human BCL6 transgene promotes the development of lymphomas in the mouse. Proc Natl Acad Sci U S A 2004; 101:14198-203.

19. Baron BW, Anastasi J, Thirman MJ, Furukawa Y, Fears S, Kim DC, Simone F, Birkenbach M, Montag A, Sadhu A, Zeleznik-Le N, McKeithan TW. The human programmed cell death-2 (PDCD2) gene is a target of BCL6 repression: implications for a role of BCL6 in the down-regulation of apoptosis. Proc Natl Acad Sci U S A 2002; 99:2860-5. 
20. Basso K, Dalla-Favera R. Roles of BCL6 in normal and transformed germinal center B cells. Immunol Rev 2012; 247:172-83.

21. Bertolo C, Roa S, Sagardoy A, Mena-Varas M, Robles EF, Martinez-Ferrandis JI, Sagaert X, Tousseyn T, Orta A, Lossos IS, Amar S, Natkunam Y, Briones J, et al. LITAF, a BCL6 target gene, regulates autophagy in mature B-cell lymphomas. Br J Haematol 2013; 162:621-30.

22. Cattoretti G, Chang CC, Cechova K, Zhang J, Ye BH, Falini B, Louie DC, Offit K, Chaganti RS, Dalla-Favera R. BCL-6 protein is expressed in germinal-center B cells. Blood 1995; 86:45-53.

23. Cerchietti LC, Hatzi K, Caldas-Lopes E, Yang SN, Figueroa ME, Morin RD, Hirst M, Mendez L, Shaknovich R, Cole PA, Bhalla K, Gascoyne RD, Marra M, et al. BCL6 repression of EP300 in human diffuse large $B$ cell lymphoma cells provides a basis for rational combinatorial therapy. J Clin Invest 2010; 120:4569-82.

24. Chang $\mathrm{CC}, \mathrm{Ye} \mathrm{BH}$, Chaganti RS, Dalla-Favera R. BCL-6, a POZ/zinc-finger protein, is a sequence-specific transcriptional repressor. Proc Natl Acad Sci 1996; 93:6947-52.

25. Ci W, Polo JM, Cerchietti L, Shaknovich R, Wang L, Yang SN, Ye K, Farinha P, Horsman DE, Gascoyne RD, Elemento O, Melnick A. The BCL6 transcriptional program features repression of multiple oncogenes in primary $B$ cells and is deregulated in DLBCL. Blood 2009; 113:5536-48.

26. Parekh S, Polo JM, Shaknovich R, Juszczynski P, Lev P, Ranuncolo SM, Yin Y, Klein U, Cattoretti G, Favera RD, Shipp MA, Melnick A. BCL6 programs lymphoma cells for survival and differentiation through distinct biochemical mechanisms. Blood 2007; 110:2067-74.

27. Phan RT, Saito M, Kitagawa Y, Means AR, Dalla-Favera R. Genotoxic stress regulates expression of the proto-oncogene Bcl6 in germinal center B cells. Nat Immunol 2007; 8:1132-9.

28. Ranuncolo S, Dierov J, Polo J, Carroll M, Melnick A. A critical BCL6 related feedback loop explains the unique phenotype of germinal center $B$ cells and their malignant transformation. Cancer Res 2007; 67:2641-2641.

29. Shaffer AL, Yu X, He Y, Boldrick J, Chan EP, Staudt LM. BCL-6 represses genes that function in lymphocyte differentiation, inflammation, and cell cycle control. Immunity 2000; 13:199-212. 
30. Duy C, Hurtz C, Shojaee S, Cerchietti L, Geng H, Swaminathan S, Klemm L, Kweon S, Nahar R, Braig M, Park E, Kim Y, Hofmann W-K, et al. BCL6 enables Ph+ acute lymphoblastic leukaemia cells to survive BCR-ABL1 kinase inhibition. Nature 2011; 473:384-8.

31. Hurtz C, Hatzi K, Cerchietti L, Braig M, Park E, Kim Y, Herzog S, Ramezani-Rad P, Jumaa H, Müller MC, Hofmann W-K, Hochhaus A, Ye BH, et al. BCL6-mediated repression of p53 is critical for leukemia stem cell survival in chronic myeloid leukemia. J Exp Med 2011; 208:2163-74.

32. Duy C, Yu JJ, Nahar R, Swaminathan S, Kweon S, Polo JM, Valls E, Klemm L, Shojaee S, Cerchietti L, Schuh W, Jäck H-M, Hurtz C, et al. BCL6 is critical for the development of a diverse primary B cell repertoire. J Exp Med 2010; 207:1209-21.

33. Phan RT, Saito M, Basso K, Niu H, Dalla-Favera R. BCL6 interacts with the transcription factor Miz-1 to suppress the cyclin-dependent kinase inhibitor p21 and cell cycle arrest in germinal center B cells. Nat Immunol 2005; 6:1054-60.

34. Shvarts A, Brummelkamp TR, Scheeren F, Koh E, Daley GQ, Spits H, Bernards R. A senescence rescue screen identifies BCL6 as an inhibitor of anti-proliferative p19ARF-p53 signaling. Genes Dev 2002; 16:681-6.

35. Wang D, Long J, Dai F, Liang M, Feng X-H, Lin X. BCL6 Represses Smad Signaling in Transforming Growth Factor- $\beta$ Resistance. Cancer Res 2008; 68:783-9.

36. Cato MH, Chintalapati SK, Yau IW, Omori SA, Rickert RC. Cyclin D3 Is Selectively Required for Proliferative Expansion of Germinal Center B Cells. Mol Cell Biol 2011;31:127-37.

37. Moore N, Lyle S. Quiescent, Slow-Cycling Stem Cell Populations in Cancer: A Review of the Evidence and Discussion of Significance. J Oncol [Internet] 2010 [cited 2013 May 29]; 2011. Available from: http://www.hindawi.com/journals/jo/2011/396076/abs/

38. Nahar R, Ramezani-Rad P, Mossner M, Duy C, Cerchietti L, Geng H, Dovat S, Jumaa $\mathrm{H}$, Ye BH, Melnick A, Müschen M. Pre-B cell receptor-mediated activation of BCL6 induces preB cell quiescence through transcriptional repression of MYC. Blood 2011; 118:4174-8.

39. Ranuncolo SM, Wang L, Polo JM, Dell'Oso T, Dierov J, Gaymes TJ, Rassool F, Carroll M, Melnick A. BCL6-mediated Attenuation of DNA Damage Sensing Triggers Growth Arrest and Senescence through a p53-dependent Pathway in a Cell Context-dependent Manner. J Biol Chem 2008; 283:22565-72. 
40. Yu RY-L, Wang X, Pixley FJ, Yu JJ, Dent AL, Broxmeyer HE, Stanley ER, Ye BH. BCL-6 negatively regulates macrophage proliferation by suppressing autocrine IL-6 production. Blood 2005; 105:1777-84.

41. Hatzi K, Melnick A. Breaking bad in the germinal center: how deregulation of BCL6 contributes to lymphomagenesis. Trends Mol Med 2014; 20:343-52.

42. Tarlinton DM. Bcl6: where too much complexity is barely enough. Eur J Immunol 2011; $41: 2148-51$.

43. Bunting $\mathrm{KL}$, Melnick AM. New effector functions and regulatory mechanisms of BCL6 in normal and malignant lymphocytes. Curr Opin Immunol 2013; 25:339-46.

44. Cooper AB, Sawai CM, Sicinska E, Powers SE, Sicinski P, Clark MR, Aifantis I. A unique function for cyclin D3 in early B cell development. Nat Immunol 2006; 7:489-97.

45. Peled JU, Yu JJ, Venkatesh J, Bi E, Ding BB, Krupski-Downs M, Shaknovich R, Sicinski $\mathrm{P}$, Diamond $\mathrm{B}$, Scharff MD, Ye BH. Requirement for cyclin D3 in germinal center formation and function. Cell Res 2010; 20:631-46.

46. Niu $\mathrm{H}, \mathrm{Ye} \mathrm{BH}$, Dalla-Favera $\mathrm{R}$. Antigen receptor signaling induces MAP kinase-mediated phosphorylation and degradation of the BCL-6 transcription factor. Genes Dev 1998; 12:195361.

47. Duan S, Cermak L, Pagan JK, Rossi M, Martinengo C, di Celle PF, Chapuy B, Shipp M, Chiarle R, Pagano M. FBXO11 targets BCL6 for degradation and is inactivated in diffuse large B-cell lymphomas. Nature 2012; 481:90-3.

48. Lock RB, Liem N, Farnsworth ML, Milross CG, Xue C, Tajbakhsh M, Haber M, Norris MD, Marshall GM, Rice AM. The nonobese diabetic/severe combined immunodeficient (NOD/SCID) mouse model of childhood acute lymphoblastic leukemia reveals intrinsic differences in biologic characteristics at diagnosis and relapse. Blood 2002; 99:4100-8.

49. Samuels AL, Beesley AH, Yadav BD, Papa RA, Sutton R, Anderson D, Marshall GM, Cole $\mathrm{CH}$, Kees UR, Lock RB. A pre-clinical model of resistance to induction therapy in pediatric acute lymphoblastic leukemia. Blood Cancer J 2014; 4:e232.

50. Liem NLM, Papa RA, Milross CG, Schmid MA, Tajbakhsh M, Choi S, Ramirez CD, Rice AM, Haber M, Norris MD, MacKenzie KL, Lock RB. Characterization of childhood acute lymphoblastic leukemia xenograft models for the preclinical evaluation of new therapies. Blood 
2004; 103:3905-14.

51. Malempati S, Gaynon PS, Sather H, La MK, Stork LC, Children's Oncology Group. Outcome after relapse among children with standard-risk acute lymphoblastic leukemia: Children's Oncology Group study CCG-1952. J Clin Oncol Off J Am Soc Clin Oncol 2007; 25:5800-7.

52. Nawrot P, Jordan S, Eastwood J, Rotstein J, Hugenholtz A, Feeley M. Effects of caffeine on human health. Food Addit Contam 2003; 20:1-30.

53. Gibson LF, Fortney J, Landreth KS, Piktel D, Ericson SG, Lynch JP. Disruption of bone marrow stromal cell function by etoposide. Biol Blood Marrow Transplant J Am Soc Blood Marrow Transplant 1997; 3:122-32.

54. Berniakovich I, Giorgio M. Low oxygen tension maintains multipotency, whereas normoxia increases differentiation of mouse bone marrow stromal cells. Int J Mol Sci 2013; 14:2119-34.

55. Chow DC, Wenning LA, Miller WM, Papoutsakis ET. Modeling $\mathrm{pO}(2)$ distributions in the bone marrow hematopoietic compartment. II. Modified Kroghian models. Biophys J 2001; 81:685-96.

56. Hathcock KS. Depletion of Accessory Cells by Adherence to Sephadex G-10 [Internet]. In: Current Protocols in Immunology. John Wiley \& Sons, Inc.; 2001 [cited 2015 Apr 16]. Available from: http://onlinelibrary.wiley.com/doi/10.1002/0471142735.im0306s08/abstract

57. Liedtke M, Dunn T, Dinner S, Coutré SE, Berube C, Gotlib J, Patel S, Medeiros B. Salvage therapy with mitoxantrone, etoposide and cytarabine in relapsed or refractory acute lymphoblastic leukemia. Leuk Res 2014; 38:1441-5.

58. Weinstein HJ, Griffin TW, Feeney J, Cohen HJ, Propper RD, Sallan SE. Pharmacokinetics of continuous intravenous and subcutaneous infusions of cytosine arabinoside. Blood 1982; 59:1351-3.

59. Joannon P, Oviedo I, Campbell M, Tordecilla J. High-dose methotrexate therapy of childhood acute lymphoblastic leukemia: Lack of relation between serum methotrexate concentration and creatinine clearance. Pediatr Blood Cancer 2004; 43:17-22.

60. Bhojwani D, Sabin ND, Pei D, Yang JJ, Khan RB, Panetta JC, Krull KR, Inaba H, Rubnitz JE, Metzger ML, Howard SC, Ribeiro RC, Cheng C, et al. Methotrexate-induced neurotoxicity and leukoencephalopathy in childhood acute lymphoblastic leukemia. J Clin Oncol 
Off J Am Soc Clin Oncol 2014; 32:949-59.

61. Van den Berg HW, Desai ZR, Wilson R, Kennedy G, Bridges JM, Shanks RG. The pharmacokinetics of vincristine in man: reduced drug clearance associated with raised serum alkaline phosphatase and dose-limited elimination. Cancer Chemother Pharmacol 1982; 8:2159.

62. Cerchietti LC, Ghetu AF, Zhu X, Da Silva GF, Zhong S, Matthews M, Bunting KL, Polo JM, Farès C, Arrowsmith $\mathrm{CH}$, Yang SN, Garcia M, Coop A, et al. A Small-Molecule Inhibitor of BCL6 Kills DLBCL Cells In Vitro and In Vivo. Cancer Cell 2010; 17:400-11.

63. Li J, Li G, Hu J-L, Fu X-H, Zeng Y-J, Zhou Y-G, Xiong G, Yang N, Dai S-S, He F-T. Chronic or high dose acute caffeine treatment protects mice against oleic acid-induced acute lung injury via an adenosine A2A receptor-independent mechanism. Eur J Pharmacol 2011; 654:295-303. 


\section{Figure legends}

Figure 1. Co-culture with BMSC or HOB reduces BCL6 in ALL cells. A. BCL6 protein in REH and Nalm-27 ALL cells when co-cultured with BMSC or HOB cells relative to media (M) controls as shown by western blot analysis. B. Flow cytometry analysis of REH and Nalm-27 ALL cell BCL6 protein levels when removed from the PD population compared to cells in media alone as shown by median florescence intensity (MFI). C. MFI of Patient 1 (P1) and Patient 2 (P2) when in physical contact with BMSC or $\mathrm{HOB}$ compared to those in media alone (ND= not detected). D. Confocal microscopy images of REH and Nalm-27 for BCL6 (yellow) and DAPI (Blue) in cells cultured in media alone compare to those recovered from the PD population of BMSC or HOB coculture. E. P1 and P2 BCL6 confocal staining of media alone cells relative to those in contact with BMSC or HOB. Scale bar $=10 \mu \mathrm{m}$.

\section{Figure 2. Modulation of BCL6 alters cell cycle progression and proliferation of}

ALL cells. A.- B. Cell density and viability of REH, Sup-B15, and Nalm-27 following exposure to the small molecule BCL6 inhibitor $79-6(125 \mu \mathrm{M})$ relative to DMSO controls as shown by trypan blue exclusion cell counts. C. Proliferation index of 79-6 treatment of REH, Sup-B15 and Nalm-27 ALL cells compared to DMSO controls using a CSFE cell retention dye flow cytometry analysis. D. Propidium iodide (PI) DNA staining for cell cycle assessment of REH, Sup-B15 and Nalm-27 treated with 79-6 compared to DMSO controls. E. Cell density of shRNA knockdown of BCL6 (KD1 and KD3) (left panel) and BCL6 overexpression (BCL6 OX) (right panel) of REH cells over time compared to vector controls as evaluated by trypan blue exclusion counts. F. Cell cycle analysis of BCL6 knockdown (left panel) and BCL6 overexpression (right panel) in REH cells using 
PI staining. $\left({ }^{*}=p<0.05\right.$ for $79-6$ treated cells or knockdown/overexpression cells compared to DMSO or vector controls, respectively).

Figure 3. BCL6 modulates the cell cycle regulating protein cyclin D3. A. Western blot analysis of protein abundance of BCL6 and cyclin D3 in REH and Nalm-27 cells in media alone compared to PD cells recovered from BMSC or HOB co-culture. B. Comparison of REH BCL6 knockdown and overexpression to vector controls for BCL6 and cyclin D3 protein levels by western blot. C. Protein analysis by western blot of cyclin D3 in REH and Nalm-27 cells when exposed to 79-6.

Figure 4. Forced expression of BCL6 sensitizes PD ALL cells to chemotherapy exposure. A. Viability comparison of REH vector control, BCL6 overexpression, or BCL6 overexpression cells pre-treated with $79-6(125 \mu \mathrm{M})$ following exposure to three chemotherapy drugs (Ara-C [1 $\mu \mathrm{M}]$, MTX [50 $\mu \mathrm{M}]$, VCR [25 $\mu \mathrm{M}]$ ). $\left({ }^{*}=\mathrm{p}<0.05\right.$ BCL6 OX to vector control and \# $=p<0.05$ BCL6 OX to BCL6 $+79-6)$. B. REH and Nalm-27 BCL6 protein dose response to MG132 and caffeine as shown by western blot. C. Western blot analysis to determine BCL6 protein abundance of REH and Nalm-27 cells when exposed to MG132 or caffeine when recovered from media alone, and the PD population of BMSC or $\mathrm{HOB}$ co-culture. D. REH and Nalm-27 cell viability following exposure to Ara-C alone or when pre-treated with MG132 or caffeine 6 hours prior to Ara-C exposure to compare cells in media alone to those recovered from the PD population of BMSC or HOB co-culture. ( $\#=p<0.05 \mathrm{PD}$ ALL cells from BMSC/HOB relative to media and ${ }^{*}=p<0.05$ Ara-C $+M G 132 /$ Ara-C + caffeine relative to Ara-C only treatment). 
Figure 5. In vivo sensitivity to Ara-C is increased by BCL6 overexpression or pretreatment with caffeine. A. Schematic of NSG mouse experiment to determine GFP+ ALL burden in the femurs of NSG mice. B. Box plot representation of median percentage of GFP+ REH ALL cells relative to total mononuclear cells recovered from femurs of NOD-SCID Gamma (NSG) mice infected with REH vector control $(n=5)$ or REH BCL6 overexpression ( $n=4)$ ALL cells following three consecutive days of Ara-C treatment. C. Schematic of NSG mouse experiment to determine event free survival of mice pre-treated with BCL6 modulating drugs MG-132 or caffeine. D. Event free survival of NSG mice following treatment with Ara-C $(n=5)$, MG-132 + Ara-C $(n=6)$, or caffeine + Ara-C $(n=6)\left({ }^{*}=p<0.05\right.$ Ara-C relative to caffeine + Ara-C $)$. 
Figures

A
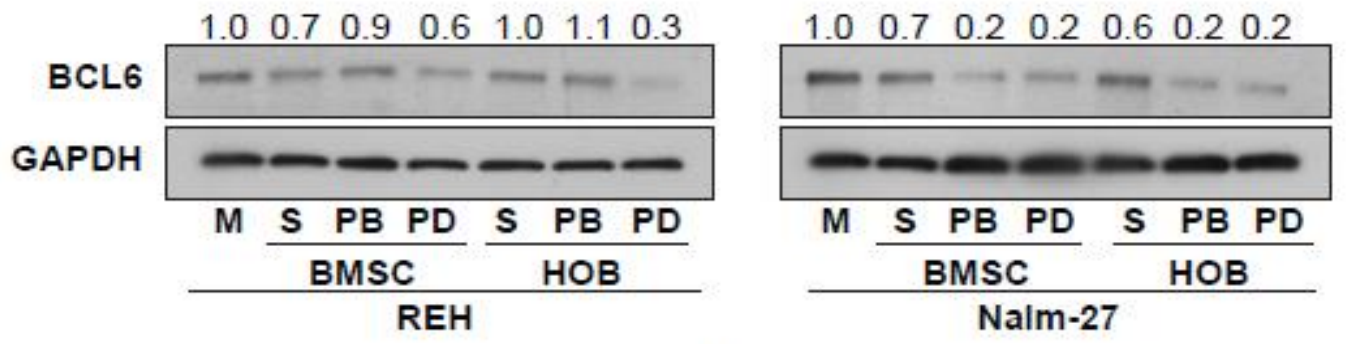

B

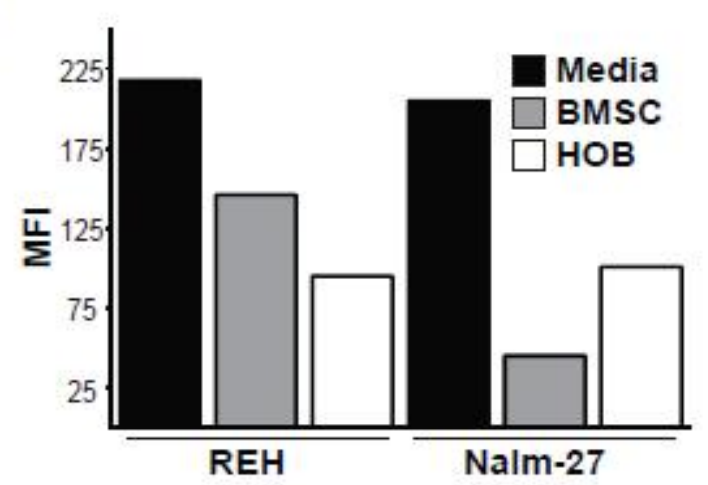

c

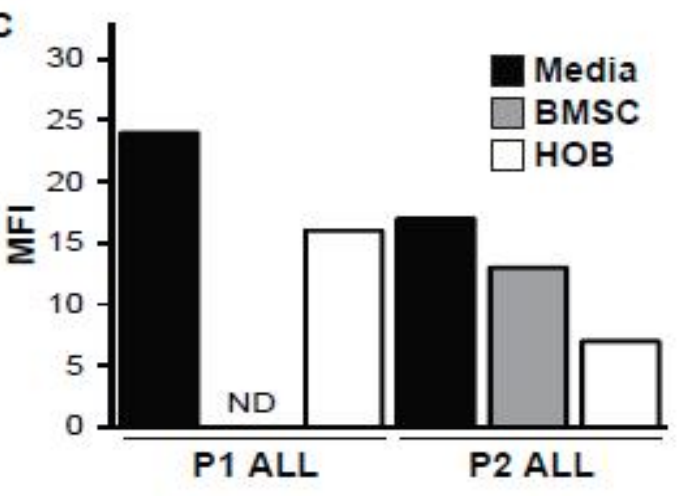

D
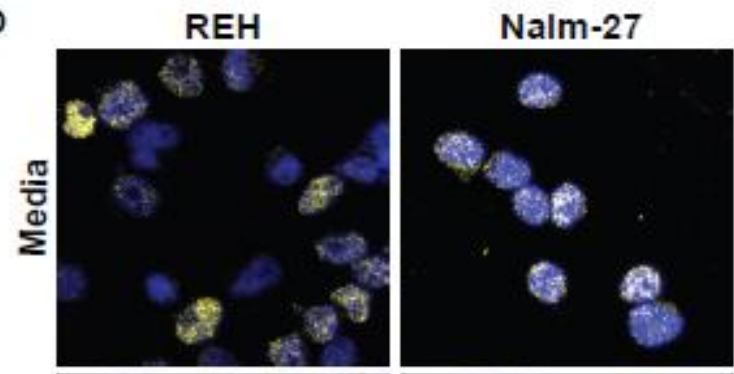

E
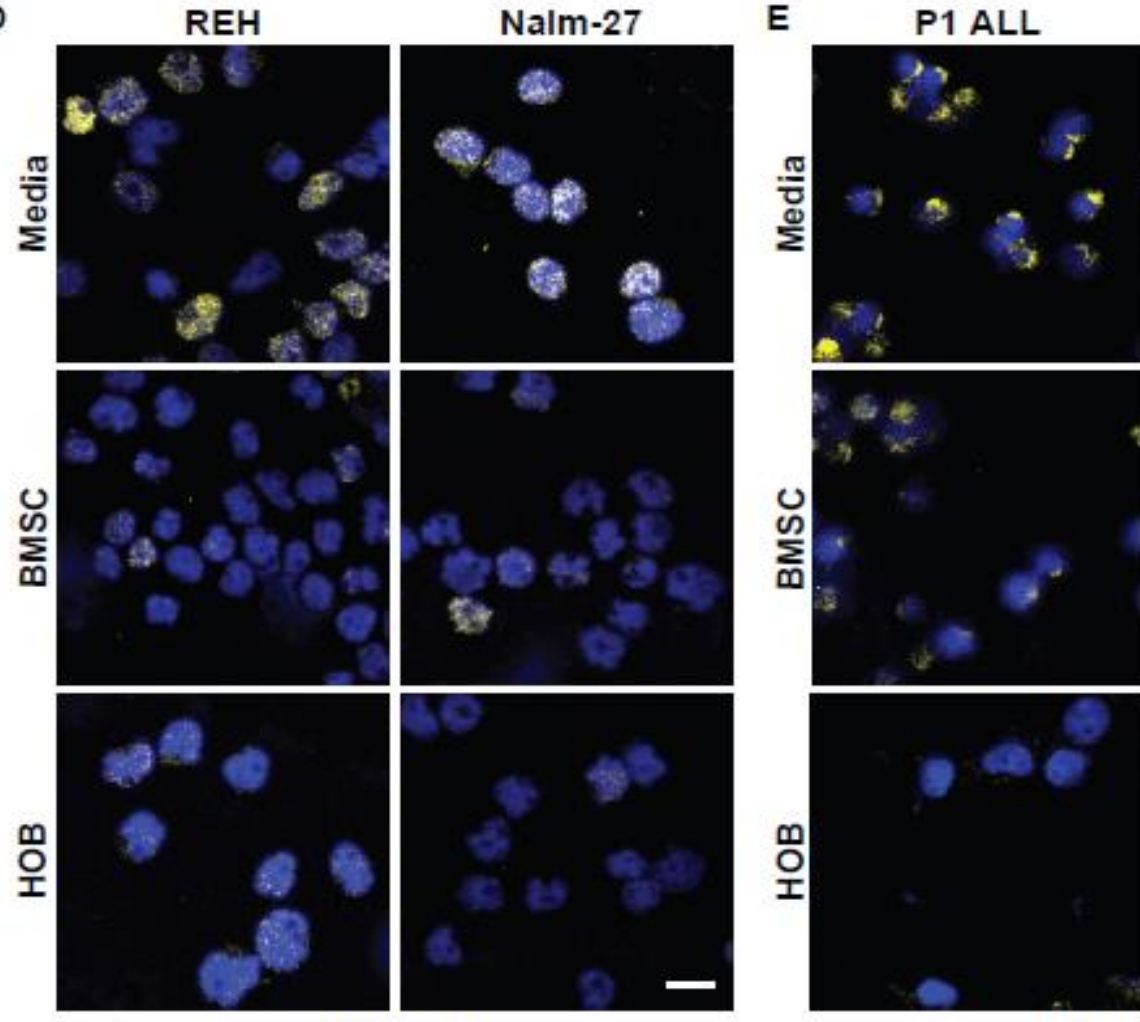

DAPI ECLB

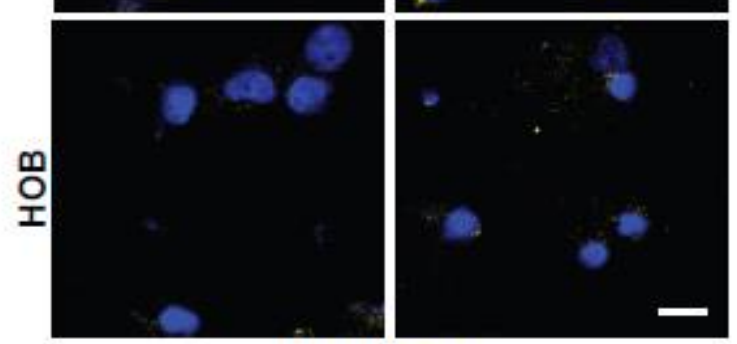

DAPI 토요

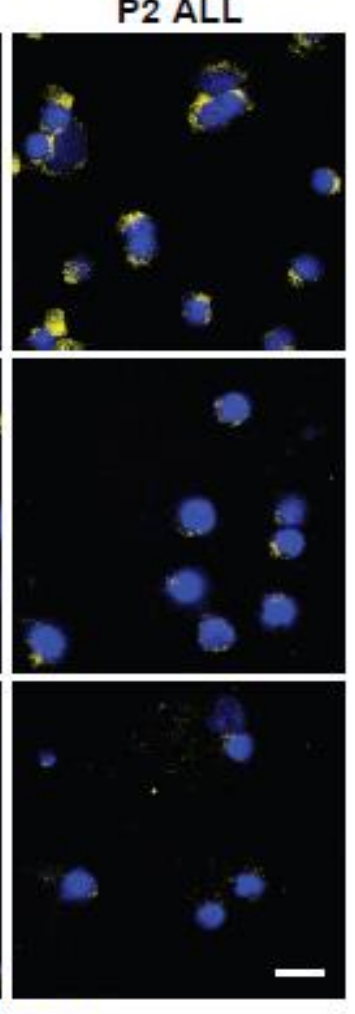

Figure 1. Co-culture with BMSC or $\mathrm{HOB}$ reduces BCL6 in ALL cells. 

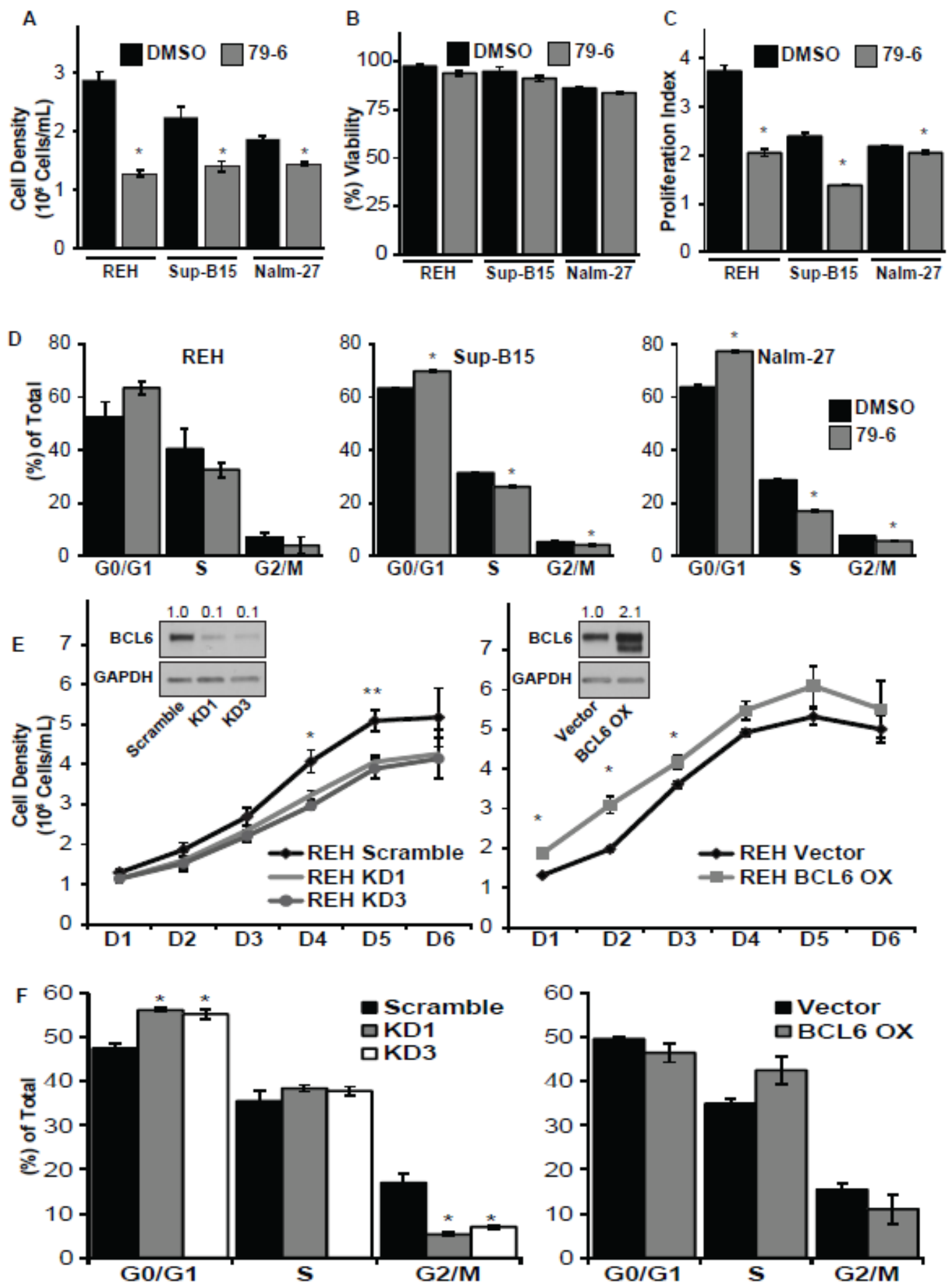

Figure 2. Modulation of BCL6 alters cell cycle progression and proliferation of ALL cells. 

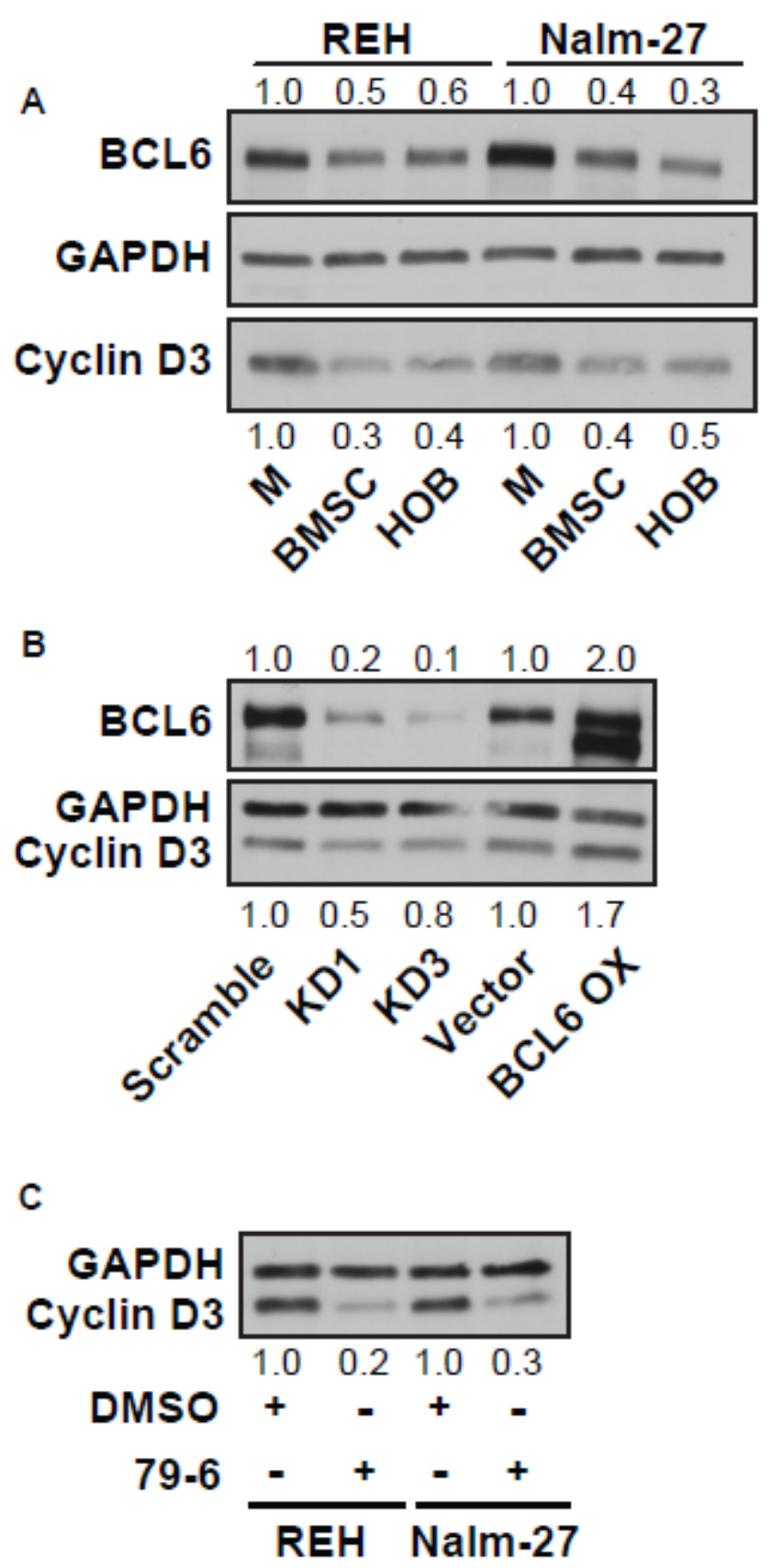

Figure 3. BCL6 modulates the cell cycle regulating protein cyclin D3. 

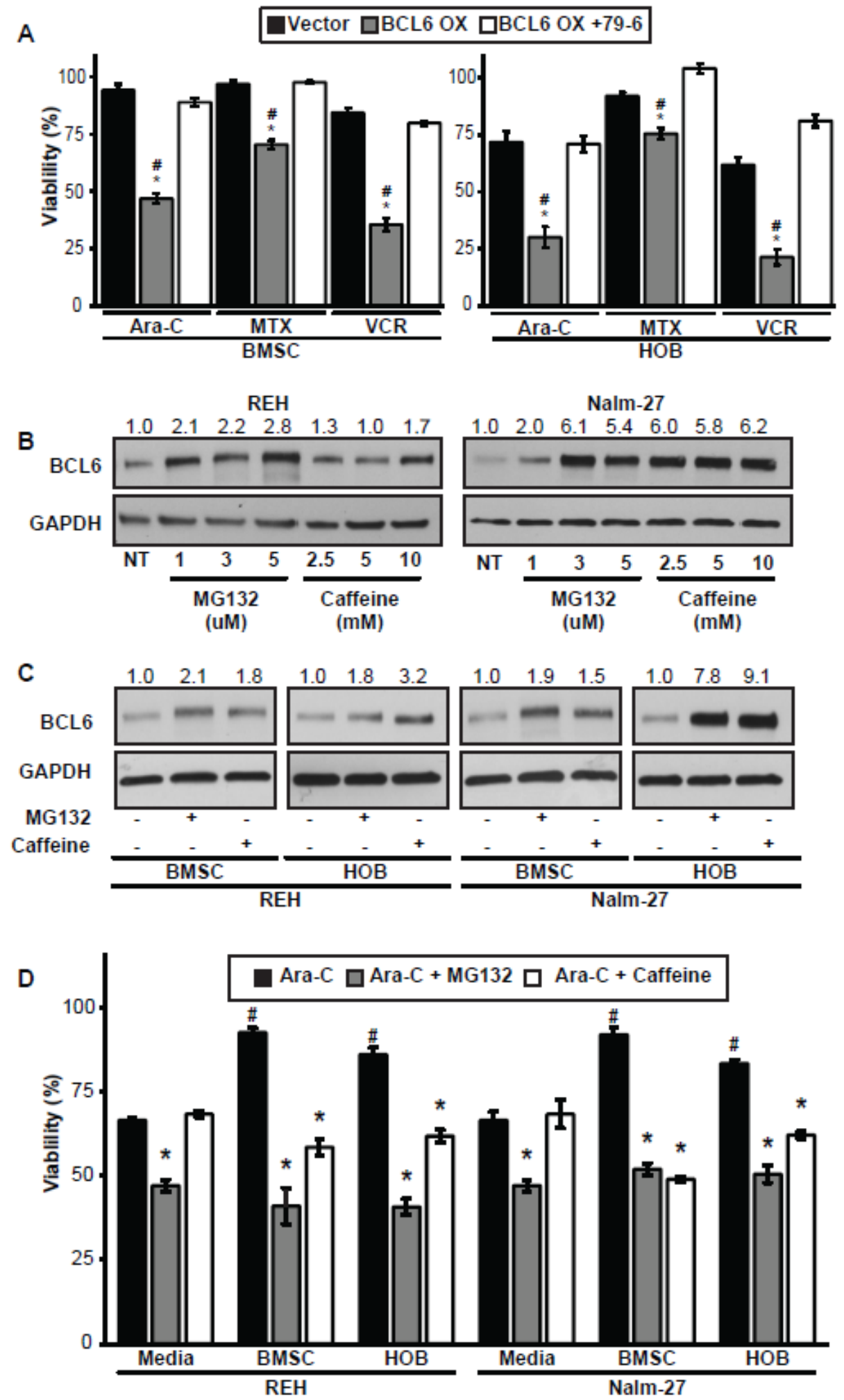

Figure 4. Forced expression of BCL6 sensitizes PD ALL cells to chemotherapy exposure. 

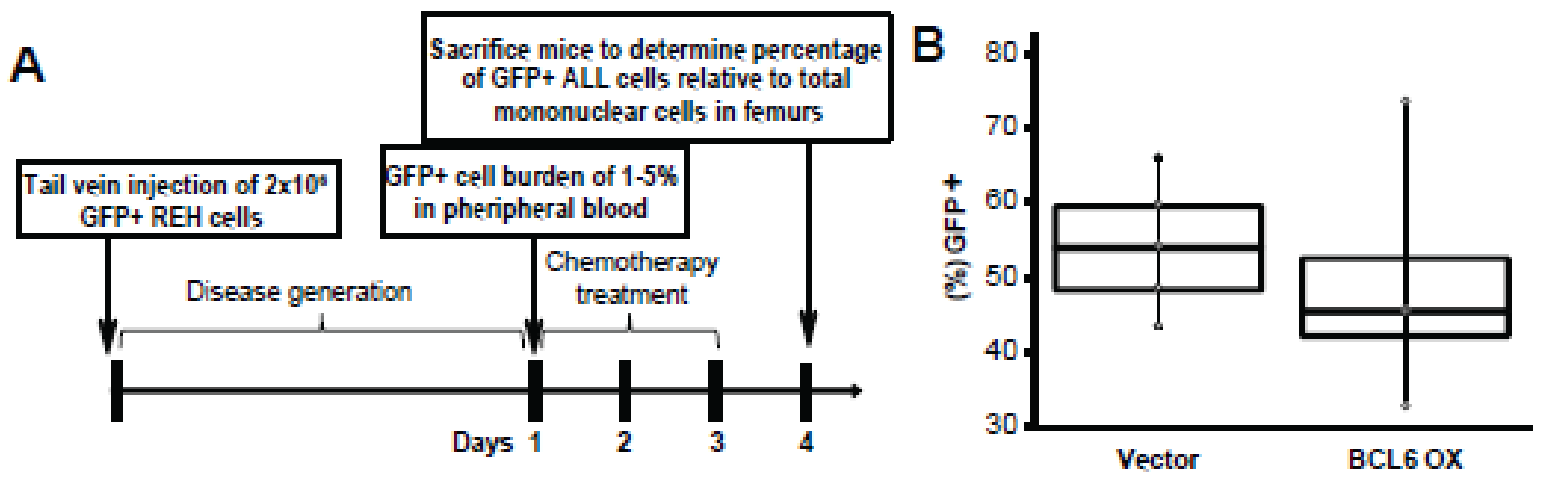

C

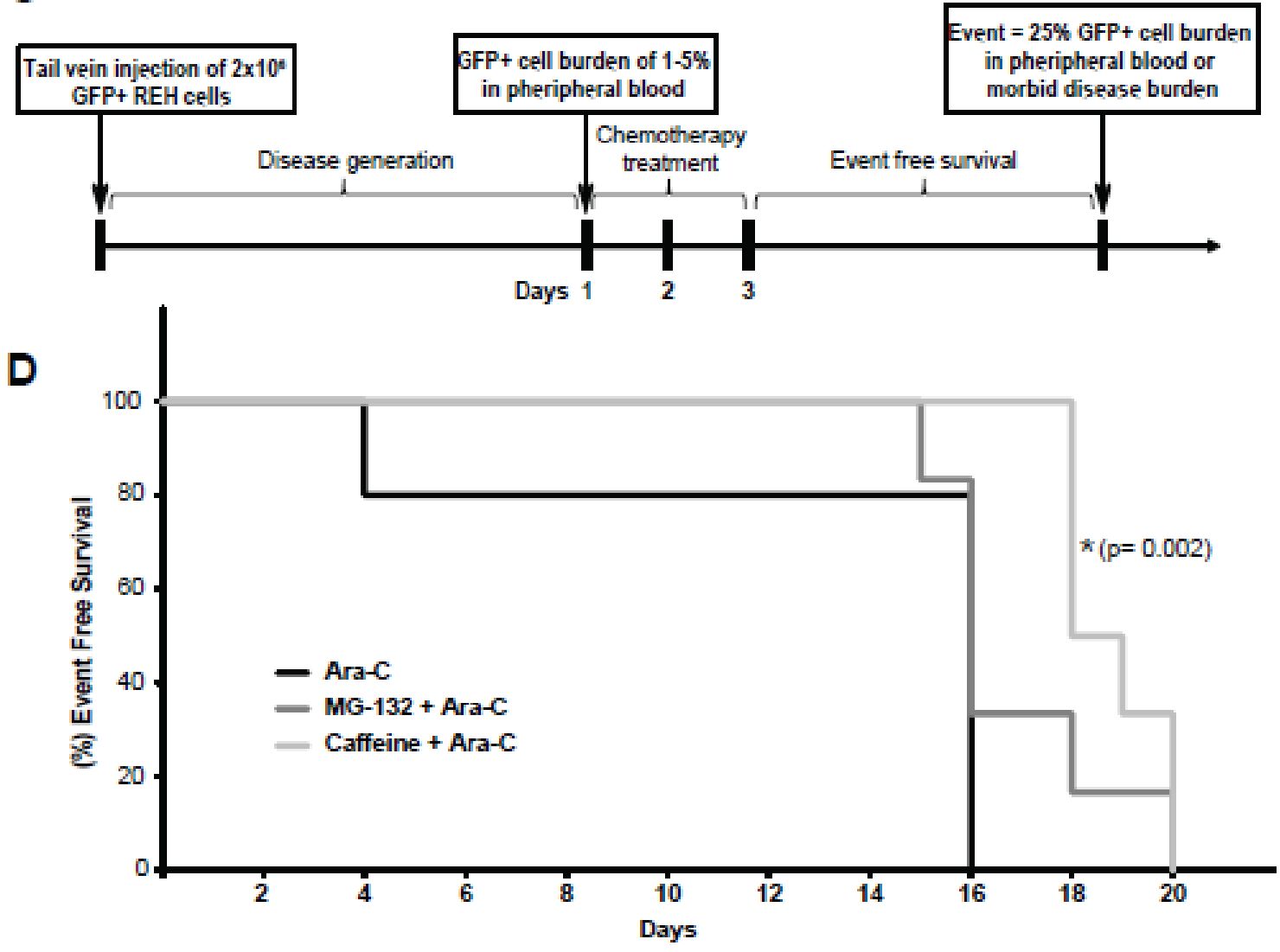

Figure 5. In vivo sensitivity to Ara-C is increased by BCL6 overexpression or pretreatment with caffeine. 
Chapter 5

General Discussion 
Modern chemotherapy regimens have transformed the once $100 \%$ fatal disease of acute lymphoblastic leukemia into a malignancy that has one of the best prognoses among all cancers. While diverse age groups are diagnosed with ALL, it is most common in children between the ages $2-5$ years old ${ }^{1,2}$. The predominance of this disease in the pediatric population highlights concerns about the necessity of dose escalated chemotherapy and repeated exposure to cytotoxic drugs as noted in Chapter 1. The positive aspect of ALL treatment is that the 5-year relative survival for all ALL patients has risen from $31 \%$ in 1975 to $67.5 \%$ based on data collected from 2005 $2011^{2}$. In addition to increased 5-year survival rates, complete remission rates for both children and adults has steadily improved with complete remission achieved in greater than $90 \%$ of childhood cases and more than $80 \%$ of adult cases ${ }^{1-3}$. These results indicate the great strides that have been achieved in the treatment of this disease. Yet, the overall 5-year survival rate of $67.5 \%$ indicates that a number of patients who achieve initial remission will subsequently relapse. Relapse of ALL occurs at a rate of $20-25 \%$ in children and greater than $50 \%$ of adult cases ${ }^{4-8}$. Relapse of ALL is often coincident with aggressive disease and poor prognosis and highlighted in Chapter 1. Of clinical significance is the frequency with which ALL relapse arises from the bone marrow. Relapse from this anatomical site, as well as the length of the initial remission, is associated with a poor prognosis relative to events arising later and from other sites $^{9,10}$. Based on this observation, research focused on the interactions between the BMM and ALL that promote chemotherapy resistance disease is of significant importance in the continued progression toward eradication of ALL. 
To address questions centered on crosstalk between the BMM and ALL that result in refractory disease, we aimed to improve current in vitro co-culture models to better model the most chemotherapy resistant ALL cells supported by the bone marrow niche. Work using normal CD34+ hematopoietic cells in co-culture with MSCs revealed that hematopoietic cells will interact with an adherent monolayer of MSCs to form three distinct spatial populations of hematopoietic cells ${ }^{11}$. This group termed the subpopulations that form as suspended (S), which are cells freely floated in the media; phase bright (PB) that adhered to the surface of the MSCs; and the phase dim (PD) which buried beneath the MSC monolayer ${ }^{11}$. In these distinct subpopulations, it was noted that proliferation and differentiation of the CD34+ cells was influenced by their location within the co-culture ${ }^{11}$. As highlighted in Chapters 2 and 3 , we built upon these findings to determine whether ALL cells in co-culture with BMSC or HOB would form three spatial populations in relation to the adherent monolayers. We found that ALL cells, similar to their normal hematopoietic counterparts, readily established three populations within the co-culture system ${ }^{12,13}$. To accurately, efficiently, and reproducibly generate this ALL co-culture model we created the protocol provided in Chapter 2 for the establishment, maintenance, and recovery of ALL cells in an in vitro model to provide us a source of leukemic cells that would represent the most treatment refractory component of the disease (PD cells $)^{12}$. One important finding from this study was that for this system to provide accurate and reproducible results, the cultures had to be maintained using a strict feeding and passage (culturing) schedule in which co-cultures were fed at 4 day intervals and transferred to new BMSC or HOB layers every 12 days $^{12}$. To enhance the usefulness of this model, we combined it with the previously 
described gel type 10 cross-linked dextran (G10) particle columns ${ }^{14}$, to provide an efficient method for separation of the ALL cells from the adherent monolayers. The ability to generate and separate the three distinct ALL populations allowed us to address questions related to potential differences in the phenotypes of the ALL populations based on their spatial location in relation to BMSC or HOB. It is well established that one critical consequence of leukemic cells interacting with BMSCs and HOBs, both in vitro and in vivo, is an increase in chemotherapy resistance ${ }^{12,13,15-21}$. We found that ALL cells of the PD population were the most chemotherapy resistant relative to the other populations, noted above. This important observation lead us to further characterize the PD population to determine the functional consequences that result from this intimate relationship between the ALL cells and the BMM in this in vitro model of treatment resistant ALL.

Based on the observation that PD ALL cells are the most chemotherapy resistant population in our co-culture model, we sought to investigate potential phenotypic changes in the PD population that contribute to chemotherapy resistance. Furthermore, we evaluated whether PD cells are unique based on intrinsic factors of the leukemic cells or if the protection is mediated by the specific interactions with the bone marrow niche cells. Consistent with the observations described in Chapter 2, we found that a variety of ALL cell lines interact with BMSC and HOB in co-culture and readily form three populations (S, PB, and PD), as highlighted in Chapter $3^{13}$. Additionally, we investigated whether the three individual groups of ALL cells had specific affinity for the location from which they were isolated. This is important as ALL disease is known to be very heterogeneous, often leading to generation of subclones which are chemotherapy 
resistant ${ }^{6}$. However, we found through the use of labeling and tracking experiments that tumor cells recovered from any spatial location (S, PB or PD) were able to reestablish the other two subpopulations when placed onto a new BMSC or HOB monolayer ${ }^{13}$. These findings show that ALL cells in our co-culture model behave in a dynamic manner, readily moving in and out of different niches within the culture. This provides the theoretical opportunity of forcing tumor cells out of resistant niches or directly targeting cells in the resistant niche (modeled by the PD), to render them more responsive to treatment interventions. Interestingly, while this co-culture model is admittedly a reductionist view of the BMM, it does somewhat recapitulate normal marrow dynamics. Both normal and malignant hematopoietic cells have been shown in vivo to migrate between different marrow niches ${ }^{22-24}$. Movement between the different niches is thought to be one mechanism by which HSCs and progenitor cells are either maintained, cued to proliferate, or stimulated to differentiate ${ }^{23}$. We speculate that while the migration in our in vitro system is simple in comparison to that in the BMM, our model may provide a tool to study signaling cues that trigger ALL cells to egress from the niche spaces. This would be of therapeutic use as mobilization of ALL cells from the protected niche may render them more susceptible to chemotherapy intervention.

We further expanded on the observation that PD ALL cells have increased chemotherapy resistance, when compared to their co-cultured counterparts ( $S$ and PB tumor cells) through experimentation with increased numbers of ALL cell lines and cytotoxic agents. In Chapter 3, we describe our observations when ALL cells in media alone and in our co-culture model are exposed to three commonly used chemotherapy drugs, Ara-C, methotrexate, and vincristine ${ }^{13}$. We found that in every treatment 
condition, across multiple tumor cell lines, PD ALL cells had little to no decrease in viability relative to untreated controls, and had significantly increased viability compared to cells cultured in media alone. Of concern was whether the increase in PD cell survival was related to interactions specific to $\mathrm{BMSC} / \mathrm{HOB}$, or whether this was the result of a generic phenomenon that would be observed related to migration and protection beneath any adherent monolayer. Additionally, it is known that uptake of chemotherapy drugs by the tumor cell greatly effects the efficacy of the treatment ${ }^{20,25}$. To address this we established co-cultures using variety of non-bone marrow derived stromal cells. While the ALL cells co-cultured with these non-bone marrow derived stromal cells did form a PD population, they were not protected from chemotherapy exposure. Moreover, our laboratory has previously shown that ALL cells in co-culture have no difference in chemotherapy uptake relative to tumor cells grown in media alone ${ }^{26}$. Together, these results suggest that interactions or cues specific to the BMM are responsible for signaling that converges on ALL resistance to chemotherapy in our co-culture model.

As described in Chapter 1, the BMM impacts the hematopoietic cell phenotype in a variety ways. One critical function of the BMM is to prevent stem cell exhaustion through regulatory signaling that promotes quiescence ${ }^{22,27,28}$. Due to similarities between ALL cells and their normal hematopoietic counterparts, ALL cells are able to hijack the normal niches and benefit from their protective signaling ${ }^{29}$. A significant instance of this is the ability of ALL cells to localize to quiescence promoting niches and as a result evade chemotherapy intervention. For example, expression of osteopontin in the osteoblastic niche has been shown to maintain HSCs in a quiescent state ${ }^{30,31}$. Likewise, Boyerinas et al. found that ALL cells localized to the endosteum and 
interacted with osteopontin resulting in a quiescent and drug resistant phenotype ${ }^{15}$. Chemotherapy resistance as a result of quiescence is not specific to ALL and it is well established that tumor cells in a dormant or quiescent state are responsible for resistant disease and relapse events in a variety of malignancies ${ }^{25,32}$. As such, we sought to investigate whether the chemotherapy resistant PD ALL population had an altered cell cycle and proliferation profile. We found that PD cells are characterized by an increased percentage of cells in $\mathrm{G}_{0} / \mathrm{G}_{1}$ and decreased $\mathrm{S}$ phase percentage compared to cells in media alone ${ }^{13}$. Additionally, we observed that the PD population had an increase in cells in Go phase, along with a reduction in $\mathrm{KI}-67$ staining relative to media alone controls ${ }^{13}$. These findings suggest that the BMM is promoting a quiescent ALL phenotype, which based on previous works is likely contributing to the chemotherapy resistance we observed in this population. Again, this model's ability to mimic well established microenvironment paradigms that promote resistant disease further validates its usefulness as a tool to model chemotherapy resistant disease in vitro. As we show in Chapter 4, it can be used as a platform to investigate the interactions that lead to quiescence in ALL cells and inform strategies to disrupt this resistant phenotype.

Interestingly, in addition to having a quiescent phenotype, we found that PD ALL cells have an altered metabolic status compared to ALL cells in media alone culture conditions. PD ALL cells appear to have increased glycolytic activity and a reduced level of oxidative phosphorylation. Consistent with the observed increase in glycolysis, we observed increased protein abundance in hexokinase 1 and 2, which are the first rate limiting enzymes of the glycolytic pathway ${ }^{13,33}$. Additionally, metabolomic analysis via mass spectrometry revealed that ALL cells in co-culture have a different metabolite 
profile compared to media alone ALL cells ${ }^{13}$. These findings are reminiscent of the classically described Warburg effect, where tumor cells are characterized by a preferential increase in glucose metabolism over oxidative phosphorylation ${ }^{34}$. Increased glycolysis and altered cellular metabolism have been associated with chemotherapy resistance through a variety of proposed mechanisms ${ }^{35}$. Future work will be needed to determine to what extent the observed increase in glycolytic activity has on chemotherapy resistance in the PD ALL cells. Moreover, we speculate that in addition to the potential for increased resistance, the increase in glycolysis might provide PD ALL cells with the ability to increase biomass, "priming" the cells for proliferation when released from the microenvironment. This speculation is based on the ability of glycolysis intermediates to be used in fatty acid, amino acid, and nucleotide synthesis ${ }^{36}$. A greater understanding of how this increase in glycolysis impacts ALL cell resistance and potential contributions to biomass production may provide strategies to target ALL cells that have altered metabolic profiles.

The overall goal of studies presented in Chapters 2 and 3 was to establish and characterize an in vitro model, which in part recapitulates dynamic interactions between ALL cells and the BMM that promote ALL resistance. While it is appreciated that murine models will remain the standard for investigation of therapeutic agents, our in vitro model provides a relatively fast and cost effective method to model resistant ALL. While we do not suggest that the PD population of tumor cells in our model are identical to the cells that initiate relapse of disease in patients, they are a treatment refractory, quiescent population that provides a very valuable tool for investigation of critical anti- 
apoptotic and cell cycle regulatory pathways. As such, utilizing this system, we investigated whether interaction with BMM influences ALL expression of BCL6.

The goal of the study presented in Chapter 4 was to investigate a fundamental gap in knowledge focused on whether BCL6 abundance in ALL cells was affected through interaction with the BMM and the consequence of BCL6 levels in terms of tumor cell phenotype. BCL6 is a proto-oncogene that was discovered and classically described in germinal center biology and cases of DLBCL ${ }^{37-40}$. BCL6 has been shown to promote proliferation in a variety of contexts through the regulation of cell cycle regulating proteins such as p27, p21, BLIMP-1, and by rendering cells unresponsive to anti-proliferative signals arising from the p19 (ARF)-p53 pathway ${ }^{40-43}$. Consistently, high BCL6 protein expression is associated with rapidly proliferating germinal center B-cells ${ }^{44}$ and has been shown to positively correlate with proliferation associated protein $\mathrm{Ki}-67^{45}$. Conversely, BCL6 has also been presented as a mediator of cell cycle repression and senescence. Nahar et al. demonstrated that BCL6 expression could result in repression of MYC leading to cell cycle arrest and quiescence ${ }^{46}$. Similarly, Ranuncolo et al. found that BCL6 could trigger growth arrest and senescence through a p53 dependent pathway ${ }^{47}$. These findings illustrate the complexity and diversity of BCL6 regulation. They also highlight the need for studies that explore BCL6 functions through context specific experimentation, with focus on normal and tumor microenvironment influences that may affect BCL6 driven phenotypes. To this end, this study explored the role BMM derived cells have on BCL6 protein abundance in ALL cells. Utilizing our in vitro coculture model, we found BMSC and HOB interaction results in decreased BCL6 levels in ALL cells ${ }^{48}$. Furthermore, we show that BCL6 abundance is impacted to the greatest 
extent in the chemotherapy resistant PD ALL cells ${ }^{48}$. These findings were striking because elevated BCL6 expression in CML and ALL cells has been shown to promote chemotherapy resistance through tolerance to DNA damaging stress via repression of p53 signaling ${ }^{49,50}$. This apparent ambiguity lead us to investigate other tumor strategies, which can lead to a chemotherapy resistance and that may be influenced by BCL6 downregulation. As described in the Chapter 3 study, we found that the resistant PD population was characterized by a quiescent phenotype ${ }^{13}$. Consistent with this observation and the known function of BCL6 as a driver of proliferation, we found that inhibition of BCL6 in our hands lead to diminished proliferation and blunted cell cycle progression in ALL cells, with overexpression leading to the reverse phenotype ${ }^{48}$. Additionally, we discovered that cyclin D3 protein abundance was regulated downstream of BCL6 inhibition or overexpression ${ }^{48}$. These findings are significant as cyclin D3 has been shown to be a key regulator of $B$-cell progression through the $G_{1}$ phase of cell cycle ${ }^{51-53}$. Together, these findings point to microenvironment downregulation of BCL6 as a mechanism to blunt ALL cell cycle progression and subsequent chemotherapy resistance through induction of a quiescent phenotype.

Due to the fact that many chemotherapy regimens target dividing cells, standard treatments are often less effective against quiescent tumor populations ${ }^{25,32}$. Based on this premise, one goal of this study was to investigate strategies to improve the efficacy of chemotherapy treatments against quiescent ALL cells in the BMM. With the findings that PD ALL cells have a quiescent phenotype, which is in part mediated through BMSC and $\mathrm{HOB}$ driven reduction of BCL6 protein abundance in ALL cells, we sought to determine whether combination strategies aimed at chronically increasing BCL6 would 
sensitize ALL cells to chemotherapy. To this end, we found that chronic constitutive BCL6 expression lead to increased sensitivity of ALL cells to chemotherapy exposure ${ }^{48}$. Additionally, we investigated MG132 and caffeine exposure as an approach to chemically modulate BCL6 expression in ALL cells. Both MG132 and caffeine have been shown to stabilize BCL6 expression through repression of pathways (proteasome and ATM/ATR inhibition respectively) that lead to proteasomal mediated degradation of BCL6 ${ }^{48,54}$. Consistent with these observations, we found that exposure to MG132 or caffeine increased protein abundance of BCL6 in ALL cells, and that both drugs were able to increase BCL6 expression in target PD ALL cells ${ }^{48}$. Employing these two drugs to chronically increase BCL6 in the PD population, we discovered that combination treatment with chemotherapy resulted in sensitization of PD ALL cell compared to chemotherapy only treated groups ${ }^{48}$. While it is appreciated that neither MG132 or caffeine specifically target BCL6, they both represent a tool to sensitize ALL resistant ALL cells to chemotherapy, which is in part mediated through their influence on BCL6 expression. Based on these encouraging in vitro results, we investigated both MG132 and caffeine as sensitization agents in a murine model of ALL disease. In these studies, we found that caffeine treatment in combination with Ara-C significantly increased the event free survival of mice compared to treatment with chemotherapy alone ${ }^{48}$. Again, while caffeine is not likely acting through BCL6 modulation exclusively, it does appear to be useful in sensitizing ALL cells to chemotherapy. These findings in concert with the results of the in vitro studies supports further investigation of BCL6 modulation and caffeine treatment as potential approaches to target resistant ALL disease. We speculate that caffeine treatment might be a beneficial addition to 
consolidation regimens to potentially bring quiescent residual tumor cells into cycle so that they may be more effectively targeted by chemotherapy. Overall, the findings of the study presented in Chapter 4 begin to address the lack of understanding of how the BMM influences ALL expression of BCL6. We hope that this study will provide a springboard for further investigations into context specific BMM regulation of BCL6 and inform potential treatment strategies targeting resistance in the marrow niche.

The studies presented herein further advance the field of ALL research through establishment of an in vitro co-culture model in which BMM supported and chemotherapy resistant disease can be further investigated. To our knowledge, this work represents the first time that BMM influence on ALL BCL6 protein abundance has been investigated. The presented studies show the progression from establishment of the in vitro model, to its use in the investigation of BCL6 as a mechanism of chemotherapy resistance in ALL cells, and finally its ability to provide a platform for investigations which informed the treatment strategies used in our in vivo murine studies. We envision that future work will be able to build upon this research in a variety of ways. For example, the observation that the PD ALL cells have increased glycolytic activity will require additional investigation to determine the impact of this altered metabolism on resistant disease and potential for relapse. Additionally, it will be critical to expand on the findings surrounding BCL6 modulation downstream of the BMM. A mechanistic insight into how this modulation is mediated may provide additional targets for sensitization strategies against refractory ALL. Moreover, it will be important to gain a better understanding of the cellular context in which BCL6 is altered in ALL cells, as changes in pathways such as p53, ATM/ATR, PI3K, and BCL family proteins can 
dramatically affect BCL6's regulation of cell phenotype as highlighted above. Finally, the observation that caffeine sensitizes ALL cells to chemotherapy warrants further investigation. Caffeine's long history of safe use in humans and our observation of its use as a sensitizing agent give it the potential to become an attractive addition to the current treatment regimens. In this way, we are hopeful that this work will fit into the long history of successful additions to the combination treatment advances that first began to improve outcomes in ALL patients of the corporative children's groups of the 1950's. Finally, we are optimistic that this work, as well as those similarly investigating strategies to disrupt bone marrow microenvironment protection of ALL, will provide the final brick in the long road to curing this once uniformly fatal disease. 


\section{References}

1. Inaba H, Greaves M, Mullighan CG. Acute lymphoblastic leukaemia. The Lancet. 2013;381(9881):1943-1955.

2. Howlader N, Noone A, Krapcho M, et al. SEER Cancer Statistics Review, 1975-2012, National Cancer Institute. Bethesda, MD, http://seer.cancer.gov/csr/1975_2012/, based on November 2014 SEER data submission, posted to the SEER web site, April 2015. 2014;

3. Bassan R, Hoelzer D. Modern therapy of acute lymphoblastic leukemia. J. Clin. Oncol. Off. J. Am. Soc. Clin. Oncol. 2011;29(5):532-543.

4. Szczepanek J, Styczyński J, Haus O, Tretyn A, Wysocki M. Relapse of Acute Lymphoblastic Leukemia in Children in the Context of Microarray Analyses. Arch. Immunol. Ther. Exp. (Warsz.). 2011;59(1):61-68.

5. Gökbuget N, Stanze D, Beck J, et al. Outcome of relapsed adult lymphoblastic leukemia depends on response to salvage chemotherapy, prognostic factors, and performance of stem cell transplantation. Blood. 2012;120(10):2032-2041.

6. Choi S, Henderson MJ, Kwan E, et al. Relapse in children with acute lymphoblastic leukemia involving selection of a preexisting drug-resistant subclone. Blood. 2007;110(2):632639.

7. Pui C-H, Campana D, Evans WE. Childhood acute lymphoblastic leukaemia - current status and future perspectives. Lancet Oncol. 2001;2(10):597-607.

8. Pui C-H, Relling MV, Downing JR. Acute Lymphoblastic Leukemia. N. Engl. J. Med. 2004;350(15):1535-1548.

9. Gaynon PS, Qu RP, Chappell RJ, et al. Survival after relapse in childhood acute lymphoblastic leukemia: impact of site and time to first relapse--the Children's Cancer Group Experience. Cancer. 1998;82(7):1387-1395.

10. Nguyen K, Devidas M, Cheng S-C, et al. Factors Influencing Survival After Relapse From Acute Lymphoblastic Leukemia: A Children's Oncology Group Study. Leuk. Off. J. Leuk. Soc. Am. Leuk. Res. Fund UK. 2008;22(12):2142-2150.

11. Jing D, Fonseca A-V, Alakel N, et al. Hematopoietic stem cells in co-culture with mesenchymal stromal cells--modeling the niche compartments in vitro. Haematologica. 2010;95(4):542-550.

12. Slone WL, Moses BS, Evans R, et al. Modeling Chemotherapy Resistant Leukemia In Vitro. J. Vis. Exp. JoVE. 2016;(108.).

13. Moses BS, Slone WL, Thomas $\mathrm{P}$, et al. Bone marrow microenvironment modulation of acute lymphoblastic leukemia phenotype. Exp. Hematol. 2016;44(1):50-59.e2.

14. Hathcock KS. Depletion of Accessory Cells by Adherence to Sephadex G-10. Curr. Protoc. Immunol. 2001. 
15. Boyerinas $B$, Zafrir M, Yesilkanal AE, et al. Adhesion to osteopontin in the bone marrow niche regulates lymphoblastic leukemia cell dormancy. Blood. 2013;121(24):4821-4831.

16. Dong-Feng Z, Ting L, Yong Z, et al. The TPO/c-MPL pathway in the bone marrow may protect leukemia cells from chemotherapy in AML Patients. Pathol. Oncol. Res. POR. 2014;20(2):309-317.

17. Saito $\mathrm{Y}$, Uchida N, Tanaka S, et al. Induction of cell cycle entry eliminates human leukemia stem cells in a mouse model of AML. Nat. Biotechnol. 2010;28(3):275-280.

18. Mudry RE, Fortney JE, York T, Hall BM, Gibson LF. Stromal cells regulate survival of Blineage leukemic cells during chemotherapy. Blood. 2000;96(5):1926-1932.

19. Iwamoto S, Mihara K, Downing JR, Pui C-H, Campana D. Mesenchymal cells regulate the response of acute lymphoblastic leukemia cells to asparaginase. J. Clin. Invest. 2007;117(4):1049-1057.

20. Meads MB, Hazlehurst LA, Dalton WS. The Bone Marrow Microenvironment as a Tumor Sanctuary and Contributor to Drug Resistance. Clin. Cancer Res. 2008;14(9):2519-2526.

21. Tesfai Y, Ford J, Carter KW, et al. Interactions between acute lymphoblastic leukemia and bone marrow stromal cells influence response to therapy. Leuk. Res. 2012;36(3):299-306.

22. Boulais PE, Frenette PS. Making sense of hematopoietic stem cell niches. Blood. 2015;125(17):2621-2629.

23. Ratajczak MZ. A novel view of the adult bone marrow stem cell hierarchy and stem cell trafficking. Leukemia. 2015;29(4):776-782.

24. Duan C-W, Shi J, Chen J, et al. Leukemia propagating cells rebuild an evolving niche in response to therapy. Cancer Cell. 2014;25(6):778-793.

25. Moore N, Lyle S. Quiescent, Slow-Cycling Stem Cell Populations in Cancer: A Review of the Evidence and Discussion of Significance. J. Oncol. 2010;2011.:

26. Fortney JE, Zhao W, Wenger SL, Gibson LF. Bone marrow stromal cells regulate caspase 3 activity in leukemic cells during chemotherapy. Leuk. Res. 2001;25(10):901-907.

27. Schofield $\mathrm{R}$. The relationship between the spleen colony-forming cell and the haemopoietic stem cell. Blood Cells. 1978;4(1-2):7-25.

28. Lord $\mathrm{BI}$, Testa NG, Hendry $\mathrm{JH}$. The relative spatial distributions of CFUs and CFUc in the normal mouse femur. Blood. 1975;46(1):65-72.

29. Colmone A, Amorim M, Pontier AL, et al. Leukemic Cells Create Bone Marrow Niches That Disrupt the Behavior of Normal Hematopoietic Progenitor Cells. Science. 2008;322(5909):1861-1865.

30. Stier S, Ko Y, Forkert R, et al. Osteopontin is a hematopoietic stem cell niche component that negatively regulates stem cell pool size. J. Exp. Med. 2005;201(11):1781-1791. 
31. Nilsson SK, Johnston HM, Whitty GA, et al. Osteopontin, a key component of the hematopoietic stem cell niche and regulator of primitive hematopoietic progenitor cells. Blood. 2005;106(4):1232-1239.

32. Aguirre-Ghiso JA. Models, mechanisms and clinical evidence for cancer dormancy. Nat. Rev. Cancer. 2007;7(11):834-846.

33. Robey RB, Hay N. Mitochondrial hexokinases, novel mediators of the antiapoptotic effects of growth factors and Akt. Oncogene. 2006;25(34):4683-4696.

34. Wu W, Zhao S. Metabolic changes in cancer: beyond the Warburg effect. Acta Biochim. Biophys. Sin. 2013;45(1):18-26.

35. Ganapathy-Kanniappan S, Geschwind J-FH. Tumor glycolysis as a target for cancer therapy: progress and prospects. Mol. Cancer. 2013;12:152.

36. Lunt SY, Vander Heiden MG. Aerobic Glycolysis: Meeting the Metabolic Requirements of Cell Proliferation. Annu. Rev. Cell Dev. Biol. 2011;27(1):441-464.

37. Baron BW, Nucifora G, McCabe N, et al. Identification of the gene associated with the recurring chromosomal translocations $\mathrm{t}(3 ; 14)(\mathrm{q} 27 ; \mathrm{q} 32)$ and $\mathrm{t}(3 ; 22)(\mathrm{q} 27 ; \mathrm{q} 11)$ in B-cell lymphomas. Proc. Natl. Acad. Sci. U. S. A. 1993;90(11):5262-5266.

38. Kerckaert JP, Deweindt C, Tilly $\mathrm{H}$, et al. LAZ3, a novel zinc-finger encoding gene, is disrupted by recurring chromosome $3 \mathrm{q} 27$ translocations in human lymphomas. Nat. Genet. 1993;5(1):66-70.

39. Cattoretti G, Chang CC, Cechova K, et al. BCL-6 protein is expressed in germinal-center B cells. Blood. 1995;86(1):45-53.

40. Shaffer AL, Yu X, He Y, et al. BCL-6 represses genes that function in lymphocyte differentiation, inflammation, and cell cycle control. Immunity. 2000;13(2):199-212.

41. Phan RT, Dalla-Favera R. The BCL6 proto-oncogene suppresses p53 expression in germinal-centre B cells. Nature. 2004;432(7017):635-639.

42. Phan RT, Saito M, Basso K, Niu H, Dalla-Favera R. BCL6 interacts with the transcription factor Miz-1 to suppress the cyclin-dependent kinase inhibitor p21 and cell cycle arrest in germinal center B cells. Nat. Immunol. 2005;6(10):1054-1060.

43. Shvarts A, Brummelkamp TR, Scheeren $F$, et al. A senescence rescue screen identifies BCL6 as an inhibitor of anti-proliferative p19ARF-p53 signaling. Genes Dev. 2002;16(6):681686.

44. Allman D, Jain A, Dent A, et al. BCL-6 expression during B-cell activation. Blood. 1996;87(12):5257-5268.

45. Bai M, Agnantis NJ, Skyrlas A, et al. Increased Expression of the bcl6 and CD10 Proteins Is Associated with Increased Apoptosis and Proliferation in Diffuse Large B-Cell Lymphomas. Mod. Pathol. 2003;16(5):471-480. 
46. Nahar R, Ramezani-Rad P, Mossner M, et al. Pre-B cell receptor-mediated activation of BCL6 induces pre-B cell quiescence through transcriptional repression of MYC. Blood. 2011;118(15):4174-4178.

47. Ranuncolo SM, Wang L, Polo JM, et al. BCL6-mediated Attenuation of DNA Damage Sensing Triggers Growth Arrest and Senescence through a p53-dependent Pathway in a Cell Context-dependent Manner. J. Biol. Chem. 2008;283(33):22565-22572.

48. Slone WL, Moses BS, Hare I, et al. BCL6 Modulation of Acute Lymphoblastic Leukemia Response to Chemotherapy. Oncotarget. 2016. doi: 10.18632/oncotarget.8273.

49. Duy C, Hurtz C, Shojaee S, et al. BCL6 enables Ph+ acute lymphoblastic leukaemia cells to survive BCR-ABL1 kinase inhibition. Nature. 2011;473(7347):384-388.

50. Hurtz C, Hatzi K, Cerchietti L, et al. BCL6-mediated repression of p53 is critical for leukemia stem cell survival in chronic myeloid leukemia. J. Exp. Med. 2011;208(11):2163-2174.

51. Cato MH, Chintalapati SK, Yau IW, Omori SA, Rickert RC. Cyclin D3 Is Selectively Required for Proliferative Expansion of Germinal Center B Cells. Mol. Cell. Biol. 2011;31(1):127-137.

52. Cooper AB, Sawai CM, Sicinska $E$, et al. A unique function for cyclin D3 in early B cell development. Nat. Immunol. 2006;7(5):489-497.

53. Peled JU, Yu JJ, Venkatesh J, et al. Requirement for cyclin D3 in germinal center formation and function. Cell Res. 2010;20(6):631-646.

54. Phan RT, Saito M, Kitagawa Y, Means AR, Dalla-Favera R. Genotoxic stress regulates expression of the proto-oncogene Bcl6 in germinal center B cells. Nat. Immunol.

2007;8(10):1132-1139. 